\title{
MECHANISMS OF RADIATION INTERACTION WITH DNA: POTENTIAL IMPLICATIONS FOR RADIATION PROTECTION
}

\author{
DOE/CEC Workshop \\ January 21-22, 1987 \\ at the \\ University of California, San Diego \\ La Jolla, California \\ Published: January 1988
}

\author{
Sponsor: \\ U.S. Department of Energy \\ Office of Energy Research \\ Office of Health and Environmental Research \\ Washington, D.C. 20545
}

Co-sponsor:

Commission of European Communities

CONF-870163--

DE88 005314 
The Office of Health and Environmental Research (OHER) of the U.S. Department of Energy conducts a broad multidisciplinary research program which includes basic biophysics, biophysical chemistry, molecular and cellular biology as well as experimental animal studies and opportunistic human studies. This research is directed at understanding how low levels of radiation of various qualities produce the spectrum of biological effects that are seen for such exposures. This workshop entitled "Mechansims of Radiation Interaction with DNA: Potential Implications for Radiation Protection" was held January 2 and 3, 1987, in San Diego, California. It was jointly sponsored by the Department of Energy and the Commission of European Communities. The aim of the workshop was to review the base of knowledge in the area of mechnaisms of radiation action at the DNA level, and to explore ways in which this information can be applied to the development of scientifically sound concepts and procedures for use in the field of radiation protection. The overview of research provided by this multidisciplinary group will be helpful to the office in program planning.

This report includes a summary of the presentations, extended abstracts, the meeting agenda, research recommendations, and a list of participants. The Department greatly appreciates the contributions of each participant and is expecially grateful to Dr. John Ward and his staff for invaluable assistance to Drs. Benjamin J. Barnhart and Matesh Varma (OHER) in organizing and hoisting this very successful workshop at the University of San Diego School of Medicine. The Department also acknowledges the fine job by the ad hoc committee which was assembled to write the summary. This dedicated group was co-chaired by Drs. Warren K. Sinclair (NCRP) and R.J. Michael Fry (ORNL) and included Drs. Aloke Chatterjee (LBL), Charles Geard (Columbia), Rohert Griffith (LLNL), Eric Hall (Columbia), Herwig Paretzke (I. fur St.rahlenschutz, Munich), Kenneth Wheeler (Bowman Gray), and Robert Yoder (DOE).

Robert W. Wood, Ph.D.

Acting Associate Director for Health and Environmental Research

Office of Energy Research 


\section{TABLE OF CONTENIS}

o Summary of Presentations. . . . . . . . . . . . . .

○ Agenda of the Meeting .................. 19

- Cancer Induction: The Influence of Dose and LET --. R. J. M. Fry, (Oak Ridge National Laboratory, Oak Ridge, USA) . . . . . . . $2:$

o The RBE roncept, It's Inadequacies and a suggested Replacement -V. P. Bond, M. N. Varma and C. A. Sondhaus (Brookhaven National Laboratory, New York, USA)................

- Energy Deposition at the Molecular and Cellular Levels - Radiation Track Structure Concepts -... H. G. Paretzke (GSF Munich FR Germany).......................

o Linking Physical Interactions with Late Chemical and Biological Events in Irradiated Liquid Water --- H. A. Wright, R. N. Hamm and J. E. Turner (Oak Ridge National Laboratory, Oak Ridge, USA) and A. Chatterjee and J. L. Magee (Lawrence Berkeley Laboratory, Berkeley, USA ...................

- Dynamic Models in Radiobiology -- C. A. Tobias (Lawrence Berkeley Laboratory, Berkeley, USA) . . . . . . . . . . . . . .

- Status of Phenomenological Models of the Response of Cells to Ionizing Radiation -- L. A. Braby, N. F. Metting and J. M. Nelson (Pacific Northwest Laboratory, Richland, USA). . . . . . . . . .

- Production of Hydroxyl Radical Induced Strand Breaks by High LET Particles: A Theoretical Approach ---- A. Chatterjee, (Lawrence Berkeley Laboratory, Berkeley, USA) . . . . . . . . . . . 95

- Radiation Induced Radical Species in DNA -- M. D. Sevilla, (Oakland University, Rochester, USA). . . . . . . . . . 111

- Molecular Damage to DNA: Types, Frequencies and Consequences J. F. Ward (University of California at San Diego, La Jolla, USA).

- Radiation Induced Nucleotide Damage: Methods and Models K. T. Wheeler (Bowman Gray School of Medicine, Winston-Salem, NC, USA).

- Mutagenic Mutations: Xeroderma Pigmentosum and the Question of the XP Variant ---- J. D. Regan and A. A. Francis (Oak Ridge National Laboratory, Oak Ridge, USA) . . . . . . . . . . . . .

- Repair/Misrepair and Linear Dose Dependencies ---- M. M. Elkind (Colorado State University, Fort collins, Colorado, USA) . . . . . 141 
- Chromosomal Abberations from Radiation Inducsd DNA Lesions ---A. T. Natarajan and L. H. F. Mullenders (Inter University Institute for Radiopathology and Radiation Protection, (Leiden, The Netherlands). . . . . . . . . . . . . . .

- Chromosomal Damage as a Function of Radiation Quality ---C. R. Geard (Columbia University, New York, USA) . . . . . . . .

- Factors Affecting Individual Sensitivity to Radiation and other Envirormental Mutagens --. R. C. Leonard, J. C. Leonard, J. M. Wieland, M. A. Bender, and R. B. Seilow (Brookhaven National Laboratory, Upton, USA). . . . . . . . . . . . .

- Estimating the Radiation Induced Germinal Gene Mutation Rate: Current Status and Future Prospects --- H. W. Mohrenweiser, (Lawrence Livermore National Laboratory, Livermore, USA). . . . .

\section{APPENDICIES}

I. Recommendations for Future Research . . . . . . . . . 183

II. List of Participants. . . . . . . . . . . . . 193 
Concepts of RBE and Absorbed Dose:

Improvements in risk estimates of exposures to occupational, environmental and diagnostic low-LET radiation require more human data from exposures to high doses and approprlate models of dose response on which to base extrapolation from high to low doses. Molecular and chromosome studies W' 11 Improve the understanding of mechanlsms and therefore, dose-response relationships of the inftial events. Although the initial events are obligatory, it is the host or constitutional factors that determine expression of the Initial events and thus the incidence of cancer. The host factors also have to be studied at the tissue and whole-animal level.

In the case of high-LET radiation, risk estimates must depend upon experimental animal data, and perhaps human chromosome studies, because there are no appropriate human cancer data. There is some discontent with the current use of RBE values. One alternative is to determine directly the risk of Induction of specific cancers by neutrons, and other high-LET radiations, In experimental animals and to extrapolate the risk across species. Such an approach entalis valfdation and acceptance of the methods of extrapolation. While studies at the molecular level are 1mportant, studies at the wholeantmal level are essential. 
Dosimetry is central to the determination of dose-effect responses. Wh1le absorbed dose is an approprlate description for high-level exposures that Involve mult1-cell effects, it is quite unsultable for single cell effects, such as cancer at low exposure levels. Dose confounds physics with b1ology and it is suggested that the correct approach to dose and RBE Involves the use of the hit-size effectiveness function (HSEF). The HSEF represents the probabillty of a blological response as a function of the lineal energy density ( $f Z)$. The use of this function allows responses to be related to the deposition of energy in a more meaningful way than dose. The deficiencles of absorbed dose become particularly apparent in the determinations of relative blological effectiveness (RBE). In 1ts current use, there is the implication that RBE 15 a measure of both the probability and severfty of the effect combined in one variable. But, in fact, severity is not appropriately represented. The use of the HSEF and hit-size distribution can replace RBE. Th1s approach appears to have promise but further research 1s required to bring its potential to fruttion and establish how it can be applied.

Energy Deposition at the Molecular and Cellular Levels

Revilews were presented of work a1med at understanding and describing energy deposition from lonizing radiation (charged particles) in molecular and cellular dimensions. Research in this area has involved development and use of computer codes that predict the spatial distribution of energy from charged particles with a range of LET values. The problems assoctated with accurate 
dosimetry of particles having ranges that are short compared with cellular dimensions were discussed, as were the results of calculations that predict the dose responses of individuals, using lCRP concepts. These calculations Illustrate the degree of statistical uncertainty associated wh the blological response, and thus indicate the need to avold placing undue emphasts on the exact shape of the dose response curve.

Sample calculations were presented from a Monte Carlo code, developed at ORNL, that simulates the energy deposition patterns from charged particles in water, and the subsequent migration of the reactant chemical species $(\mathrm{OH}, \mathrm{H}$, e- aq, $\mathrm{H}_{3} \mathrm{O}^{+}, \mathrm{OH}^{-}$, and $\left.\mathrm{H}_{2} \mathrm{O}_{2}\right)$. These species were tracked from $10^{-1} 1_{\mathrm{S}}$ to 2.8.1 $10^{-7} \mathrm{~S}$. Calculations have been performed for electrons, protons and alphas that 1 llustrate energy deposition patterns in relation to DNA molecular dimensions. These predict the number of direct physical and Indirect chemical reactions that occur with the DNA as a function of time after primary particle passage. G-value calculations are in good agreement with data from other researchers. An experimental technlque was proposed for studying 1ndividual charged particle interactions using optical detection of electron Interactions by 11 ght emission from exclted gas molecules.

Models of Radiation Action on DNA

Many models of radiation action have been proposed over the past half a century, and at different times have played a significant role in the development of the field. Some models are restricted to a specific in vitro situation and serve little purpose other than curve f1tting. Other models are "global" In the Bense that they attempt to describe the behavior of Intact cells to lethal damage or to heritable non-lethal effects such as mutagenesis 
and carcinogenesis. Most earlier models attempted to describe observable biological effects in terms of early physical events concerned with the pattern of energy deposition. Later models attempt to introduce repalr of radiation damage, and therefore also to take into account the time sequence in which radialion is delivered.

Within a given class of models, the basic philosophy and explanation for the sequence of events may be very different for the various models, but nevertheless they are all sufficlently flexible that they provide an acceptable fit to the data! The basic problem is that experimental data are never sufficlently preclse, nor predictions of the various models sufficiently different, for definitive cholces to be made between rival hypotheses or models.

There is a distinction between models which fit data and may be useful to extrapolate and interpolate and models which are based on a theory or a hypothesis. A model should do two things. F1rst, adequately fit the data with a minimum number of parameters and second, be formulated in such a way that the basic hypothesis or premise can be tested by experiment.

Radical Production in DNA by Radiations

Reviews focused on the role of radical production on DNA damage. These Included theoretical concepts Involved in DNA strand breaks. Base release always accompanies $\mathrm{OH}$ radical attack resulting in a single strand break. The hydroxyl radicals are most 1 mportant, and the damage that results is more 1mportant than direct excitation in the DNA molecule for low-LET (11ghtly lonfing) radiation. For high-LET radiation, however, direct fonlzation of 
the sugar moleties is most Important, and RBE values greater than 1 are due to direct interaction by the charged particle. In systems that are highly scavenged, such as the cell, double strand breaks vary linearly with dose.

Experimental studies primarily focused on production of radical species In DNA. Measurements were made at $77^{\circ} \mathrm{K}$, using election spin resonance (ESR) spectroscopy. Measurements at higher temperatures are difflcult because other processes compete wth electron transfer. Thymine anions and guanine cations were the only radicals detecied using ESR, and sugar radicals have not been found. Recent work on plasmids suggests that these Ion radicals are 11 kely to lead to double strand breaks which may domlnate those produced by hydroxyl radicals.

Molecular Changes in DNA and VI. DNA Repa1r Processes

Aithough 1 t has been known for decades that radiation can cause cells to mutate, to transform and to die, the exact mechanisms responsible for these biological phenomena remain largely unknown. The data argue convincingly that the genetic material is usually the critical target. Energy deposition events Interact wh the DNA and its assoclated protelns to initiate a chain of events that results in the cell being elther 1ndistingulshable from its unirradiated state or mutated, transformed or k1lled. Evidence is rapidly accrulng that most, if not all, the blological consequences of these energy depozition events are potentlally modiflable by repalr processes; e.g., the presence of repair genes or changes in temperature during repalr can alter the slope of dose-response curves that have no shoulder.

Time for repalr appears to be an important consideration in estimating 
r1sk. Complete recovery or repalr may require days or weeks rather than minutes or hours. The data suggest that when cell lethality is used as the endpoint, complete repali or recovery is possible even at moderately high total doses if the dose rate is low enough or the time Interval between doses is adequate. Furthermore, the number of transformed foct induced in some cell systems seems to be dose rate dependent for both low- and high-LET radiation. Repalr rate may also be important for mutation induction. Delaying repalr for a few hours can increase both cell killing and the mutation frequency in repalr proficlent or repalr deficient mamalian cells.

The spectrum and distribution of lesions may also be important for assessing the risks from exposure to radiation of different qualities. The spectrum of lesions induced in DNA can vary with wavelength, size of the energy deposition event, base sequence, conformation of the DNA and redox state of the cells. The distribution of strand breaks and base lesions on opposite strands of the DNA can create situations where no template exists to Insure that the correct base sequence is restored during repalr. The probabllity of Inducing these local multiple damage sites increases with Increasing size of the energy deposition events. Repair of these sites must Involve recomblnation mechanlsms, if such mechanisms exist in mammalian cells.

To determine the relative role of each of these mechanisms in the production of the blological consequences of exposure to low and moderate doses of radiation requires the development of sensitive assays for detecting chemically distinct DNA lesions. Monoclonal and polyclonal antibodfes, high performance liquid chromatography (HPLC) and gas chromatography combined with mass spectrometry (GC/MS) techniques are being developed for the detection of specific DNA lesions. HPLC with fluorescence detection of adenosine damage 
products and GC/MS are able to detect quantitatively nucleoside damage at doses below 10 Gy in mammalian cells; this 1 s approaching the dose range required to provide information relevant to many risk assessment questions.

Chromosomal Aberrations

In considering the biological consequences of ionizing radiations it is a logical progression to move from the physics of energy deposition, to the Induction and early dispersion of radiolytic products, to the formation of radicals in or around DNA, to molecular changes in DNA, their repair and/or misrepair and ultimately to chromosomal changes. Chromosomal alterations are responsible for a significant proportion of cellular lethal1ty and of genet1c mutations, as well as being specifically associated with human cancers. Given that chromosomal alterations are the harbingers of later change, Information pertinent to the nature of the responsible lesions, the spectrum of aberration types as a function of LET, and thefr relevance as a source of comparatively readily obtalned data for the regulation of human radiation exposures are matters of considerable 1mportance.

Among the extensive array of lesions induced in cellular DNA by lonizing radiations, [single strand breaks (SSB's), double strand breaks (DSB's), base damage, mismatches, DNA-DNA cross links and DNA-proteln cross-11nks] double atrand breaks seem to be of most 1mportance in the production of chromosomal aberrations. A number of approaches using selective Inhibitors of DNA repalr/replication and enzymes to modify radiation-1nduced damage in viable cel1s were considered. The use of Neurospora endonuclease that recognizes $\mathrm{SSB}^{-} \mathrm{s}$ in DNA and converts them into $\mathrm{DSB}^{-} \mathrm{s}$; of restriction endonucleases as Inducers of specific lesions, elther blunt or cohesive ended DSB's; and of DNA 
repal $r$ inhlbitors along with an evaluation of chromosomal types and frequencles all Indicate the 1mportance of the DSB in aberration formation. However, analyzing chromosomal aberrations at mitosis is still far removed in time from the initial energy deposition events. This has been elegantly clrcumvented by examing chromosomal changes in interphase using the premature chromosome condensation (PCC) technique, which also allows eluctdation of the role and timing of repair processes in the formation of chromosomal aberrations. The results of such studies have reinforced the importance of the DSB in aberration formation.

Developing further from this understanding is the realisation that aberrations form largely from the interaction of palrs of entities (breaks/lestons/DSB's) and hence interaction distance can control aberration formation. This is at present puzzling in that (for low-LET radiations) Interaction distances for lesion interaction appear to be of the order of a few to a few tens of nanometers in the intial (1inear) part of the doseresponse curve and micrometers in the latter (quadratic) part of the doseresponse curve. Overall, for lonizing radiations an Important determinant of aberration frequency is the linear energy transfer (LET) of the radiation. When studying radiations of well charecterlzed LET, knowledge of the morphometry of the Lrradiated cell leads to a direct est1mate of aberrations per particle. One energy deposition event per nucleus is the ultimate low dose and such an approach bypasses traditional concepts of absorbed dose and relat 1ve blological effectiveness. Furthermore, while there are vartations in sensitivity to aberration induction through the cell cycle which must be accounted for, as LET per particle increases linearly, aberration frequency Increases quadratically. For example, if one particle per nucleus at 100 keV/rem Induces about 1 aberration in every 10 cells, then one particle per 
nucleus at $1 \mathrm{keV} / \mathrm{rem}$ induces $\mathrm{l}$ aberration $1 \mathrm{n}$ every $10^{5}$ cells (based on in vitro studies).

The regulation of radiation exposures on the basis of frequency of chromosome breaks or measurable alterations in DNA is appealingly simple but it can only be considered in relation to an established baseline. The variability in the frequency of genetic diseases, the susceptibility to specific cancers and heterogenelty of the human species emphastzes the importance of differences. Ongoing surveys examining individual cellular sensitivities to a variety of agents (1ncluding radiation) and establishing correlations will provide a benchmark, but it is not improbable that establishlng causality between dose and effect at low doses will be masked by inherent variabilities. Establishing individual sensitivities raises the possibility (or specter) of genet1c screening of individuals for particular occupational roles. Alternatively (or concomtantly) understanding the biochemfcal basis of sensitivity and hence mechanisms allows consideration of reducing risk by designed intervention.

Establishment of benchmarks is particularly pertinent for germinal mutations in man. Though the number of well characterized genetic diseases in man 18 increasing rapidly and frequencies of many can be readily established from studies of newborns and/or older cohorts the rarity of new events renders difficult ascertainment of probable cause. Protein electrophoretic patterns, hemoglobin variants and enzyme deflciencies ponderously establish some est1mates of genetic change while the frequency of sentinel phenotypes arid of the pre- and post-natal mortalities allow other est1mates. Clearly chromosomal abnormalities are associated with spontaneous abortion and gross chromoromal changes overwhelm 81 ngle gene mutations in early mortal1ty, 
however, estimating genetic change per se in survivors is undergolng a transformation. Newer techniques, such as $2 \mathrm{D}$ electrophoresis and $d 1 \mathrm{r} \geq \mathrm{ct}$ examination of DNA sequences by restriction endonuclease digestion, by DNA-DNA hybridisation, and by DNA-RNA hyridisation, can establish unique heritable changes in offspring that are not present in parents. It should however be noted that these approaches allow addition to the data base on overall genetic change whlle not necessarlly contributing to the data base on genet1c load.

The extensive recent studies of chromosome aberrations, particularly with human lymphocytes, add welght to the contention that double strand breaks are probably, efther directly or 1ndirectly, the most important lesions that lead to aberration formation. The evidence, while still clrcumstantial, is very convincing.

One of the most exc1ting areas to evolve in recent years has been the observation of an association between certain cancers and specific chromosome changes. This has two most important 1mplications. First, it is one of the most encouraging pleces of evidence that it may one day be possible to put a "signature" to a spec1fic malignancy - 1.e., to know with some certainty whether radiation, chemical or virus was the causative agent. Second, it provides observable and convincing support for the mechanisms of cancer induction at the molecular level.

An Important area is the use of chromosome observations as a blological dosimeter. It is important to develop techniques to 1mprove sensitivity at low doses (less than $10 \mathrm{rads}$ ). 


\section{Genotoxic Survey}

A presentation was made on the potential of screening in human populations for varlations in responses to certain genetfc assays (1.e., a genotoxic survey). The assays include those for unscheduled DNA synthesis, lonfzing radiation sensftivity, susceptibllfty to cross linking agents, (mitomycin C) and susceptibility to alkylating agents (MNNG, etc.). Some preliminary studies had already been undertaken in a volunteer population but no very signiflcant differences have been observed.

In another human population of special clinical interest, measurements of radiosenstivity Indicated lower values of Do (the reclprocal of the slope of the exponential survival curve for cloned cells) than for normal people in AT homozygotes. A small number of AT heterozygotes had incermediate values.

These studies are very preliminary ard the potential of genotoxic screenting has yet to be exploreci. 
A number of selected speakers set the scene for discussions of subjects ranging from the pragmatic approach to the setting of radiation protection standards and their application, to the salient radiation-induced molecular, chromosomal and cellular changes involved in genet1c effects and cancer. Ionizing radiation is ubiquitous, in the form of nacural background radiations but, In addition, an appreciable number of persons are exposed occupationally. However, the average occupational dose is low and in fact is comparable, but additional, to that recelved by the general population from natural sources. Two major sources of population exposure, radon from natural sources and $x$ rays and radionuclides 1 medical procedures, vary considerably In their contribution to individual population doses. Because all of these doses, Including occupational, are low, it is the effects, if any, of low doses that are of special interest in radiation protection. At these low doses the blological effects of concern are cancer and gerotic effects.

The increasing amount of data from the study of atomlc bomb survivors and from some other sources wll allow better risk estlmates of cancer induction from low-LET radiation as t1me goes on. However, the improvement in risk estimates wil largely be for doses greater than about 50 rem. Therefore, the estimates of risk from low-LET radiation at low doses will st111 depend on extrapolation and dose-response models. Currencly, curvilinear responses are considered approprlate for all solld cancers except breast and thyrold, for which linear responses are favored. Although the simpliclty of these doseresponse models has practlcal advantages, such a complex process as radiationInduced cancer, Involving a number of time- and dose-dependent factors requires considerable sophistication. Indeed, experimental observations of 
an1mal tumors show a wide varlety of responses. Since occupational exposures are at low-dose rates or in small fractions it is essential to understand the effects of dose rate and fractionation. Some experimental observations of the effects of protraction and fractionation, with high-LET radiation, appear to be at odds with accepted biophysical and blological models because the effect with protraction is greater than with single doses. A better understanding of Lhe variety of phenomona observed is requlred. Furthermore, l1ttle 1s known about the role of repair in the induction of cancer following 1rradiation.

In the case of high-LET rad1ation, risk est1mates will, for some t1me, stiIl depend on the use of RBE values determined on experimental systems and more and more information is needed on the more relevant of these systems. Alternatives, however, must also be sought. Some of the discussants were quite optimistic about the possibilities of extrapolating risk estimates Instead of $R B E$ values across species. Possible methods of extrapolation across species can be tested using the accumulating data frcm human and experimen:al animal studies.

A driving force in the radiation protection field is the As Low As Reasonebly Achievable (ALARA) principle. Improvements in technology and the comparatively minor economlc 1mpact of reduclng exposures have made $1 \mathrm{t}$ possible to decrease occupational exposure levels, especially in the nuclear Industry. These reductions instigated by the industry have preceeded the decreases in maximum permissible doses considered by the regulatory bodies.

In health physics, Improvements in dosimetry must be practical and çost effect1ve. The advantages of measurement of $Y$ spectra 1 nstead of dose are 11mited, but 1mportant in the case of mlxed flelds that occur in cerialn activities in the nuclear industry. Such measurements can be carried out by 
small portable proportional counters that have been developed In Europe and the U.S. For radiation field measurements, a size of a $7 \mu \mathrm{m}$ sphere was considered practical and suttable on the criterion that it would represent a "dose" at a size comparable to a cell. It was emphasized that for most of the experimental work, measurements need to be made at the much smaller stzes that are approprlate to the question belng asked, perhaps, of the order of nanometers. It was stressed that there was a need for continual intercommunication between those in health physics and in basic sciences.

In considering a different approach to radiation protection of workers the question was ralsed whether molecular technfques could be applied to the identification of radiosensitive subpopulations. If such sensitive populations could be Identified, would screening exposed worker populations be worthwhlle? We know little about the distribution of sensitivity to radiation-induced chromosome aberrations and the fmplications, or whether or not heterozygosity for certain traits carries any increased susceptibility to radiation. It was polnted out that other screening programs had not met with success. Based on current knowledge, selection of nonsmokers and support of programs to help workers stop smoking should be a better cholce of action.

The formal presentations at this workshop had concentrated largely on techniques and phenomena and some felt that models of carcinogenesis had been given too little attention. It 18 a tall order to model the entire trall of relevant changes that link the Inftial events caused by deposition of energy (wth Important times limited to fractions of a second) to those that end with some Increased probabllity, perhaps decades later, of an overt cancer. Th1s 18 nevertheless, our overall alm, but because it is so complex we often deal with parts of the problem. These parts need integration eventually into a comprehens1 ve whole. 
Two Important observations must be taken into account in the models of radiation-1nduced cancer. First, in the case of some human and experimental tumors there are marked age-dependent changes in susceptibility. For example, In humans the risk of radiation-1nduced breast cancer decreases from relatively high after exposure at a young age to no excess risk with exposures at about 45 years or older. Th1s suggests that if carcinogenesis is a multistage process, the later stages must be relatively radioresistant. Second, the radiation-1nduced excess of some cancers only starts to appear at an age when the Incldence of the same type of tumor starts to 1ncrease in the unexposed population.

Although the information about the interaction of radiation with DNA is very considerable much remains to be done. How does the spectrum of energy deposition relate to the spectrum of molecular and cellular damage, and in turn, to the subsequent blological effects? Is the Induction of mal1gnant transformation more likely at one stage of the cell cycle than at others? We st111 know little about the probabilities of the occurrence of each of the sequential changes that bring about the end effect. For example, it is clear that there are many more intlated cells than cancers, and yet we know nothing, directly, about the repair of the molecular lestons in the lnttial events that lead to cancer induced ty radiation, wth perhaps the exception of those Induced by ultraviolet radiation. The long latent period between exposure and the appearance of overt sol1d cancers offers a very good opportunity for 1ntervent1on. Perhaps the greatest contribution molecular etudies could make to radiation protection is the development of methods.of Intervention whereby the growth and progression of Inttiated cells could be -topped. To do so wll require detalled knowledge of not only the molecular processes Involved, but, also, cell-cell interaction and t1ssue and systemic 
control of growth and differentiation. The catchy phrase, "molecular epldemlology", is not yet reflected in the development of techniques, of 1dentifying elther the subpopulation at risk or the tell-tale radiationInduced changes in cells that may lead to cancer. The quest for markers of potential cancer cells, if successful, could provide the criterion for Intervention. Another aspect of the changes assoclated with cancer induction was whether the type of carcinogenic agent that caused a specific cancer could be 1dentifled by what was called the "signature of malignancy". Th1s 1mplies that some of the changes may be agent-dependent. For example, can a profile be prepared for a speciflc cancer from the Information about spec1fic chromosome aberrations, the type of oncogenes activated and from other changes In the genome and the cell membrane, and can these be shown to be characteristic of a specific causative agent? The possibilfty was ralsed that deletions involving repressor genes or anti-oncogenes might be a characteristic of some radiation-induced cancers because of the propensity of radiation to cause deletions.

It is obvious that there is a need for in vitro cell systems for Investigating questions that cannot be answered at the whole-animal 1 evel. Indeed, such systems, because of the opportunity they present to observe single cell changes, offer some unique possibllities. While rodent cell systems have provided a considerable body of data about radiation-1nduced malignant transformation, it is the responses of human cells, particularly eptthellal cells, that are needed. Unfortunately, the morphological changes assoclated with the malignant phenotype that are the basis of rodent cell transformation assays are not apparent in humen cells. Different and appropriate assays appear to be required for human cells. 
Workers that are exposed occupationally to radiation are also exposed to many other agents that may interact with radiation. These interactions are complex and may be additive, superadditive and even subadditire. Some agents will interact with radiation at the initiation stage. For example, agents that alter levels of radiation-induced free radicals may alter inftiation. Whereas, many agents, including hormones, influence expression. In vitro cell systems are well sulted for the study of many of these Interactions at the cell level. A number of different in vitro, in vivo-in vitro and whole-animal model systems are now avallable that complement each other in the study of 1nteractions of agents.

Studies at various levels, from human epldemlologlcal surveys to the Identification of radiation-induced changes in the gene all have a role in unravelling the puzzle of the mechantsms of carcinogenesis. Experimentally, It $1 \mathrm{~s}$ Important that the system selected is sultable for the questions that are posed. Although the goal of understanding mechanlsms is as worthy as can be, for quite some time yet, risk estimates of radiation-1nduced cancer will have to come from direct studies of those risks. Molecular studies have made 1mpressive advances, some of which have been described at this workshop, but they have not as yet made a contribution to risk estimates. They may do so in the future. 
DOE/CEC Workshoy

January 21-22, 1987

Mechanisms of Radiation Interaction with DNA: Potential

Implications for Radiation Protection

Co-chairs: M. Varma

B. Barnhart

Introduction: C. DeLisi (DOE)

I. Concepics of RBE and Absorbed Dose

M. Fry (ORNL) - Biological Response to LET and Dose

v. Bond (BNL) - RBE and Alternatives

II. Energy Diposition at the Molecular and Cellular Levels

H. Paretzke (Neuherberg) - Track Structure Concepts

H. Wright (ORNL) - Physical and Chemical Interactions

III. Models of Radiation Action on DNA

C. Tobias (IBL) - Status of Mechanistic Models

L. Braby (PNL) - Status of Phenomenological Models

IV. Radical Production in DNA by Radiations

A. Chatterjee (IBL) - Theory of Radiation Production

M. Sevilla (Oakland Unniversity, MI) - Radical Species

v. Molecular changes in DNA

J. Ward (California) - Types, Frequencies and Effects of DNA Damage Sites

K. Wheeler (Bowman Gray) - DNA Base Lesions and Adducts

VI. LNA Repair Processes

J. Regan (ORNL) - Damage, Repair and Mutagenesis

M. Elkind (CSU) - Repair Related to Linear Low Dose Damage

VII. Chromosamal Aberrations

A. Natarajan (Lieden) - Chramosamal Aberrations from DNA Lesions

C. Geard (Columbia) - Crramosamal Damage as a Function of Radiation Quality

VIII. Human Polymorphisms

R. Ieonard (BNL) - Radiation Sensitivity Measurements in Individuals

H. Mohrenweiser (Michigan) - Mutation Frequencies in Human Populations

IX. Future Directions and Recommendations - Round Table Discussion 


\section{PRESENTATIONS}

$21 / 22$ 
CANCER INDUCTION: THE INELUENCE OF DOSE AND LET

\section{R. J. M. Fry}

B1ology Division, Oak R1dge National Laboratory, Oak R1dge, TN 37831

Radiation protection standards are based on 1) estimates of risk of radiation-induced damage and in particular, the induction of cancer, and

2) a Judgement on what level of risk should be considered acceptable. It 1 s with only the former that we are concerned.

For radiation protection purposes the risk estimates of cancer induced by low-LET radiation have been based on human data. In the case of ICRP's risk estimates for cancer mortality two assumptions are made: (1) the effect per rad for the Induction of leukemia is less at low doses than at high doses by a factor of 2.5 , and (2) that 5 times more solid cancers than leukemia will be induced by whole-body exposures to low-leT radiation. The influence of results from experimental data on ICRP's or other risk estimates has betn IImited to supporting the concept that the dose-response curves for at least some cancers are curvilinear. Also, that these responses can be adequately described by the so-called linear quadratic model. The second assumption cannot be tested rigorously in inbred strains of mice. Anyway, with risk estimates for specific sites now becoming available the assumption will become superfluous.

The approach to the estimate of risks is two pronged. First, a pragmatic approach involving direct determinations. Since data at low doses and low-dose rates are difficult to obtain, estimates of the effects at low doses Involye extrapolation. In order to extrapolate some model of the dose response must be assumed. The selection of an appropriate model depends on an understanding of the mechanisms. Thus, the second and parallel approach 
is the study of the mechanisms. It is important to realize that it is the mechantsms of the total process of radiation-1nduced cancer that must be taken Into account not just the Inttial molecular and cellular events.

Let us assume that chromosme aberrations or changes in two protooncogenes on separate chromosomes (not lnvolving chromosome translocat1ons) are two possible mechantsws of the induction of cancer by radiation. Then 1t would be reasonable to expect the dose-response curves from the Inttial events to be IInear quadratic. However well these 1 intlal responses can be described by that or any other responses 1 d dees not ensure that the actual cancer mortality, as a function of dose, can be described by the same equations. In the long intervening period after intilation the events occur that, in the case of solid cancers, determine whether or not an overt cancer w1ll appear. There 1s little or no understanding of how the events, which 1a large part are the result of the interaction of the host and the Initiated potential cancer cell, Influence the shapes of the dose-response curves. It 1s these latter Interactions that may well be the most important factors determining the differences in the shapes of dose-response curves for different cancers. The evidence suggest that it is the host factors that are the major determinants of whether or not a cancer develops. It w1ll certalnly be a challenge to explain these interactions on a molecular basis.

After exposure cancers, similar to those that occur in the unirradiated population, may occur in higher incldences and in some cases apparently at earlier times. The events during the latent period, except the growth that must occur during some fraction of the latent perlod, are of great inportance but are elusive. In some experimental systems, in which the incidence of the tumor reaches $100 \%$ in the controls, the only effect of 1rradiation, $1 \mathrm{~s}$ to 
shorten the latent perlod. However, at least in the case or some cancers the latent period 13 not affected by radiation but is inversely related to the age at exposure. The reason for the relationship to the age at exposure is because the radiation-1nduced cancers only appear at an age that the naturally occurring cancers of that type start to appear. Age is a dom 1nant determinant of cancer in general and age at the time of exposure to radiation has a marked influence on susceptibility. What is the basis of this age dependency? Have the cells at risk changed or decreased in number or do the factors that influence expression of intiated cells to develop into overt tumors change so radically with age? An understanding of the effect of age on susceptibility is importent for risk estimation and interpretation of the effects of exposure protracted over a significant fraction of the life span. An important concept that depends upon the curvilinearity is that low single doses at high dose rates, multiple fractionated exposures, and doses over quite a broad total dose range at low 1nstantaneous dose rates, w1ll have simllar effects per rad. Experimental evidence supports such a contention but information about interaction and repair kinetics is deficient and therefore there are not adequate models for describing fractionation effects over a range of Interfraction times.

The $\alpha / B$ ratios (the ratio of the coefficients in the II near-quadratic dose response) vary considerably between tissues. What does this reflect? Can we assume that at 1 ow doses and dose rates that the effect $1 \mathrm{~s}$ total-dose dependent and dose-rate independent? The experimental animal data suggests that it $1 \mathrm{~s}$ so but data for specific tumor types are limited.

In the case of high-LET radiation, witb perhaps the exception of Irradiation from exposure to radon, there are no direct estimates of risk of 
cancer induction in humans. Therefore, risk estimates have to be obtained indirectly.

For protection standard purposes the quant1ty, called dose equivaient is used to take into account the differences in effectiveness of different types of radiation. The dose equivalent $H$ is given by the equation $H=D Q N$ where $D$ is absorbed dose, $Q$ is the quality factor and $N$ is the product of all other modifying factors.

Dose-response curves for neutron-1nduced $11 \mathrm{f}^{\mathrm{S}} \mathrm{shor}$ tening and bigh-LET radiation Induction of tumor's bend over at low doses. This has led to the question of whether the responses to neutrons can be described by a power function or are IInear. The evidence for fission neutron-1nduced life shortenting and heavy ion tumor induction is that the inftial slopes of the responses are linear. A general model for describing the complete dose-response curves has not been derived. Some of the problems of fitting the experimental data to model curves will be 111 ustrated.

The selection of $Q$ for a specific type of radiation is essential in the setting of protection standards and the $Q$ for neutrons has recently been Increased from 10 to 20. A number of approaches can be taken to arrive at a value of $Q$. Up to the present time FBEs have been used. The question is what RBEs should be used. In the recent report of the Jolnt Task Group of the ICRP and the ICRU a number of KBE $\mathrm{m}_{\mathrm{m}}$ values for fission neutrons compared to gamma rays were l1sted. Three sets of data quoted, namely, tumors in rodents, life shortening in mice and chronosome aberrations in human lymphocytes in yitro may have relevance and are worthy of examination especially as it must be assumed that risk estimates of the induction of cancer by neutrons are going to come from experimental data. 
The attractions of chromosome aberrations 1s that they can be determined on buman cells. But despite the recognized association of specific chrcmosome aberrations and specific leukemias nel ther a causal relationship nor a quantitative relationship between chramosome aberrations and, say, myelo1d leukemla has been establ1shed. Even if we assume that the RBE for speciflc chromoscme aberrations and the speciflc leukemla are the same, Intuitively, it seems most unlikely that the same relationship will hold for various solid cancers. The questions related to myelold leukemia and chromosome aberrations can be tested experimentally.

It is easy to dismiss the use of RiEs for estimating risks of neutron Induction of cancer in humans but 1conoclasm must be accompanted by suggestions for al ternative approaches.

If $R B E_{m}$, the ratio of the initial slopes of the dose-response curves for the radiation under study and the reference radiation, is used theoretically, this eliminates the problems of RBEs being dose dependent, dose rate and fractionation dependent. However, tissue-dependent differences remain and some results both in wive and in yitro have ralsed the question of whether additivity holds for neutrons. The finding of a greater effect of neutrons when the exposure is protracted or fractionated has thrown the proverbial spanner in some concepts. In the case of Iife shortening (probably accounted for by excess incldence of cancer) an increased ef fect of neutrons with fractionation occurs only with total doses in excess of 20 rad. In one tumor system reducing the size of dose per fraction to $2.5 \mathrm{rad}$ el Iminates any increased effect of fractionation.

There is increasing evidence of a view long held by several of us in radiation carcinogenesis tnat the mechanlsm, in particular, of the initial 
events of radiation-1nduced cancer, are likely to be similar in various species. The reasons for apparent differences in susceptibility to induction could Ile in differences in rates of Induction of the inftial events or in the rates of expression. Where retroviral genes are involved the difference In susceptibility to specific tumors becomes extreme. Nevertheless, if the analysis of the response to radiation takes into account, fully, the relative underlying susceptibility extrapolation of the actual radiation effect on the tumor incidence across strains or species may be and appears to be posslble.

In the case of radiation-1nduced life shortaning, which at $1 \mathrm{cw}$ doses and low-dose rates we consider to be caused by excess cancer, extrapolation based on mortality ratios might be used. The advantage of life shortening, in particular in mice, is that the total tumor response is integrated into an easily determined endpoint. A valid objection to life shortening is that in Inbred stralns of life shortening is influenced by the type of tumor prevalent in the specific strain. In fact the RBEs used by ICRU and ICRP were derlved from one strain and one hybrid. But this problem can bo solved. Data for I1fe shortening and specific tumor induction by fission neutrons should be obtalned using terminated Iow-dose rate neutron 1 rradiation regimes. Sufficlent strains should be used to obtain a representative life shortenting effect per rad and responses for speciflc cancers. Also, we need to test methods of extrapolation from low-LET radiation since data exist for both humans and mice. If the method proves rellable then 1 t can be applied to high-LET radiation risks.

The relationship of RBE to LET has been determined for a number or endpoints including in yitro mallgnant transformation and a start has been made on determining the relationship for cancer induction in mice. The 
relationship has been examined only for one tumor system. The results are qualitatively similar but quantitatively different from those obtained for other endpolnts. The problems of the use of dose w11l be discussed by Bond and $\mathrm{RBE}$ based on dose may not be approprlate w1th particles with a large "core" and that are of considerably length. An attraction of tumor induction studies as a function of LET is the possibility of studying the relationship of energy deposition to tumor induction and the relative importance of direct and 1 ndirect effects. 
The RBE Concept, Its Inadequacies and a Suggested Replacement

Bond, V. P., Varma, M. N. and Sondhaus, C. A. Brookhaven National Laboratory, Upton, New York 11973

The Inadequacies of the relative blological effectiveness (RBE) concept as a means of taking linear energy transfer (LET) Into account are most severe with low-level exposure (LLE) and 1 ts consequent single cell-originating neoplas1a, which is of primary concern. The RBE concept becomes a necessity only as the result of attempting to force-fit to th1s LLE "single cell" response the quantity absorbed dose, which 18 conceptually appropriate only for high level radiation (HLE) responses, e.g., multicell death-1nduced organ fallure, or tumor control.

Both the problew and the basis for an alternative solution can be 11lustrated in the following way. The absorbed dose $D$, which 18 the average energy per unit mass in an organ, 18 the result of summing and averaging elementary doses in the organ's volume, e.g.,

$$
D=\frac{\left(H_{1}+H_{2}--\right)}{N_{E}}=\left(\frac{\sum_{H} H_{1}}{N_{H}} \cdot \frac{N_{H}}{N_{E}}\right) \quad \bar{H} I_{H}=k \Phi \sigma=i \bar{l}
$$

where $H_{1}, H_{2}-$ are the cell-genome h1t sizes ("elementary doses"), $N_{H}$ and $N_{E}$ are the number of hit and exposed cells in the organ, respectively, $I_{H}$ $18 N_{H} / N_{F,}$, the fraction of cells hit at least once, $k$ or $\vec{H} 1$ s the mean hit size, $\left(\frac{\zeta H}{N_{H}}\right)$ of the (aingly) hit cells only), and $\bar{q}$ is the primary particle fluence. The quantities $k, k^{\prime}$ and $\sigma$ are all constants.

From Eq. 1 it follows that $D=\overline{\mathrm{H}} \mathrm{I}_{\mathrm{H}}$. If $I_{\mathrm{H}} Z_{1.0}$, as occurs with HLE, then $D$ is equal to $\bar{H}$ and can serve as the independent varlable in the 
functional relationship required: D v8. the blological probability of an al1-or-nothing quantal response of the organ (or tumor), 1.e., a statistical measure of the severity of organ effect (F1nney, D.J., 1971). However, w1th LLE, the responses observed are single-cell effects. It 1s shown by Eq. 1 that in the latter case, D is a measure of only the average physical probability of a cell belng hit and "dosed" in a particle-cell genome encounter, and not of the severity of the resulting cell infury.

In the alternative approach to RBE suggested here, it is first noted (Eq. 1) that $I_{H}$ is an object-orlented quantity linearly dependent on the fleld-orlented Independent varlable, exposure, expressed in terms of $\oint_{\text {. }}$ Hence, $I_{H}$, measurable microdosimetrically (Ross1, H.H., 1968; Kellerer, A. M., 1976), Is the (fractiona 1) number of genomes hit with a distribution of stochastically-determined hit sizes. Only the area under the distribution, $I_{H}$, 1ncreases, whereas the shape of the distribution and mean hit size do not change, with 1ncreasing exposure.

To obtain the severity of cellular effect, both a distribution of hit sizes for a given exposure, and an independently determined hit size effectiveness function (HSEF) is required (Bond and Varma, 1982; Varma and Bond, 1983). The latter 1s an S-shaped relationship, which yields, as a function of hit sizc, the fraction $f_{q}$ of cells infured severely enough to trigger a quantal response. It has a small or possibly larger threshold, depending on the endpoint used. This function is the cellular analogue of the organ dose-resporse curve. The Incidence of quantal cell responses is then obtalned by summing the product of the fractional number of hits at each hit size in the distribution, and its corresponding value of $f_{q}$ from the HSEF, over al1 hit sizes in the distribution (Bond and Varma, 1983; Bond et al., 
1985). The result, $I_{q}$, is the effect on the total cell population from the given exposure, in terms of the incidence of those cells infured to the common degree of severity Indicated by the presence of a quantal response (see Fig. 1). The risk to the "average" Individual cell is equal numerically to $I_{q}$. W1 th the present system, the one Independent variable D, as shown by Eq. 1, Is actually an Inseparable composite of two parameters, one ( $I_{H}$ ) representing the probability of a hit and the other, $(\vec{H})$, related to $R B E$ and the chance that cells with a given hit size will respond with a given degree of sever1ty (a quantal response). Although, w1th LLE, $I_{H}$ changes w1th increasing $D, \vec{H}$ remains constant. Thus, with a radiation of a given LET, D Is not a measure of elther $H$ or $\bar{H}$, and thus not of the severity of cell effect. It was this Inability of a supposedly single Independent variable to do the Job of both of 1 ts component varlables, that necessitated the introduction of a separately determined physical "severity factor", RBE, In which severity is represented by $\vec{H}$ in the ratio of absorbed doses for equal effect. However, thls stop-gap approach to providing some indication of the severity of cell Infury from varlous hit sizes is inapproprlate because 1) each RBE is the ratio of the product of the two variables $\bar{H}$ and $I_{H}$, so that no measure of RBE reflects the Influence of elther varlable alone (see Fig. 2 and caption explanation), and 2) it is mathematically incorrect to take the average of a distribution of hit sizes as the varlable for blological response because the HSEF 18 non-11near. Also, the use of the term "dose" 1at the RBE rat1o 1mpl1es that the differences in effectiveness are due entirely to the amount of energy deposited ("elementary dose"), when in fact they are strongly influenced by the probability of a cell receiving a "dose" during a given exposure. The essence of the HSEF and hit-size distribution approach described above for LLE can be viewed as the decoupling of the two varlables comprising 
D. It substitutes an absolute for a relative messure of severity of cell effect. The approach can, in principle, replace the crude "single function"-KBE tactor approach, and with it the absorbed dose, a "standard" radiation, Q, and dose equivalent.

If the HSEP approach, or any model for simple cell transformation by radiation is to be applied directly for prediction of cancer Incidence in animals or human beings, then at least five factors must be known. These are:

$$
A=B \cdot C \cdot D \cdot D \cdot E \text {, }
$$

In which A is cancers/animal, B 18 stem cells/animal, C is surviving cells/exposed cell, D is transformed cells/ourviving cell, and E 18 cancers/transformed cell. " $A$ " above can be determined experimentally, e.g., myelocytic leukemia rates in mice exposed to radiations of one or several LET's. "B" can be determined by the spleen colony technique, with the assumption that the leukem la precursor cells are the uncommitted (or some specifically committed) bone marrow sten cells. " $C$ " $1 \mathrm{~s}$ readily determinable using the spleen colony technique. " $D$ " can be determined as outlined in this paper, using elther an HSEF derived from leukemia Induction with radiations of different $L E T$, or assuming that an HSEF for another endpoint, e.g., for chromosome aberrations, w11l represent adequately the HSEF for leukemla Ithis assumption tas been used prevlously (Zalder and Brenner, 1985; ICRU 40, 1986)]. "E" Is an unknown, which can be solved for when the values for the other terms in the equation have been estimated. The above indicates that in principle the Information necessary for application of the HSEF to the Intact animal can be obtalned. Although very preliminary estimates for all of the terms in Eq. (2) have been made, further study is required to obtain values that are sufficlently reilable for use. 
It has been suggested that a form of the HSEF approach, modified to obtain values of RBE, may be useful in radiation protection (ICRU Report 40 , 1986). Al though the method suggested may be useful as a compromise measure, the full HSEF approach in which absolute values of risk can be provided, and the use of absorbed dose in LLE avoided, appears to be the conceptually desirable goal.

Bond, V. P. (1982). The conceptual basis for evaluating risk from low-level radiation exposure. In: Critical Issues in Setting Radiation Dose Limits, No. 3, pp. 25-65, National Council on Radiation Protection and Measurements, Bethesas, MD

Bond, V. P. and Varra, X. N. (1983). Low level radiation response explained in terms of fluence and cell critical volume dose. In: Eighth Symposium on Microdosimetry, Julich, West Germany. pp. 423-439, Commission of the European Communitles, Harwood, Iondon.

Bond, V. P., Varma, M. N., Sondhaus, C. A. and Feinendegen, I. E. (1985). An alternative to absorbed dose, quality and RBE at low exposures. Radiat. Res. 104: 552-557.

Finney, D. J. (1964). Probit Analysis, 2nd ed., Cambridge University Press, London.

ICRU 40 (1986). Report of the International Commission on Radiation Units and Measurements. Bethesda, MD.

Kellerer, A. M. (1976). Microdosimetry and its implication for the primary processes in radiation carcinogenesis. In: Biology of Radiation Carcinogenesis, pp. 1-11, J. M. Yuhas, R. W. Tennant, and J. D. Regan, eds.. Raven Press, New York.

Varma, M. N. and Bond, V. P. (1983). Empirical evaluation of a cell critical volume dose vs. cell response function for pink mutations in Iradescantia. In: Eighth Symposium on Microdosimetry, Jullch, West Germany, pp. 439-450, Commission of the European Communities, Harwood, London. 


\section{Figure Captions}

FIgure 1. Use of the HSEF with a high-and a low-LET radiation exposure (schematic). In elther case, the probability distribution of hit sizes per event shown in (a) is multiplied by the HSEF in (b) to yleld the distribution of Incremental products shown in (c). The summation of the latter ylelds the fractional number of hit cells which will respond quantally per event. Mulifiying the latter by the total number of events and scaling gives the fractional number of all exposed cells responding quantally due -o the exposure. (In (c), the curves are magnifled to Indicate the relative fractional number of responding cells per event at low and high LET.) The microdosimetric quantity used for the abscissa is readily translatable into the hit slze $H$.

Figure 2. Schenatic of the Inttial proportional part of three organ absorbed dose-single cell response curves, e.g., for genetic or oncogentc cell transformation, for radiations of three different qualities. The RBE 1s, for Instance, the ratio of the value at point $\left(\overline{\mathrm{H}} \mathrm{I}_{H}\right)_{1}$, to that of e1ther of the similarly designated points, but with subscripts 2 or 3 . However, when D (equal to $\bar{H} I_{H}$ ) Is used, not only must the values for each of the component variables $F$ and $I_{H}$ be different at each polnt, but no value of elther can be known. Thus the RBE is not a measure of the effect of elther component varlable alone. 

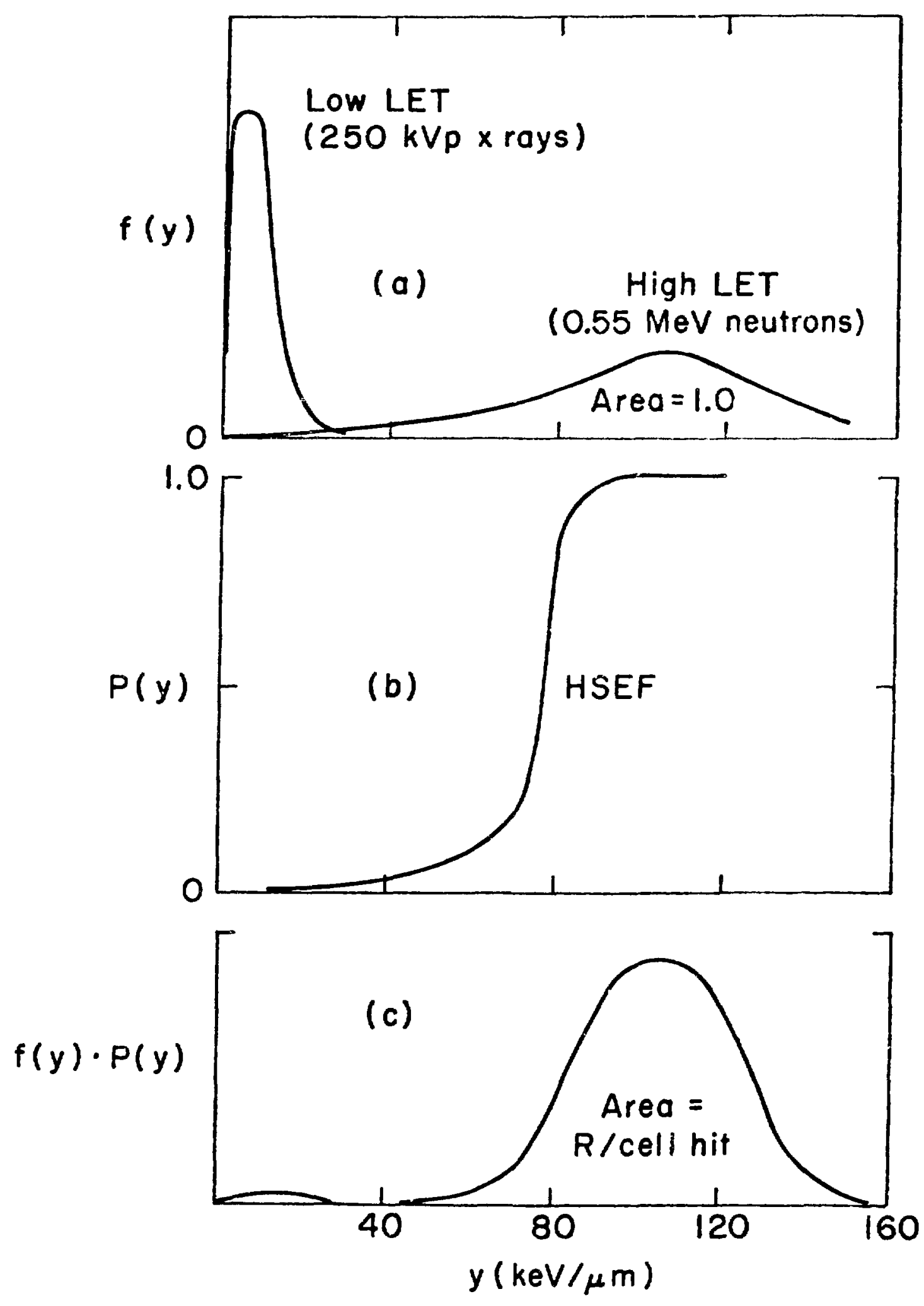
5

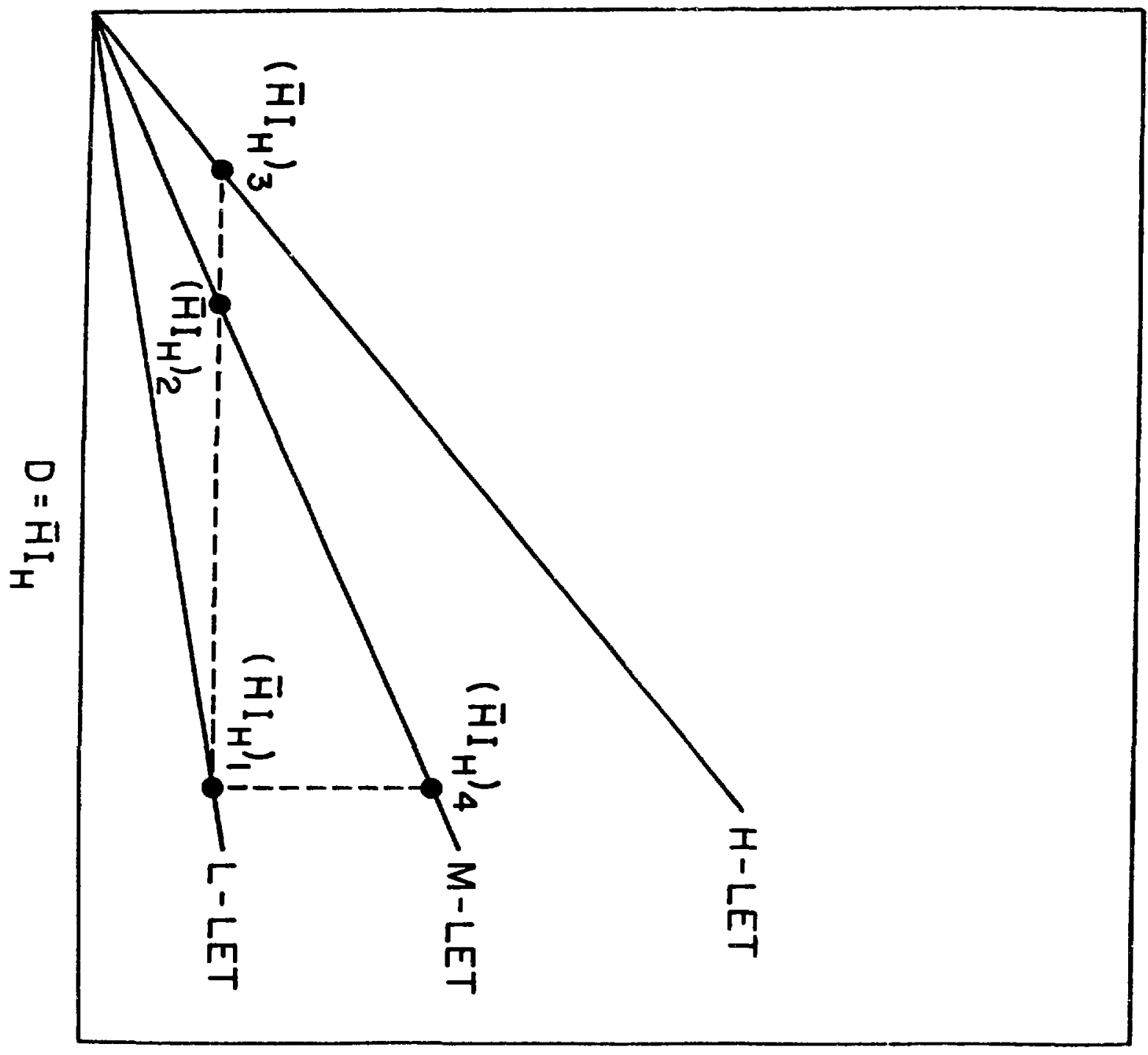


Energy Deposition at the Molecular and Cellular Levels Radiation Track Structure Concepts

\author{
Herwig G. Paretzke \\ GSF-Institute for Radiation Protection \\ D-8042 Neuherberg/Munich, F.R. Germany
}

\title{
Abstract
}

This paper presented at the DCE-CEC workshop "Mechanisms of Radiation Interaction with DNA: Potential Implications for Radiation Protection", Jan. 87, discusses the potential contributions of radiation track structure theory to this topic and some main problems encountered hereby wich need more research activities. Whereas track structure theory has obtained already interesting and reliable new results for gaseous targets, i.e. isolated atoms and molecules, progress for condensed targets is seriously hampered by lacking theoretical and experimental knowledge in particular on elastic and inelastic collision cross section of heavy charged particles and of slow electrons and on the decay modes of excited states in target molecules. Finally concepts for adequate mathematical descriptions for the time dependent spatial patterns of new chemical species or of the important properties of these patterns are still missing. Progress in this field, however, is an indispenszible prerequisite for any deeper understanding of the mechanisms of radiation action on DNA, chromosomes, cells, organs, and, thus, on living beings. 


\section{Introduction}

When ionizing radiation interacts inelastically with a biological target, it can introduce primary physical and chemical changes in these molecules, which - after a possibly long chain of subsequent reactions - might have a more or less severe biological consequence for the irradiated molecules, cells, etc. A different incident radiation field can lead to different biological effects under otherwise similar conditions. Even if these effects are manifested decades later, this difference can only be due to differences in the spatial patterns of primary species left behind in the wake of interacting particles at very early times. This is because the primary track structure represents the only - though transient - fingerprint produced by a radiation field in the irradiated medium (fig. 1); otherwise the irradiated object had no positive knowledge of this fact.

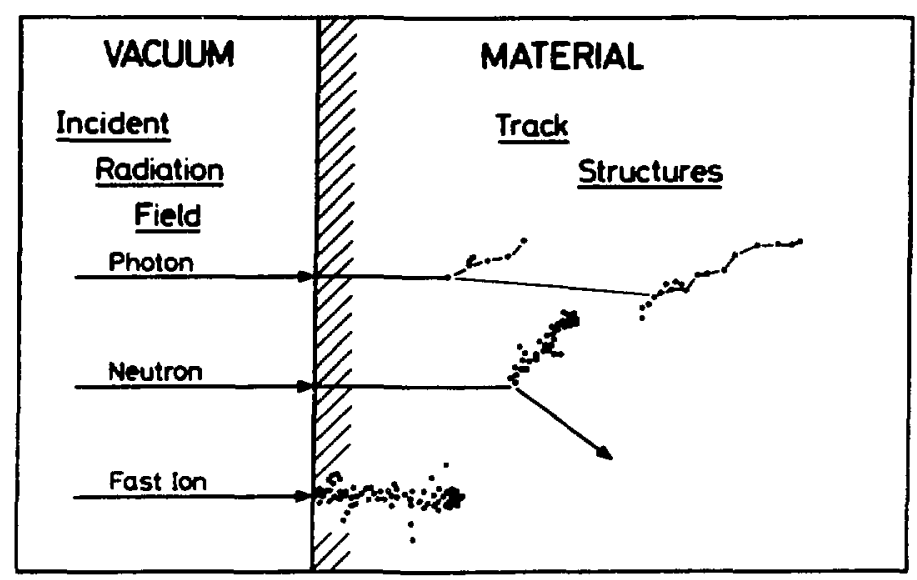

Fig. 1: Track structures as fingerprints of irradiations

A careful study of radiation track structures in biological matter, therefore, is necessary for any interpretative theory for radiobiological radiation actions. Also because of this fact, different radiation fields (including variations of dose rate) can be used to investigate chemical and biological processes initiated by the physical interaction as well as to study the response of a biological object to such a fast 
disturbance by radiation. On the other hand, the biologically important properties of track structures must be identified to be able to intercompare effects of radiations with different qualities and to develop and use adequate instrumentation to measure the relevant quantities of radiation fields. These quantities must allow e.g. an assessment of the health hazards of persons working in a radiation field or of the potential benefits from using such a field in radiation therapy.

In this context there are broadly four groups of problems which can be considered separately and which need improvement of knowledge:

a) energy and momentum transfer cross sections of heavy charged particles and of slow electrons in condensed media;

b) schemes and probabilities of decays of excited states in complex biological target molecules (e.g. DNA, proteins, etc.) and liquid water, i.e. production probabilities for new chemical species;

c) fast chemical reactions of these new species with themselves and the matrix in a spatially nonhomogeneous situation;

d) concepts for the identification of relevant track structure properties and for classification regarding similarities and dissimilarities of track structures regarding their biological consequences.

Below some aspects of problem areas a), b), and d) will be discussed; fast chemical reactions in tracks and biological responses are subjects of several other papers presented at this workshop.

\section{Energy and Momentum Transfer Cross Sections}

For isolated atoms and molecules many cross sections describing the probabilities per track segment for elastic and ineclastic collisions of fast ions and electrons are available from experiments or theories. Therefore, for gaseous targets numerical charged particle track structure programs could be developped which can be used to simulate the stochastic collision histories of fast ions and electrons encountered during their slowing down with reasonable detail and accuracy (1-5). The results of such calculations can be tested and validated, e.g. by conparison with experimental data for particle penetration through 
slabs of gases (6), emission of light (7), energy spectrometry of moderated electrons (8), yields of ion pairs (9), etc.

In gases two facts are adventageous, namely the possibility to "blow up" the region of interest by using low gas pressures, and the locations of ionization, light emission, etc. are essential identical with the locations of the preceeding inelastic events. Nevertheless, also in gaseous targets the present knowledge on differential collision probabilities for electrons of sub-excitational energies still needs improvements.

Although some tentative track structure calculations have also been performed e.g. for liquid water $(10-12)$ and soiids $(13,14)$, the state of knowledge on energy and momentum transfer cross sections for charged particles to condensed targets (15) is not satisfactory, and in improvement is complicated by additional contributions of collective phenomena (16). Experimental validation of theoretical cross sections here is more difficult than for gases since there are limits to the minimum thickness of slabs, lateral extensions of tracks are very tiny, and collective phenomena can transport energy quanta away from the location of transfer to the location of absorption over considerable distances. Usefu1 data on interaction cross sections in condensed matter can be expected to come e.g. from low energy electron transmission and backscattering (17-19), studies of radiation interactions with molecular clusters (20-22), diffusion of very low energy electrons in electric fields (23-24), beam foil spectroscopy (25-27), etc.

Particular needs exist for cross sections of low energy electrons (say, below $100 \mathrm{eV}$ ) and low energy ions e.g. for slowing down natural alpha particles and recoil atoms from neutron collisions below ca. $1 \mathrm{MeV} / \mathrm{u}$. Such data are particularly missing for biological (i.e. organic) materials, since their low conductivity and stability in experimental environments make such scattering experiments rather difficult.

3. Primary Chemica1 Species

Energy and momentum transfer cross sections determine the energy loss and change in direction of the incoming particle; they do nut directly 
contain information on how and where this energy quantum tansferred is used for the excitation or ionization of target molecules nor how the absorbing molecule will be affected (e.g. by dissociation) and modified by this change in its electron structure. On the other hand, it is mainly the resulting chemical change of the target molecuies and the production of other new chemical species which start the sequence of reactions leading finally to an expression of a radiation effect.

In gases, such primary species (e.g. excitations, ionizations, dissociations) are experimentally accessible by observation of light output, collection of charged ions, mass spectrometry of fragments, etc. Because of high photon self absorption, short ranges, fast recombination, fast chemical reactions etc. such direct observations of new species are seriously hampered, and theoretical predictions on decay schemes after a given energy absorption of complex biological molecules are still rather uncertain. Some information, however, is available from absorption spectroscopy with very high time resolution (e.g. on hydrated electrons), from deep temperature ESR-spectroscopy, ESCA-data, conductivity measurements, etc.

Solution of this problem of the coupling of primary physical excitations to one or more electrons in particular parts of large molecules in condensed targets and the estimation of the resulting chemical changes suffers also from the fact that chemical yields depend on the physical state of the irradiated medium to a much larger extend as the energy loss of the penetrating radiation. The primary yields of ionizations in liquid water, e.g., is about 50 percent higher than in water vapour $(9,28,29)$, whereas differences in stopping power of fast electrons in both physical states amount to less than 10 percent. Therefore particle transport and coarse details of energy deposition in condensed matter can more reliably be extrapolated from gases to condensed matter than can spatial distributions of yields of new species. Therefore, progress in the quantitative identification of new chemical species produced by energy absorption at early times is important for a better understanding of al1 subsequent processes determining radiation action. 


\section{Concepts for Classifications of Track Structure}

For radiation research and applications of radiations it is necessary to establish and use the underlying "exposure - response" - relationships. In spite of many years of research it is still an unsolved important probiem which quantities should be used to quantify generally "exposure" to ionizing radiation. The basic problem can be subdivided into two classes, namely specification of different amounts or rates of "exposure" transferred from the same radiation field, and specification of the same amount/rate of "exposure" from different radiation fields.

It has become well known that absorbed dose alone is not a good quanti-

ty for neither case e.g. because

- at the important regime of low values of absorbed dose ( $\leq$ rad) the patterns of track structures in cells do no longer change proportional to dose but stay almost the same and only the number of cells affected changes proportional to this quantity (30),

- the same dose from different radiations normally does not give the same biological effects.

Therefore the introduction of the quantity RBE (relative biological effectiveness) in fact might have been radiobiologist's bjggest error, since RBE is quite inadequate as a dose based quantity for correlation between quantities describing the radiation track structures and measures for the finai radiation effects.

Since preliminary classification concepts have already been proposed, e.g. the joint probability functions of primary chemical species in tracks (31), track entities (32), micro-dosimetric functions (30), radial dose profiles (34), etc. Unfortunately, all of these approaches still have essential disadventages, and new ideas might come from different scientific fields (e.g. artificial intelligence, pactern recognition, mathematical psychology, fuzzy set theory, possibility theory, quantitative decision theory) were generally similar problems await solutions. 
Since better classification of amounts and types of primary changes due to a radiation interaction is essential for the scientific understanding of radiation actions and for the applications of ionizing radiations, research is encouraged to remedy the present situation.

\section{Conclusions}

Track structure research can be expected to provide essential new input necessary for the understanding of biological actions of ionizing radiations. Particular problems of knowledge still exist of the interaction cross sections of low energy heavy ions (e.g. from natural alpha emitters or recoils from neutron exposure) and of slow electrons in condensed matter, of the decay schemes of excited biological molecules, of fast chemical reactions in particle tracks, and of classification of charged particle track structures for correlation with final effects. The solution of these problems will benefit from interdisciplinary collaboration with other scientific fields as e.g. with atomic physics, quantum chemistry, solid state physics, molecular biology, statistics, informatics, etc.

\section{References}

1 M.J. Berger, in "Methods in Computational Physics", Vol. 1, B. Adler, S. Fernbach, and M. Rothenberg (Eds.), Academic Press, New York, 1963, p. 135.

2 H.G. Paretzke, in "Kinetics of Nonhomogeneuos Processes", G. R. Freeman (Ed.), Wiley, New York, 1987, p. 89.

3 B. Großwendt, in "8th Symp. on Microdosimetry", J. Booz, H.G. Ebert (Eds.), EUR-8395, Comm. Europ. Commun., Luxembourg, 1982, p. 79.

4 M. Terrisol, J.P. Patau, and T. Eudaldo, in "6th Symp. on Microdosimetry", J. Booz, H.G. Ebert (Eds.), EUR-6064, Harwood Academic Pub1., London, 1978, p. 169. 
5 M. Zaider, D.J. Brenner, and W.E. Wilson, Radiat. Res, 96 (1983) 231 .

6 A. Cole, Radiat. Res. 38 (1969) 7.

7 A.E. Grün, Z. Naturforschg. 12a (1957) 89.

8 G. Leuthold, Report S-862, Ges. f. Strahlen- und Umweltforschung (GSF), Neuherberg, 1982.

9 D. Combecher, Radiat. Res. 84 (1980) 189.

10 R.N. Hamm, H.A. Wright, R.H. Ritchie, J.E. Turner, and T.P. Turner, in "5th Symp. on Microdosimetry", J. Booz, H.r. Ebert and B.G.R. Smith (Eds.), EUR-5452, Comm. Europ. Commun., Luxembourg, 1976, p. 1037.

i1 G.J. Kutcher and A.E.S. Green, Radiat. Res. 67 (1976) 408.

12 M. Terrisol and J.P. Patau, in "7th Symp. on Microdosimetry", J. Booz, H.G. Ebert, and H.D. Hartfield (Eds.), EUR-7147, Harwood Academic Pub1., London, 1981, p. 414.

13 D.F. Kyser, in "Electron Beam Interactions with Solids for Microscopy, Microanalysis and Microlithography", Scanning Electron Microscopy, РОB 56507, AMF O'Hare, I11., p. 119.

14 L. Reimer, Optik 27 (1968) 86.

15 C.J. Powel1, in 1oc. cit. Ref. 13, p. 19.

16 H. Raether, "Excitation of Plasmons and Interband Transitions by Electrons", Springer-Verlag, Berlin, 1980.

17 L. Sanche, J. Chem. Phys. 71 (1979) 4860.

18 L. Sanche, G. Perluzzo, et al., J. Chem. Phys. 77 (1982) 3285.

L. Sanche, Phys. Rev. Lett. 53 (1984) 1638. 
20 T.D. Märk and A.W. Castleman, jr., Adv. Atom. Mo1. Phys. $\underline{20}$ (1984) 65.

21 O.F. Hagena and W. Henkes, Z. Naturforsch. 20a (1965) 1344.

22 J. W. Otvos and D.P. Stevenson, J. Am. Chem. Soc. 78 (1956) 546.

23 G. R. Freeman, in 1oc. cit. Ref. 2, p. 19.

24 A. Humme1, in 1oc, cit. Ref. 2, p. 215.

25 H.D. Betz, Rev. Mod. Phys. 44 (1972) 465.

26 J. Bromander, Nuc1. Instr. Meth. 110 (1973) 11 .

27 J. Davidson and W.S. Bicke1, Nuc1. Instr. Meth. 110 (1973) 253.

28 T. Sumiyoshi and M. Katayama, Chem. Lett. 12 (1982) 1887.

29 J.W. Hunt, in "Advances in Radiation Chemistry", Vo1. 5, M. Burton and J.L. Magee (Eds.), Wiley, New York, 1976, p. 185.

30 International Commission on Radiation Units and Measurements, Report 36 "Microdosimetry", Bethesda, MD, 1983.

31 U. Fano, in "Charged Particle Tracks in Solids and Liquids", G.E. Adams, D.K. Bewley, and J.W. Boag (Eds.), Inst. of Physics, Conference Series No. 8, London, 1970, p. 1.

32 A. Mozunder and J.L. Magee, Radiat. Res. 28 (1966) 203.

33 International Commission on Radiation Units and Measurements, Report 16 "Linear Energy Transfer", Bethesda, MD, 1970.

34 R. Katz, S.C. Sharma, and M. Homayoonfar, in "Topics in Radiation Dosimetry - Radiation Dosimetry Supplement 1", F.H. Attix (Ed.), Academic Press, New York, 1972, p. 317. 


\section{LINKING PHYSICAL INTERACTIONS WITH LATER CIIMICAL AND BIOLOGICAL EVENTS IN IRRADIATED LIQUID WATER*}

H. A. Wright, R. N. Hamm, and J. E. Turner

Health and Safety Research Division, Oak Ridge National Laboratory

Oak Ridge. Tennessee

\section{and}

A. Chat ter jee and J. L. Magee

Lawarence Berkeley Laboratory, University of California

Berkeley, California

\section{INTRODUCTION}

A major concern of society today is the biological effects of radiation. particularly at low levels where radiobiological or epidemiological studies are either impossible or impractical to perform. Perhaps the besi hope for understanding these effects, and for establishing an effective radiation protection program, is in understanding the details of the physical and chemical interactions that are produced in biological systems by radiation. This requires an understanding of the relationship between initial physical interactions that occur following the passage of a charged particle. subsequent diffusion-controlled chemical reactions, and later biochemical and biological effects, which may not become evident for years. We have recently made significant progress toward linking the initial physical events and later chemical events in liquid water.

When a charged particle traverses matter, it undergoes physical interactions with atoms and molecules of the material producing ionizations. excitations, and secondary electrons. These physical interactions are

* Research sponsored by the Office of Health and Environmental Research. U.S. Department of Energy, under contract DE-ACO5-840R21400 with Martin Marietta Energy Systems. Inc., and contract $W-7 \cdot 105-45$ with the University of California, Lawrence Berkeley Laboratory. 
complete in a local region of space in a very short time of the order of $10^{-16} \mathrm{~s}$. These physical energy transfer events result in the production of reactive chemical species that can react with each other or with other molecules in the medium. Thus, when a charged particle penetrates a biological cell it may produce direct physical interactions with a sensitive biological molecule such as DNA, or it may interact with the surrounding medium. mostly water, producing chemical species which can diffuse through the medium and produce indirect chemical interactions with the DNA. However, these events, even though they are extremely important, are very difficult, if not impossible, to measure directly and are not well known.

The physical interactions that a charged particle undergoes with a molecule can be measured in gas phase where single interactions with isolated molecules can be observed. However, in condensed matter collective effects occur, involving a large number of molecules simultaneously. The degree to which gas phase interactions are applicable in condensed phase is not completely known. Several differences are known to exist. ${ }^{1-2}$ For example. ionization thresholds are lowered in condensed phase, w-values (energy needed to produce an ion pair) are reduced and collective oscillations (plasmons) may result in delocalization of energy transfer events to tens of angstroms away from the trajectory of the charged particle.

We have developed a Monte Carlo code to transport a charged particle through liquid water and calculate the position and identity of each energy transfer event that the charged particle and all of its secondaries undergo.J We have also developed a model to determine the reactivi: chemical species that result from these physical interactions ${ }^{4}$ and have developed a Monte Carlo code to simulate the diffusion and chemical reactions that these chemical species 
undergo with each other and with other biological molecules such as DNA in aqueous solution. $5-7$

In the following sections of this paper we briefly discuss the above code, show some of the results that can be obtained, and finally discuss a new theoretical and experimental program that we have initiated to determine the fundamental physical and chemical mechanisms of radiation induced damage to biological molecules such as DNA.

\section{DESCRIPTION OF THE CALCULATIONS}

When a charged particle penetrates a condensed medfum such as liquid water. much of the energy transferred to the medium appears first as a collective oscillation (plasmon) that may involve the coherent collective oscillation of $10^{9}$ electrons. The plasmon then decays into a specific energy transition producing an excitation or ionization in a molecule that may be located tens of angstroms from the trajectory of the charged particle. This process occurs very rapidly within a time of the order of $10^{-16} \mathrm{~s}$. These individual energy loss events cannot be measured directly for the liquid phase as they can for gas phase. Consequently much less is known about energy transfer mechanisms in condensed media. However. since biological systems exist in the condensed phase it is essential to understand such events in order to understand the mechanisms of radlation damage to biological systems. We have recently made significant progress toward understanding these mechan isms.

We have developed a technique to determine elementary cross sections (differential inverse mean free paths) for charged particles traversing liquid water. 8 -10 We start with optical data on liquid water, develop a dielectric response function, and from that the energy loss function. Collective effects that are present in the liquid phase are therefore included a priort. We have 
used these cross sections to develop a Monte Carlo transport code, ORFC, to transport charged particles such as electrons, protons, and alpha particles. through liquid water and calculate the position and identity of each individual energy transfer event produced by the primary particle and all of its secondaries. The species that are present at $\sim 10^{-15} \mathrm{~s}$ after the passage of the particle are ionized water molecules, $\mathrm{H}_{2} \mathrm{O}^{+}$, excited water molecules. $\mathrm{H}_{2} \mathrm{O}^{*}$, and subexcitation electrons, $e^{-}$. We have developed a model for the ion-molecule interactions that occur from these species in the prechemistry time frame before approximately $10^{-12} \mathrm{s.}$ These reactions produce the reactive chemical species $\mathrm{i}, \mathrm{OH}, \mathrm{H}_{3} \mathrm{O}^{+}, \mathrm{O}_{\text {aq }}^{-}$and $\mathrm{H}_{2} \mathrm{O}_{2}$. A Monte Carlo code has also been developed to determine the identity and location of each of these chemical species produced as a result of the passage of the charged particle. Furthermore, we have developed a model to simulate the diffusion and chemical reactions that these species undergo as a function of $t$ ime and have developed a Monte Carlo program to follow each individual reactant through the diffusion and chemical reaction stage of the track evolution out to $10^{-6} \mathrm{~s}$ after passage of the primary charged particle. ${ }^{6-6}$ Finally, we have developed a very simple model of a DNA molecule as a right circular cylinder with alternating "sugar" and "base" sites on two helical strands around the surface of the cylinder. We have performed calculations for charged particles that traverse the water at various distances from the DNA and have calculated the direct physical and indirect chemical events on the DNA. ${ }^{7}$

This program represents the first time that calculations have been performed forward in time from initial physical events $\left(10^{-16} \mathrm{~s}\right)$ through diffusion and chemical reactions to $10^{-6} \mathrm{~s}$. It therefore provides the first direct link between radiation physfcs and radiation chemistry in liquid water. The code follows each individual chemical specles through the diffusion 
process, and thus the position and identity of each single species is known at any time and the chemical yields or G-values (number per $100 \mathrm{eV}$ of energy) can be tabulated as a function of time after the passage of the primary charged particle.

\section{RESULTS}

Since the input cross sections that are used in the calculations cannot be measured directly in liquid water, experimental verification of the calculations must be done in some other way. He have calculated chemical yields that occur at later times which can be measured and have been encouraged at the agreement we have abtained. Experimental data are available for the Fricke dosimeter, and we have calculated the Fricke G-value by the formula $a^{5}$

$$
\mathrm{G}\left(\mathrm{Fe}^{3+}\right)=2 \mathrm{G}_{\mathrm{H}_{2} \mathrm{O}_{2}}+\mathrm{G}_{\mathrm{OH}}+3\left(\mathrm{G}_{\mathrm{H}}+\mathrm{G}_{\mathrm{e}_{\mathrm{aq}}^{-}}\right)
$$

We have obtained good agreement with measured Fricke yields for electrons, protons, and alpha particles of various energies. However, a much more $r$ igorous experimental test of the calculations is the comparison of the time decay of $e_{a q}^{-}$and $O H$ measured in pulsed radiolysis experiments for high-energy electrons in liquid water. Figure 1 shows a comparison of the G-values of $O H$ and $e_{a q}^{-}$as a function of time as obtained in these calculations with experimentally measured values. ${ }^{1-13}$ There is excellent agreement with the OH yield and also with the $e_{a q}^{-}$at about $10^{-9} \mathrm{~s}$ and later. The discrepancy in the $e_{\text {aq }}^{-}$yield at times earlier than $10^{-9} \mathrm{~s}$ is not considered significant and is thought to be due to an assumption in the calculations that certain high-lying excited states of the water molecule autoionize and give rise to extra 
electrons. The model allows for some of these excitations to relax without autolonizing. but since there are no data at present which give the fractlons of the excitations that relax we have. for now. assumed that all of them autoionize. This comparison with experiment is considered an excellent test of both the physical cross sections and the chemical diffusion simulation that is used in the calculations. The agreement is quite encouraging that the calculations are providing a reasonable simulation of the physical and chemical processes that occur.

Figure 2 shows the chemical evolution of a $0.7-\mu m$ segment of the track of an 8-MeV alpha particle. The data represent the positions of the reactive chemical species resulting from the passage of the alpha particle and all of its secondary electrons. Some of the energetic secondary electrons produce delta-ray tracks, which can be clearly seen in the figure. The upper left panel shows the track at $10^{-11} \mathrm{~s}$, the beginning of chemical diffusion. At that time there were 9932 species in the track segment shown by the positions of the 9932 dots on the figure. The remaining panels show the positions and number of species at various later times as the species diffuse and react. At $10^{-6} \mathrm{~s}$ there were 2069 species lef $\mathrm{t}$ as shown in the lower $r i g h t$ panel.

Figure 3 shows the tracks of a $4-M e V$ alpha particle, 1-MeV proton, and a 10-MeV proton traversing a segment of DNA in liquid water. As noted above. at present we only consider a very crude model of DNA as a right circular cylinder. This figure shows the relative density of reactive chemical species, shown by the points in the track. as compared with the size of the DNA. It is seen that a 10-MeV proton may pass directly through the center of the 20- diameter DNA molecule and not produce a single event there. However. the chemical species produced in the surrounding water can diffuse and reach a reactive site on the DNA. 
Finally. we show in Fig. 4 the calculated total number of physical and chemical reactions that would be produced in a segment of DNA by protons and alpha particles of various energies that pass directly through the center of the DNA. It is seen that a 4-MeV alpha particle wlll, on the average. produce between 60 and 70 interactions on the DNA whereas a 10-MeV proton will produce only 3 or 4 such events.

It should be noted that in the computer code. the nature of each single interaction is known. and therefore such information as the number of $\mathrm{OH}$ radical interactions with the DNA could be tabulated.

\section{OONCLUDING REMARKS}

This program offers great promise of being able to identify the specific interactions that produce molecular damage in biological molecules, and we have recently initiated a program to do just that. In the program we propose to measure various types of damage to biological molecules under a variety of irradiation conditions. Measurements will be made for different types of radiation such as electrons and alpha particles under a variety of conditions such as in the presence or absence of oxygen. various concentrations of scavengers, etc. We will then perform calculations to simulate the irradiation conditions and compare the results with the measurements. We will start with simple amino acids where the structure of the molecules is simple enough to be Included in the calculations. The results of the measurements will then be used to establish the parameters of the model and to verify the ability of the model to predict the experimental results under all of the irradiation conditions. The calculations will then identify the specific events that produce the biological damage. We will then move to more complex molecules such as oligonucleotides and double-stranded DNA subunits with various base sequences. 
Although it is realized that this is an ambitious program, we are confident that the techniques that we have developed over the last decade now puts us in a position to have a high probability of success which wll make significant contributions to understanding the fundamental mechanisms of radiation damage to biological systems.

This program therefore offers great promise of contributing significantly to a radiation protection program for obtaining radiation risk estimates even for very low doses of radiation where the greatest concern exists today.

\section{REFERFNCTS}

1. J. E. Turner, H. G. Paretzke, R. N. Hamm, H. A. Wright, and R. H. Ritchie, "Comparative Study of Electron Energy Deposition Yields in Water in the Liquid and Vapor Phases," Radiat. Res. 92, 47-60 (1982).

2. H. G. Paretzke, J. E. Turner, R. N. Hamm, H. A. Wright, and R. H. Ritchie, "Calculated Yields and Fluctuations for Electron Degradation in Liquid Water and Water Vapor," J. Chem. Phys. 84, 3182-88 (1986).

3. R. N. Hamm, J. E. Turner, R. H. Ritchie, and H. A. Wright, "Calcuation of Heavy-Ion Tracks in Liquid Water." Radiat. Res., Suppl. 8, 104. S-20-S-26 : :985;

4. J. E. Turner, J. L. Magee, R. N. Hamm. A. Chatterjee. H. A. Wright, and R. H. Ritchie. "Early Events in Irradiated Water," Proceedings of the Seveniti Symposium on Microdosimetry, Oxford. England, EUR 7147 (London. Harwood Academic), Vol. I, pp. 507-17 (1081).

5. J. E. Turner, J. L. Magee, H. A. Wright, A. Chat terjee, R. N. Hamm, and R. H. Ritchie. "Physical and Chemical Development of Electron Tracks in Liquid Water," Radial. Res. 96.437-49 (195:3). 
6. H. A. Wright, J. L. Magee, J. E. Turner, A. Chat ter Jee, R. N. Hamm, and R. H. Ritchie. "Physical and Chemical Evolution of an Electron Track in Liquid Water." Proceedings of the Eighth Symposium on Mtcrodostmetry. Jülich (London, Harwood Academic), pp. 101-09 (1983).

7. H. A. Wright, J. L. Magee, R. N. Hamm, A. Chat terjee, J. E. Turner. and C. E. Kiots. "Calculations of Physical and Chemical Reactions Produced in Irradiated Water Containing DNA," Radiat. Protec. Dosim. 13, 133-36 $\{1985)$

8. R. H. Ritchie, R. N. Hamm, J. E. Turner, and H. A. Wright, "The Interaction of Swift Electrons with Liquid Water." Proceedings of the Sixth Symposium on Microdosimetry, Brussels, Belgium, EUR 6064 (London. Harwood Academic). Vol. I, pp. 507-17 (1981).

9. R. N. Hamm, H. A. Wright, R. H. Ritchie, J. E. Turner, and T. P. Turner, "Monte Carlo Calculation of Transport of Eiectrons Through Liquid Water." in Fifth Symposium on Microdosimetry. Verbania-Pallanza. Italy (J. Booz. H. G. Ebert, and B.G.R. Smith, Eds.), pp. 1037-50, Commission of the European Communities, Luxembourg, 1976.

10. R. N. Hamm, R. H. Ritchie, J. E. Turner, and H. A. Wright, "Inelastic Cross Sections for Electron Interactions in Liquid Water." Proceedings of the Workshop on the Interface Between Radiation Chemistry and Radiation Physics. Argonne National Laboratory. September 9-10, 1982. pp. 32-36. Report ANL-82-88, Argonne National Laboratory. Argonne. Illinois (1982).

11. Charles D. Jonah and John R. Miller. "Yield and Decay of the OH Radical frum 100 ps to 3 ns," J. Phys. Chem. 81, 1974-76 (1977).

12. C. D. Jonah, M. S. Matheson. J. R. Miller, and E. J, llart, "Yield and Decay of the Hydrated Electron from 100 ps to $3 \mathrm{~ns} . " J$. Phys. Chem. 80. $1267-70(1976)$ 
13. Conrad N. Trumbore, Walter Youngblade, and David R. Short, "Computer Modeling of Data from Pulse Radiolysis Studies of Aqueous Solucions Containing Scavengers of Spur Intermediates." J. Phys. Chem. 88, 5057-61 (1984).

\section{FIGURE CAPTIONS}

Fig. 1. Comparison of calculated and measured yields of OH radicals and hydrated electrons as a function of time after passage of high-energy electrons.

Fig. 2. Chemical development of an 8-MeV alpha particle track of length $0.7 \mu \mathrm{m}$. The number $N$ of reactive species remaining at different times is shown in each of the panels and the dots show the positions of the species.

Fig. 3. Tracks of a 4-MeV alpha particle, a 1-MeV proton, and 10-MeV proton are shown superimposed on a segement of a DNA molecule. approximated by a right circular cylinder with alternating sugar and base reactive sites on two helical strands around the cylinder.

Fig. 4. The total number of both direct physical and indirect chemical interactions with DNA produced by protons and alpha particles of different energies that pass directly through the center of the DNA and perpendicular to its axis. 
ORNL-DWG 85C-8973

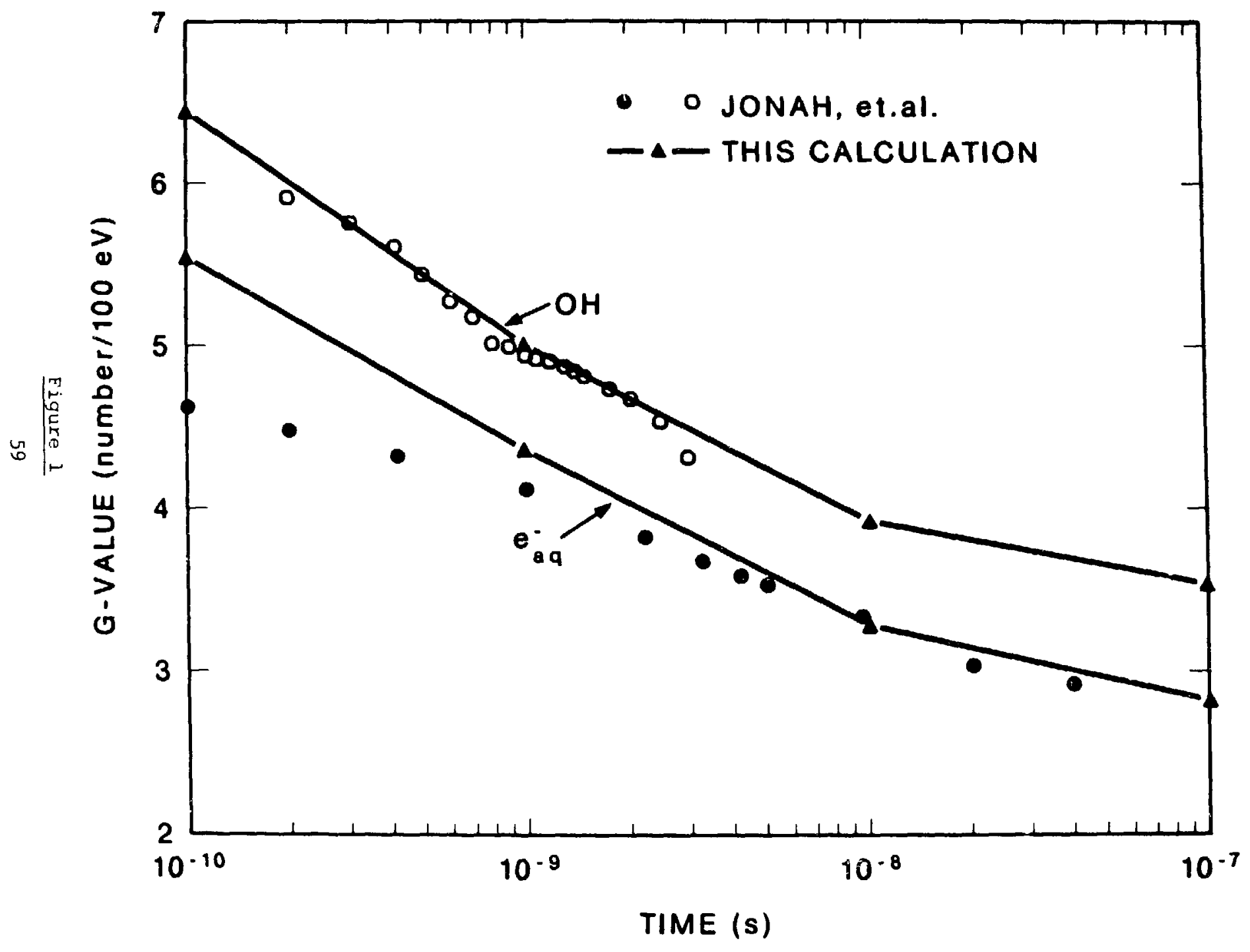




\section{$8 \mathrm{M} \in V$ ALPHA}
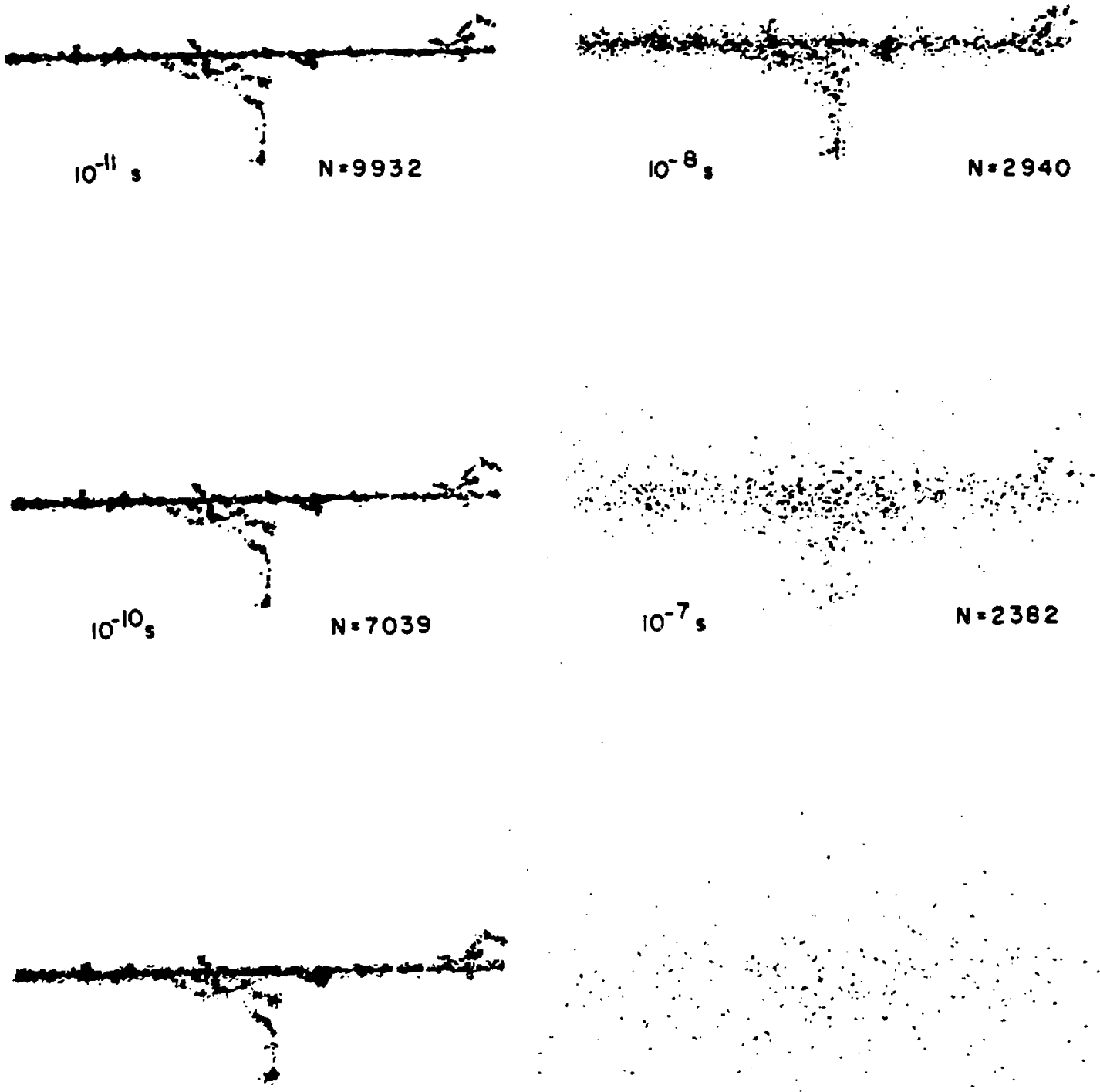

$$
10^{-9}
$$

$$
10^{-6} \mathrm{~s}
$$

$N=2069$ 


\section{4-MeV ALPHA}

\section{1-MEV PROTON}

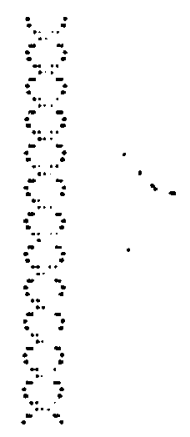


OANL-DWO 85C-9872

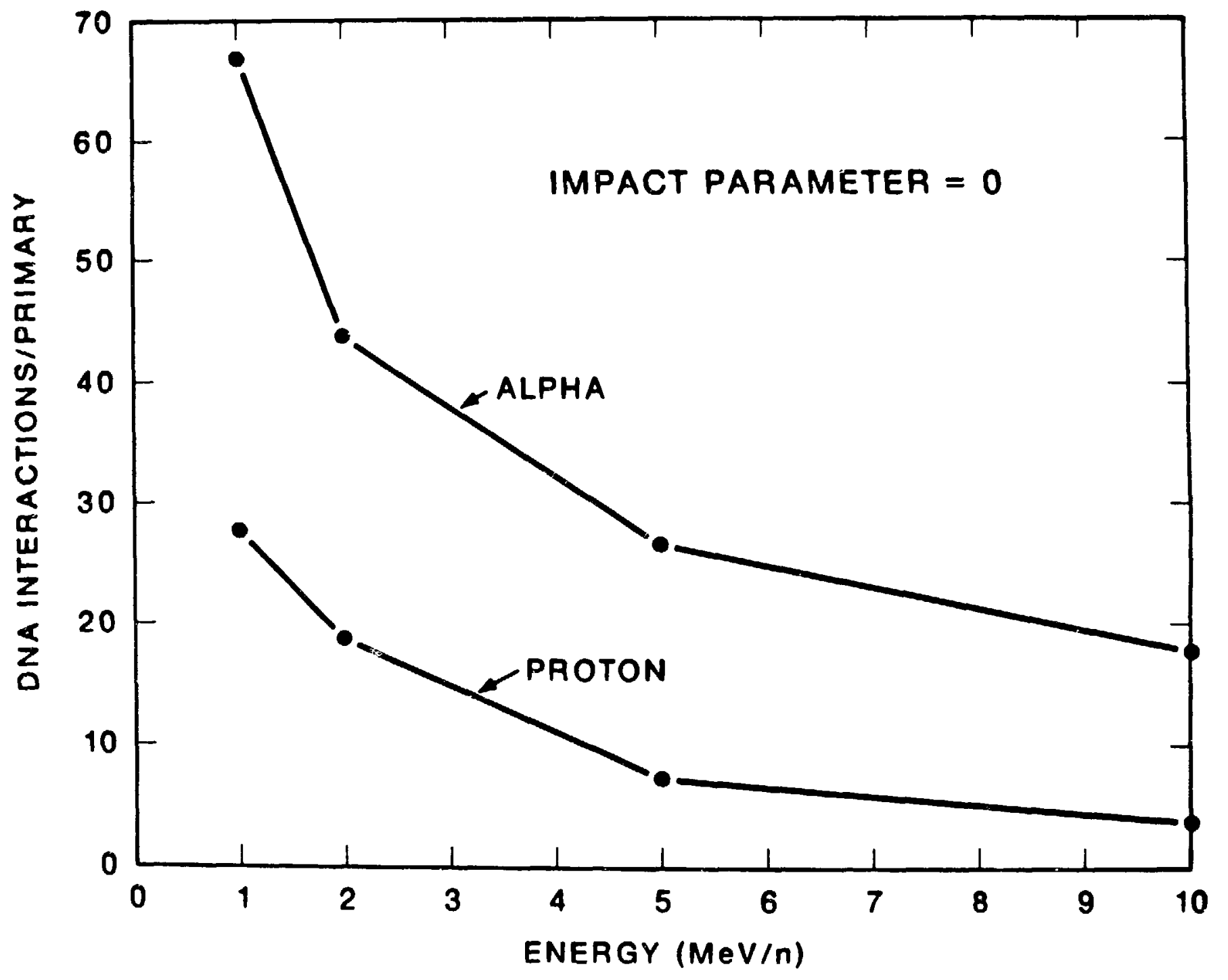




\section{DYNAMICS MODELS IN RADIOBIOLOGY \\ Cornelius Tobias \\ Lawrence Berkeley Laboratory \\ University of Caljfornia, Berkeley, CA 94720}

\section{INTRODUCTION}

When a physicist is asked to describe a system in a quantitative manner, he usually attempts to reduce the system to a minimum number of meaningful variables consistent with available experimental findings and to provide a nonredundant number of relationships between these. Such efforts led physicists to conceive the existence of a Few "elementary particles" and to propose a very small number of possible interactions between these.

It seems difficult to quantitatively describe cellular responses to radiation or to other environmental agents in terms of one or two variables. We are becoming more and more aware that the behaviour of even the simplest living systems depends on thousands of independent parameters that are determined by the large numbers of separate genes in the cell nuclei. The early models for radiobiology were based on simple quantitative assumptions, as in the target theory. As a wealth of information became available, it seemed important to add variables as needed, so that a variety of experimental observations could be quantitatively described.

Theoretical Modeling of Biological Effects

Models can be classified as being either restrictive or global. "Restrictive" models are applied to macromolecular changes in well-defined systems with controlled environments; e.g., in the study of radiation effects on circular DNA. In contrast, "global" models attempt to predict sequences of events in complete biological systems, such as the radiobiology of living, cultured cells, or of tissues in vivo. It is very important to establish valid relationships between the restrictive concepts and the more global understanding of radiobiological phenomena.

It is well known that radiation effects are essentially quantum phenomena in the sense that in some systems the exchange of a single quantum of energy 
can lead to a permanent macroscopic change in the properties of the entire system. For all quantum phenomena there are serious limitations in our ability to measure. In the case of living cells, we are usually limited to macroscopic observations on the system before the exchange of radiant energy occurs. Usually we must wait for a considerable time until the effects caused at smaller scales are finally expressed at the macroscopic scale. Such observations gave rise to early phenomenological models. These predicted the eventual expression of radiation damage from the inttial absorption events. These models I have classified as "static", because the passage of time is not explicit. Static models are adequate to describe some specific effects in molecular systems extracted from living cells. However, in intact cells all phenomena progress in time. Hodels that describe the progression of radiobiological events, we may classify as "dynamic". Table I lists sereral static and dynamic models.

The static models recognize that injury to some structures in the cell nucleus is crucial. The target theory (1) assumes that dose and target rolume are the only important variables. The effects of hits in the target are all or none. The dual-action theory (2) recognized that there is a microscopic distribution of energy transfer events and postulated that there are different kinds of lesions, these either cause irreversible effects, or are sublesions that interact to form irreversible lesions. The assumption of a critical volume in microdosimetry, has caused some conceptual difficulties, however. The proponents of this theory (3) have changed their approach from "microdosimetry" to "nanodosimetry". In order to move away from the all or none approach, the hit-size effectiveness model (4) recognizes that various distributions of energy transfer events might produce various degrees of 
effects in living cells. The hit-size effectiveness may be determined directly by bioexperiment, or by appropriate modeling assumptions.

Most of the dynamic models recognize that the fate of cells with radiation-induced lesions depend on enzymatic repair processes. The molecular model of Chadwick and Leenhouts $(6-8)$ is formally similar to the dual action theory. It makes the specific assumption that DNA double-strand (DS) breaks are responsible for cellular lethal effects, and that interactions between the repair processes of two separate single-strand (SS) breaks produce DS breaks with some time delay. However, in spite of early encouraging results (9) the formation of additional DS breaks in the time period following radiation injury has not been convincingly demonstrated. Roesch and associates $(10,11)$ assumed that an important variable is dose rate. They reyrote the dual-action model using the assumption that there is a linear time-dependent repair process for sublesions. Haynes (12) introduced the concept that the rate of repair within cells might become saturated, and Goodhead (13) calculated some relationships that depend on the availability of repair enzymes.

Ionizing radiations produce a variety of different lesions in living cells and the process of producing lesions is quite different from the processes of repair. Unfortunately the word "repair" is not unequivocally defined. To the molecular scientist, repair often means repair synthesis of DNA. Cleaver (14) demonstrated that various DNA lesions are repaired at very different rates in time. Single-strand breaks are repaired in a few minutes, whereas covalent DNA crosslintes might take 24 hours to repair. To the cell biologist, repair means more complex biological processes, such as the repair of . "sublethal damage" (15) or "potentially lethal damage" (16). These can be quantitated by measuring cell survival probabilities. 
The Repair Misrepair (RMR) model (17-19) has offered a method to separate two of the essential phases of the process of infury from lonizing radiation: the production of radiolesions and their repair. Kappos and Pohl1t (20) in their cybermetic model assumed a time dependent branching process. Curtis (21) merged some of the ideas of the dual action, cybermetic and RMR models. The great majority of initial events of energy transfer and diffusion-controlled, free-radical reactions occur usually in less than $10^{-3}$ seconds. These result in metastable macromolecular lesions in chromatin. The repair processes, which involve recognition of the leions and enzymatic processes, occur much slower for mammalian cells, usually in a time frame of minutes to hours. Hathematically, the kinetics of the two processes are also separable.

The nature and distributions of lesions depend on the physical parameters of the energy transfer, the structure and geometry of distribution of DNA in the cell nucleus, and on the chemical milieu vithin the nucleus. Repair processes on the other hand are performed by enzymes and apparently recognize the nature of the lesions. The kinetics of repair therefore depend not only on rate constants but also on the availability, synthesis and degradation of the repair enzymes. It was also necessary for the RMR model to distinguish bet:een "Eurepair", where the structure of DNA is reestablished without error and "Misrepair". Misrepair usually means that the chemical process of repair has been completed, but that the coding sequences of DNA have been changed. It is possible that ordinary chemical kinetic studies of repair would usually not detect misrepair.

The Elkind (22) split-rose repair process indicates that living cells have time-dependent memories tor the presence of earlier radiation-induced lesions. The kinetics of processes that have memory cannot be adequately 
described with linear differential equations and for this reason, the equation that describes the mean rate of repair in the RMR model is a nonlinear differential equation. The simplest form of this equation postulates two kinds of repair: self repair of lestons proceeds with linear kfnetics, whereas cooperative repair has quadratic kinetics. The RMR model requires some knowledge of the nature and distribution of radiation-induced lesions in the genome. When these are available, the RMR equations can describe cellular survival in split-dose experiments in an adequate manner. The quadratic term in the differential equation has an obvious relationship to well-known cytogenetical findings: the occurrence of chromosome deletions and translocations.

An important role for models is to suggest new avenues for research and interpretation. The formalism of the RMR model suggested interactions between the effects of low- and high-LET radiations at a time when it was believed that these two modes act independently (23). The RMR model also provided a quantitative framework for the analysis of the effects of mixed radiations and an experimental effort is still underway to verify the method of analysis.

We know that ionizing radiations produce a variety of classes of lesions in genetic material. Models can help to assign appropriate roles to some of these lesions in the course of development of permanently-expressed effects (See Fig. 1). Base-alterations or small deletions or the formation of pyrimidine dimers are very efficiently repaired, and therefore are not the most likely causes of the effects of ionizing radiation. A lethal dose of ionizing radiation does not produce enough such lesions in normal mammalian cells. The RMR model has led to the conclusion that single-strand scissions also do not appear to be a major cause of lethality. The rate of repait of single-strand scissions does not correspond to the rate of cellular repair. 
Tire primary role of Diva double-strand scissions in producing lethality in Yeast cells has been experimentally demonstrated by direct measurements of DS breaks and by the high radiosensitivity of recombinational repair-deficient cells (24). In the case of mammalian cells, the role of DNA DS breaks has long been suspected, but never clearly proven. The rate of DS-break repair has not been very reliably measured for short time intervals. The slow component of DS break repair is about the same as the split-dose repair time of living cells. However, it appears that the number of DS breaks per genome, measured by elution techniques, is too high.

Most of the published models for cellular radiobiology assume that radiation-induced lesions occur independently from each other and following Poisson statistics. When we considered this problem from the point of view of the RMR model, it became apparent that a specific arrangement in the spatial distribution of chromatin in the cell nucleus might change the statistical distribution of lesions. It has also become obvious that a single highly-ionized charged particle is capable of producing an array of lesions along its track. Since the distribution of delta rays along the track of an ionizing particle may be regarded as a cluster, we are developing a new model for the distribution and repair of radiolesions: the RMR Cluster model (Tobias, in preparation).

A cluster of delta rays on a cluster of genetic material produces a cluster of radiolesions. Repair and misrepair are modifications of the clustering of lesions. Formally the cluster model is using distributions, similar to those derived by Neyman (25). Neyman used superimposition of Poisson distributions, whereas for track effects, the combinatica of Poisson and binomial distributions appear more germane. Figure 2 shows a typical theoretical distribution of lesions at various dose levels. 
Edwin Goodwin in our laboratory (26) has used the method of premature chromosome condensation (PCC) in order to study chromatin scission produced by ionizing particles of various LET. He has shown that a single, heavy, high-LET particle can make as many as 12 separate chromatin breaks in the nucleus of a single cell. At low LET the probability of a single lesions by a single particle crossing the cell nucleus is very low. Figure 3 shows that the mean number of particle "hits" differs considerably from the mean number of lesions per cell nucleus. The number of chromatin breaks detected by this technique is several times lower than the number of DNA breaks measured after the cells are chemically processed. A possible explanation for the discrepancies might be that DNA DS breaks are not the same as chromatin breaks. Lethality and chromosome aberrations correlate sell with the chromatin lesions per cell. Chromatin breaks might involve additional lesions in the proteinaceous nucleoskeleton. The essential lesions are not merely DNA DS breaks, but perhaps special forms ó́ DS breaks accompanied by greater structural damage.

There is a strong current conviction among biophysicists that the radiobiological mechanisms must be understood at the molecular level. We should point out that the existence of multilesions along tracks would not have been discovered with standard techniques of measurements of DNA strand breaks. An important aspect of radiobiology should be the study of the microscopic organizations within the cell nucleus, and how these relate to multimolecular events, such as chromosome aberrations.

The RMR model has allowed us to relate mathematical concepts involving the rates of repair to proposed molecular schemes for repair. Briefly, it appears that the "self" repair of individual lesions that involve DS breaks is a process in mammalian cells similar to homologous recombinational repair in 
yeast cells. However, mammalian cells can readily integrate foreign DNA without the necessity of a complete template in the cell. This type of repair is nonhomologous repair. The possibility exists that rejolning of two pieces of DNA depends oriy on small structurally homologous sections. The elucidation of the complete mechanism is an immediate challenge for molecular radiobiology.

There are hamster, mouse, and human cell lines that are highly sensitive to ionizing radiation because the repair mechanisms for DS breaks are Eauly (27-31). The faulty DNA in the sensitive cells can be complemented by DNA from repair-competent human cells. Progress is being made to isolate and learn the sequence of at least one of the human repair genes (Chen, Los Alamos National Laboratory, private communication).

The chemical identification of crucial repair genes is only a step in unraveling the mechanism. From the point of view of the physicist, ve need an understanding of the dynamic process of repair, including knowledge of the pathways for information exchange and the energetics of the repair process. Further, it will be necessary to know how the kinetics of repair fits into the systematical events occurring during the cell division cycle.

A very modest effort has been started, aimed at understanding the systematics of DNA application in mammalian cells and the effects of radiation on this process (see Fig. 4). We plan to model DNA replication as a self-propagating mechanism. When DNA replication is initiated at one site, a protein messenger signal propagates to other replicons in order to sustain the chain of events. 
ACKNOWLEDGEMENTS

The author is grateful to Dr. Eleanor Blakely for helpful discussions, and to Mardel Carnahan and Lilian Hawkins for their assistance in preparing the manuscript. This work was supported by NCI \#CA-15184 and DOE \#DE-AC03-76SF00098. 


\section{REFERENCES}

1. D.E. LEA, Actions of Radiations on Living Cells: Cambridge University Press (1946).

2. A.M. KELLERER and H.H. ROSSI, A generalized formulation of dual radiation action. Radiat. Res. 75, 471-488 (1978).

3. M. ZAIDER and H.H. ROSSI, Dual radiation action and the initial slope of survival curves. Radiat. Res. 104, S-68-S-76 (1985).

4. V.P. BOND, i1.N. VARMA, C.A. SONDHAUS, and L.E. FEINENDEGEN, in alternative to absorbed dose, quality, and RBE at low exposures. Radiat. Res. Suppl. 8, 104 S-52-S-57 (1985).

5. V.P. BOND and M.N. VARMA, Stochastic-weighted hit-size theory of cellular radiobiological action. In Proceedings of the Eighth Symposium on Microdosimetry, Julich, Nest Germany. Commission of the European Communities, Luxembourg (1982).

6. K.H. CHADWICK and H.P. LEENHOUTS, A molecular theory of cell survival. Phys. Med. Biol. 13, 78-87 (1973).

7. K.H. CHADWICK and H.P. LEENHOUTS, The rejoining of DNA doutle strand breaks and a model for the formation of chromosomal rearrangements. Int. J. Radiat. Biol. 33, 517-529 (1978).

8. K.H. CHADWICK and H.P. LEENHOUTS, The molecular model for cell survival following radiation. In The Molecular Theory of Radiation Biology, pp. 25-50. Springer Verlag, New York (1981).

9. D.L. DUGLE, C.J. GILLESPIE, and J.D. CHAPYAN, DNA strand breaks, repair, and survival in X-irradiated mammalian cells. Proc. Matl. Acad. Sci. (USA) 73, 809-812(1976). 
10. H.C. ROESCH, In Third Symposium on Neutron Dosimetry in Blology and Medicine (G. Burger and H.G. Ebert, Eds.), p. 1. Commission of the European Communities, Luxembourg (1978).

11. L.A. Braby and W.C. ROESCH, Testing of dose-rate models with chlamydomonas reinhardi. Radiat. Res. 76, 259-270 (1978).

12. R.H. HAYNES, The influence of repair processes on radiobiological survival curves. In Cell Survival after Low Doses of Radiation ( $T$. Alper, Ed.) pp. 197-208. Institute of Physics, Viley, London (1975).

13. D.T. GOODHEAD, Saturable repair models of radiation action in mammalian cells. Radiat. Res. 104, S-58-S-67 (1985).

14. J.E. CLEAVER, DNA repair and replication. In Biochemical Mechanisms of Genetic Disorders (B.J. Benke, Ed.). New York: Dekker (1984).

15. M. D. ELKIND and $H$. SUTTON, Radiation response of mammalian cells gro:n in culture. I. Repair of $x$-ray damage in surviving Chinese hamster cells. Radiat. Res. 13, 556--593 (1960).

16. R.A. PHILLIPS and L.J. TOLMACH, Repair of potentially lethal damage in X-irradiated HeLa cells. Radiat. Res. 29, 413-432 (1966).

17. C.A. TOBIAS, E.A. BLAKELY, F.O.H. NGO, and T.C.H. YANG, The repair-misrepair model of cell survival. In Radiation Biology and Cancer Research (R.A. Meyn and H.R. Withers, Eds.), pp. 195-230 (1980).

18. C.A. TOBIAS, N. ALBRIGHT, and T.C. YANG, The roles of ionizing radiation in cell transformation. From Proceedings of the Berkeley Conference in Honor of Jerzy Neyman and Jack Kiefer, Volume I, (L.i. LeCam and R.A. Olshen, eds.). Vads'sorth, Inc. 1985.

19. C.A. TOBIAS, The repair-misrepair model in radiobiology: Comparison to other models. Radiat. Res. 104, S-77-S-95 (1985). 
20. A. KAPPOS and W. POHLIT, A cybernetic model for radiation reactions in living cells. I. Sparsely ionizing radiations; stationary cells. Int. J. Radiat. Biol. 22, 51-65 (1972).

21. S.8. CURTIS, Lethal and potentially lethal lesions induced by radiation: a unified repair model. Radiat. Res. 106, 252-270 (1986).

22. M.M. ELKI:ID, Repair processes in radiation biology. Radiar. Res. 100, 425-449 (1984).

23. F.Q.H. :GO, E.A. BLAKELY, and C.A. TOBIAS, Sequential exposures of mammalian cells to low- and high-LET radiations. I. Lethal effectd following X-ray and neon-ion irradiation. Radiat. Res. 87, 59-78 (1981).

24. K.S.Y. HO and R.K. HORTIMER, Two mutations which confer temperature-sensitive radiation sensitivity in the yeast saccharonyces cerevisize. Mutat. Res. 33, 157-164 (1975).

25. J. Vleyman, On a new class of "contagious" distributions, applicable in entomology and backteriology. Am. Math. Stat. 10, 35-37 (1939).

26. E.H. GOODIIN, E.A. BLAKELY, and C.A. TOBIAS, Neon ions produce a non-poissonian distribution of radiolesions. Submitted to Int. J. Radiat. Biol.

27. P.A. JEGGO and L.A. KEMP, $X$-ray sensitive mutants of Chinese hamster ovary cell line: Isolation and cross-sensitivity to other DNA damaging agents. Mutat. Res. 112, 313-327 (1983).

28. L.A. KEMP, S.G. SEDGWICK, and P.A. JEGGO, X-ray sensitive mutants of CHO cells defective in double-strand break rejoining. Hutat. Res. 132, $189-196$ (1984).

29. P.A. JEGGO, X-ray sensitiye mutants of Chinese hamster ovary: radiosensitivity of DNA synthesis. Mutat. Res. 145, 171-176 (1985). 
30. U.K. EHMANN, H. NAGASAWA, D.F. PETERSON and J.T. LETT. Symptoms of X-ray damage to radiosensitive mouse leukemic cells: asynchronous populations. Radiat. Res. 60, 453-472 (1974).

31. M.N. CORNFORTH and J.S. BEDFORD, On the nature of a defect in cells from individuals with Ataxia-telangiectasia. Science 227, 1589-1591 (1985). 


\section{FIGURE CAPTIONS}

Figure 1 Comparison of differences in the yield of DNA-DS breaks between the theoretical expression of Chadwick and Leenhouts' molecular model $(6-8)$ and the RMR model $(17-19)$. Note that the yield of lesions as a function of dose at $t=2$ is the same for each, but at $t=0$ these yields are different.

Figure 2 Theoretical Neyman frequency plots of lesion clusters for three dose levels. Abscissa: number of lesions per cell. Peaks are clearly seen for zero, one, two or three particles crossing the cell nucleus. The distribution becomes Poisson for large doses.

Figure 3 The mean number of lesions per cell as functions of dose. (0) experimental data, (0) Neyman distribution, ( ) poisson fitted to probability u (0).

Figure 4 Model of serial and parallel processing of DNA progression and repair. Critical repair enzymes and their relationship to normal DNd replication are indicated. Specific known radiation effects are also shown. 
TABLE I

MATHEMATICAL MODELS IN RADIOBIOLOGY

\section{STATIC:}

Quantitate initial energy transfer to quantity of expressed effects. target \& hit theory Lea (1) dual-action theory Kellerer and Rossi (2); Zaider and Rossi (3) hit-size effectiveness Bond et al., (4); Bond and Varma (5)

DYNAMIC LESION-REPAIR:

Describe dose-time development of lesions and repair.

molecular model

dose-rate model

cybernetic model

repair saturation

repair-misrepair

lethal-potentially lethal
Chadwick \& Leenhouts $(6-8)$

Roesch, (10); Braby and Roesch (11)

Kappos and Pohlit (20)

Haynes ((12); Goodhead (13)

Tobias et al. (17-19)

Curtis (21) 
Differences in the Yield of DNA-DSB Between Two Models
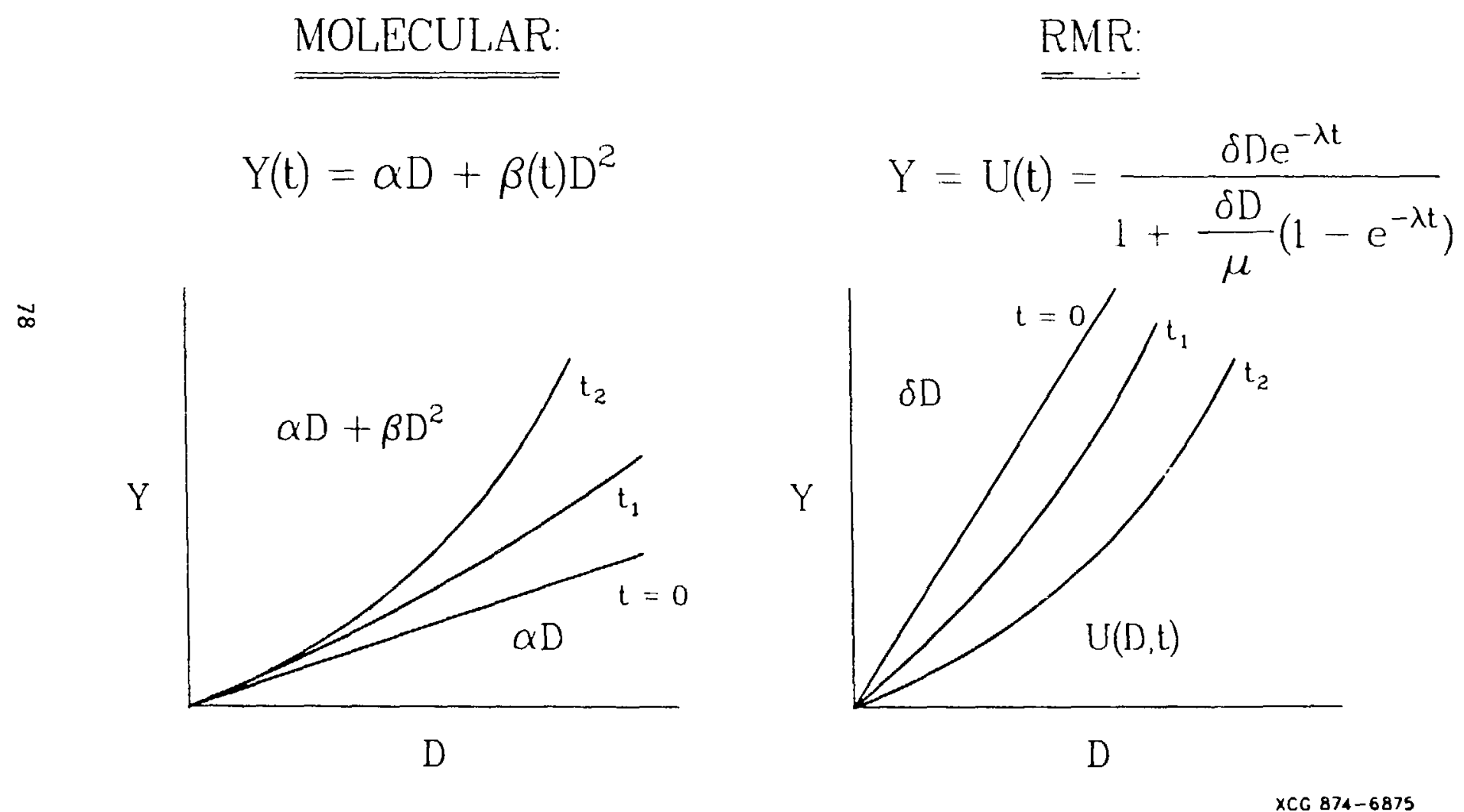


\section{Theoretical Neyman A Distribution of Chromatin Lesions}

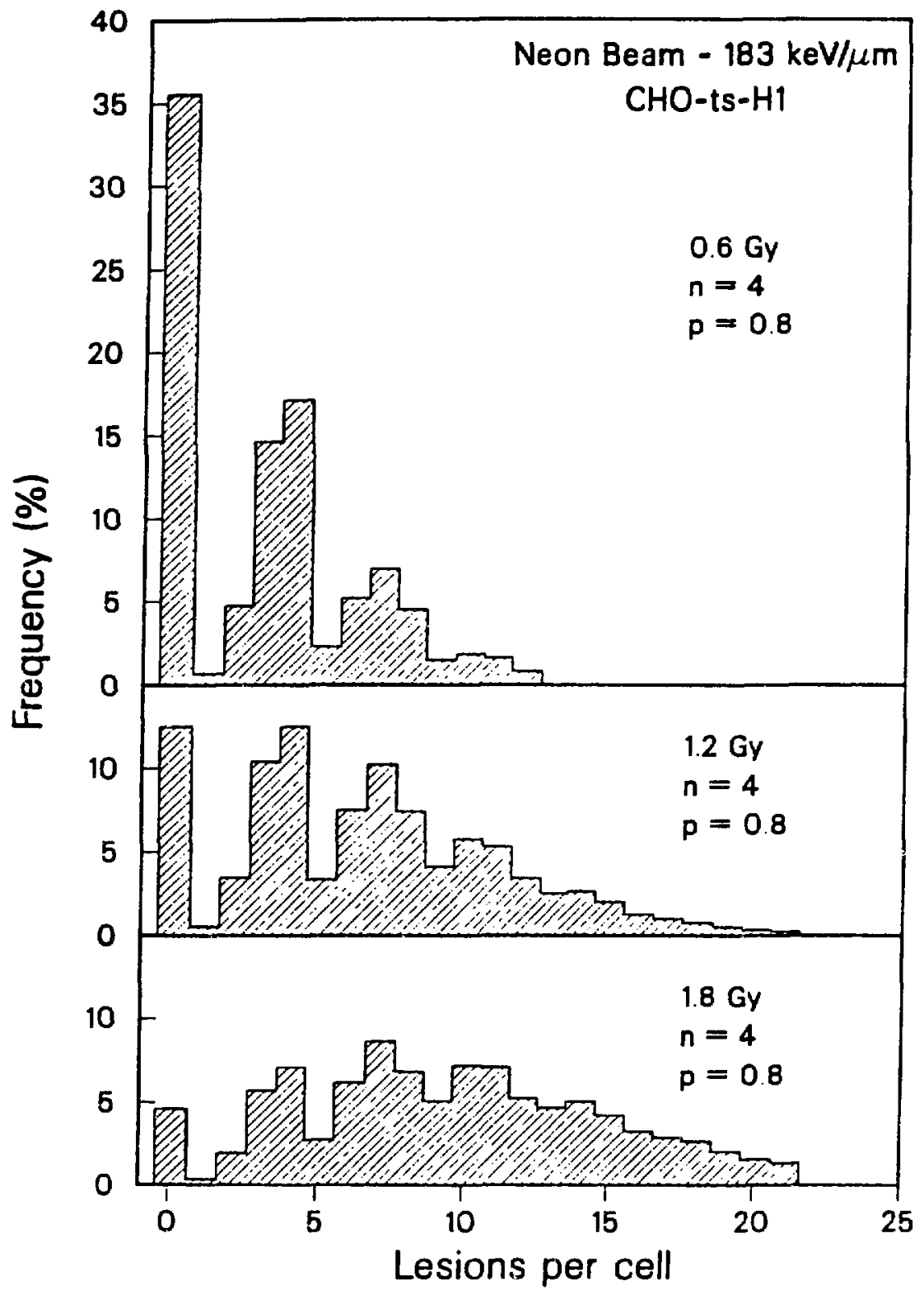

$x \operatorname{CC~} 864-7192$ 
Chromatin Breaks in $G_{1}$-phase Cell Nuclei (CHO-ts-H1 cells)

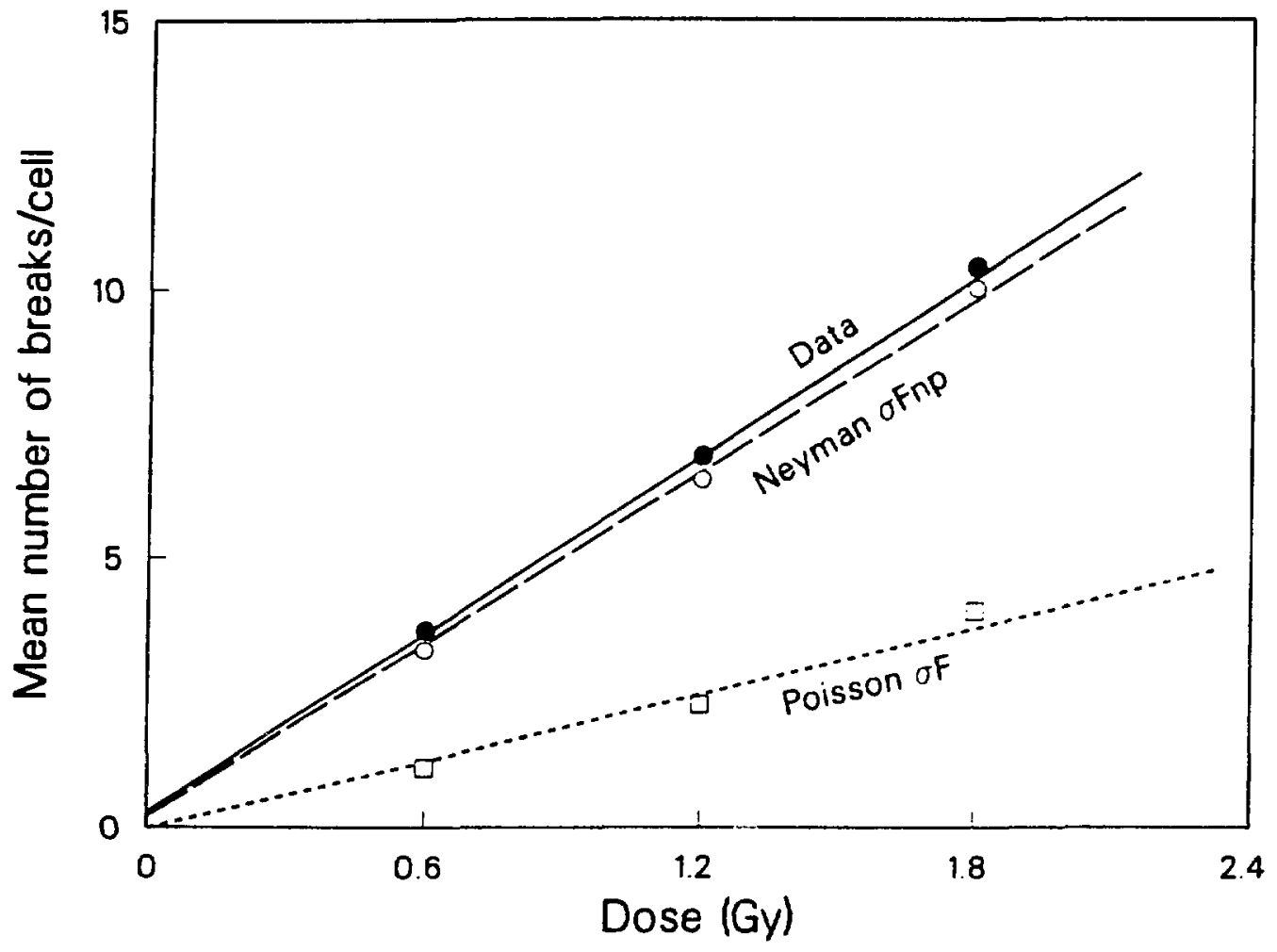

Tobias

Figure 3 
DNA Progression and Repair Depend on Serial and Parallel Processing

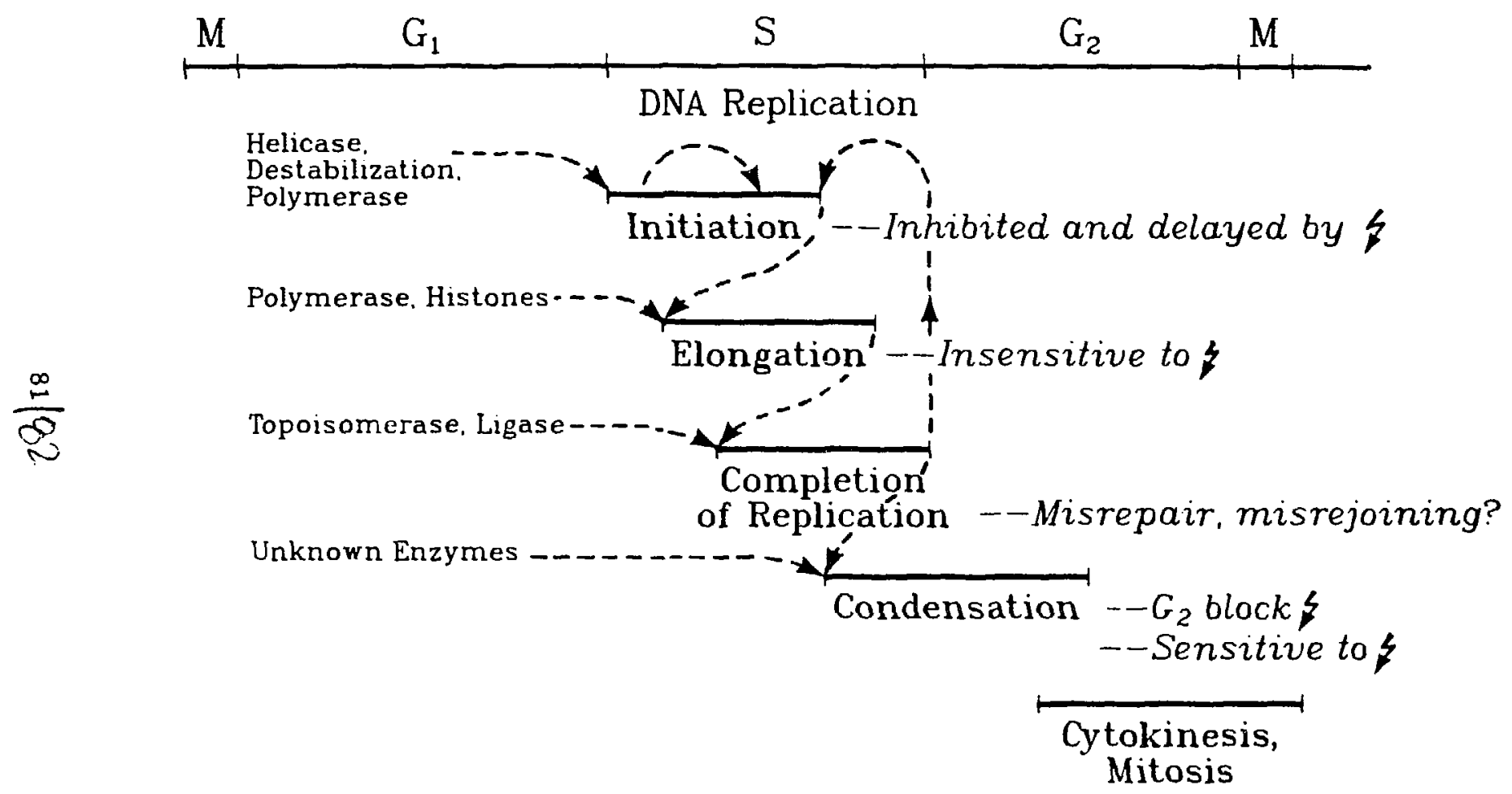

xCC 874-6976 
STATUS OF PHENOMENOLOGICAL MODELS OF THE RESPONSE

\section{OF CELLS TO IONIZING RADIATION}

L.A. Braby, N.F. Metting, and J.M. Nelson

Paciflc Northwest Laboratory, RIchland, WA 99352

Abstract: Mathematical models, based on widely differing assumptions about the mechanisms by which cells are inactivated, may lead to equivalent expressions for survival as a function of dose. To test these models they must be applied to a wider range of irradiation protocols. Results of a variety of experiments indicate that no single type of damage or repair mechanism dominates, and that models incorporating several mechanlsms will be required.

Introduction: Models used to describe the response of cells to ionizing radiation generally incorporate features based on assumed mechanisms, but are largely phenomenological in nature. They generally ignore the detalls of radiation chemistry, chromatin structure, enzymatic repair, molecular genetics and cell growth and substitute simplified expressions which are hoped to characterize the limiting step in the entire sequence of events. These models are used for a wide varlety of purposes, and many are quite successful in describing cellular response over the range of doses for which experimental results are avallable. However, other appllcations, notably establishing radiation protection standards, require use of models at doses and dose rates far below the ranges normally accessible in experimental studies. In order to justify the use of a model outside the range for which

*Work supported by the Office of Health and Environmental Research (OHER) U.S. Department of Energy under Contract DE-AC06-76RLO 1830. 
It can be tested, it is necessary to establish that the kinetics it Incorporates are a valld and complete representation of the kinetics actually governing the response in question. There appears to be no way to make this determination except by carefully eliminating all of the alternatives.

Types of Models: Some models, for example that developed by Butts and Katz (1), have been developed to relate the blological effects of di? rerent radiations to physical characteristics of those radiations. In these models no attempt is made to incorporate the chemical and blological processes Involved. Instead, those processes are hidden within a description of the response of cells to a standard radiation, and the effects of other radiations are estimated from the fraction of the dose delivered by secondary particles having physical properties similar to those produced by the reference radiation. This approach is quite successfui (2) but is limited to doses and dose rates for which the response to the reference radiation is known.

Another approach to predicting effects of various radiations was Introduced by Bond and Varma (3). They assume that a spherical tissue volume a few micrometers in diameter is a suitable phantom for a cell nucleus. Based on measured response of cells to low doses of a varlety of radiations they calculate the response function of the cell. This response funci:an and the microdosimetry spectrum for a different radiatiol, can be used to predict response at low doses where only single events occur during the time required for a cell to repair damage. At these low doses and low dose rates maximum repalr occurs and dose rate is not a concern. However, the data needed to obtain the response function must also be obtalned at very low doses, and may 
not be avallable for crittcal cells. The lack of a clear connection with underlying mechanisins makes it difficult to justify applying response functions for some cell types to estimate risks to other cell types.

In order to overcome the $11 \mathrm{~m} 1$ tations on applicabllity lllustrated in the above models, many workers have attempted to incorporate features characteristic of classes of biochemical mechanisms into models of radiation response. The importance of blochemical repalr was recognized soon after the discovery of split dose repalr (4). However, there remains considerable controversy over the consequences of unrepatred damage remaining in cells. Although models differ in many additional ways, they generally start with either the assumption that any unrepaired damage will produce the observable effect, or that one or more types of lesions are innocuous individually but become effective when they interact in some way. Both types of model can be made to fit survival data quite well, but the shoulder in the curve results from a $11 \mathrm{mited}$ amount of repair in the former and from interaction of damage In the latter. This difference becomes very important at low doses where the probability of interaction of sub effective lesions would be very small, but the probability of repair of potentially lethal lesions would be very large.

Generally the models deal with only one type of damage, assuming that it dominates in determining the response. In many cases it is also suggested that there may be direct production of irrepairable damage whici adds a linear comporient to the overall effect.

Since models which yield markedly different results at very low doses and dose rates often give indistinguishable dose effect curves at experimentally testable doses and high rates, Fig. 1, other means have to be 
found to try to eliminate unsultable models. Split dose and delayed plating experiments often provide this needed additional information.

If all damage is assumed to be lethal or potentially lethal, a shouldered survival curve will result if either of two further conditions applies. One possibility is that a repair system of limited capacity is present and becomes "saturated" with increasing dose (5). The other is that there is a process which depends on the square of the concentration of damage and results in misrepair or damage fixation (6). Goodhead has provided a repair saturation model with the simplifying assumption that the enzyme remains bound to the damage for the duration of the experiment. This results in an analytical expression for the amount of damage remaining at any time after an irradiation, which can be used to calculate survival as a function of time in a delayed plating experiment. The amount of damage produced in the second dose of a split dose experiment can be added to the amount remaining from the first exposure, to determine survival. Results of such calculations are presented in Fig. 2 which shows that this type of model predicts higher final survival in a delayed plating experiment than in a split-dose one. The repair time avallable to the cell between trypsinization and damage fixation is unknown, and reduces the difference between the split dose and delayed plating curves, but does not reverse their order. Repair saturation models which involve realistic enzyme binding and release characteristics such as that developed by (7) must be solved by numerical methods, but give results equivalent to the Goodhead model. However, experimental results for plateau phase CHO cells clearly show a higher final survival for a split dose of $4 \mathrm{~Gy}$ in each of two fractions separated by time T. with replating immediately following the second dose, than in a delayed 
plating experiment with 8 Gy given in a single dose followed by holding in their depleted medium until trypsinization at time $T$. These results are shown In Figure 3. It appears that only a darage interaction or fixation process which depends on the square (or other power greater than one) of the damage concentration can result in this observed advantage to cells receiving protracted exposures. However, there are significant differences in the assumption that the damage is potentially lethal with the interaction resulting in misrepalr, and the assumption that the damage is sutlethal with the Interaction making it lethal. One of these differences is that in the lethal-potentially lethal damage model (6) the split dose and delayed plating effects are manifestations of the same repair process, while in the sublethal damage models a delayed plating experiment measures one type of repair while split dose experiments measure a combination of that and a second type of repair which is effective only if it occurs before irradiation ends.

Although a complete answer to the question of the nature of the initial damage is not yet avallable, evidence from anoxic irradiation and repair studies seems to show that two separate repalr processes are responsible for the split dose and delayed plating effects. When plateau phase CHO cells are Irradiated anoxically the split dose effect is essentially eliminated. Fig. 4, but the delayed plating effect is unaltered. This situation depends only on the oxygen concentration during irradiation, not on the presence or absence of oxygen during the repair interval. Thus it seems that two types of damage must be involved. One, which is produced independently of oxygen concentration, is potentially lethal and its repair is most easily observed during a plating delay. Another, produced only in the presence of oxygen, is apparently sublethal and is repalred during split dose exper!ments. 
Conclusion: Models of the processes governing the response of cells to irradiation provide a way of organizing data and predicting the results of untried experiments. As models based on specific assumptions about the mechanisms governing the response of cells are found to be inadequate, new and more sophisticated models develop. However, most modelers have avolded the need for large numbers of varlables by assuming that a single type of damage and repair dominate in the production of the observed endpoint. Recent data suggest that this is an unacceptable oversimplification, that at least two types of damage and repalr are involved. More complex models and well designed combinations of experiments will be needed to Investigate these combinations of damage pathways. 
Figure Captions

Figure 1. High dose rate survival calculated for a simple linear-quadratic model (०.) a saturable repair model (5) (--) and the lethal-potentially lethal model (5) (-) are essentially indistingulshable over most of the survival curve, but differ significantly at low cioses.

Figure 2. Saturable repair models predict lower final survival in split dose experiments than in delayed plating experiments when cells are replated Immedlately after the end of the plating delay or after the second dose (upper panel). If the cells repair some damage after trypsinization, the difference is reduced but delayed plating still gives the greater final survival (lower panel).

Figure 3. Experimental data for plateau phase CHO celis clearly shows higher survival following the split dose irradiation.

Figure 4. Split dose repalr does not occur in plateau phase CHO cells irradiated in nitrogen. 
References

1. Butts, J.J. and R. Katz. 1967. "Theory of RBE for Heavy Ion Bombardment of Dry Enzymes and Viruses." Radiat. Res. 30, 855-871.

2. Katz, R., D.E. Durn, and G.L. Sinclalr. 1985. "Thindown in Radloblology." Radiat. Dosimet. 13, 281-284.

3. Bond, V.P. and M.N. Varma. 1982. "A StochastlC, Weighted HIt Size Theory of Cellular Radioblological Action." In Proceedings of the Elghth Symposium on Microdosimetry ed. by J. Booz and H.G. Ebert, Commission of the European Communitles, Luxembeurg, p. 424-437.

4. ElkInd, M.M. and H. Sutton. 1959. "X-ray Damage and Recovery in Mammallan Cells in Culture." Nature 184, 1293-1295.

5. Goodhead, D.T. 1985. "Saturable Repalr Hodels of Radiation Action In Maminallan Cells." Radlat. Res. 104, S-58-S-67.

6. Curtis, S.B. 1986. "Lethal and Potentlally Lethal Lesions Induced by Radiation - A Unified Repalr Mode1." Radiat. Res. 106, 252-270.

7. Calkins, J. 1971. "A Method of Analysis of Radlation Response Based on Enzyme Kinetics." Radlat. Res 45, 50-62. 


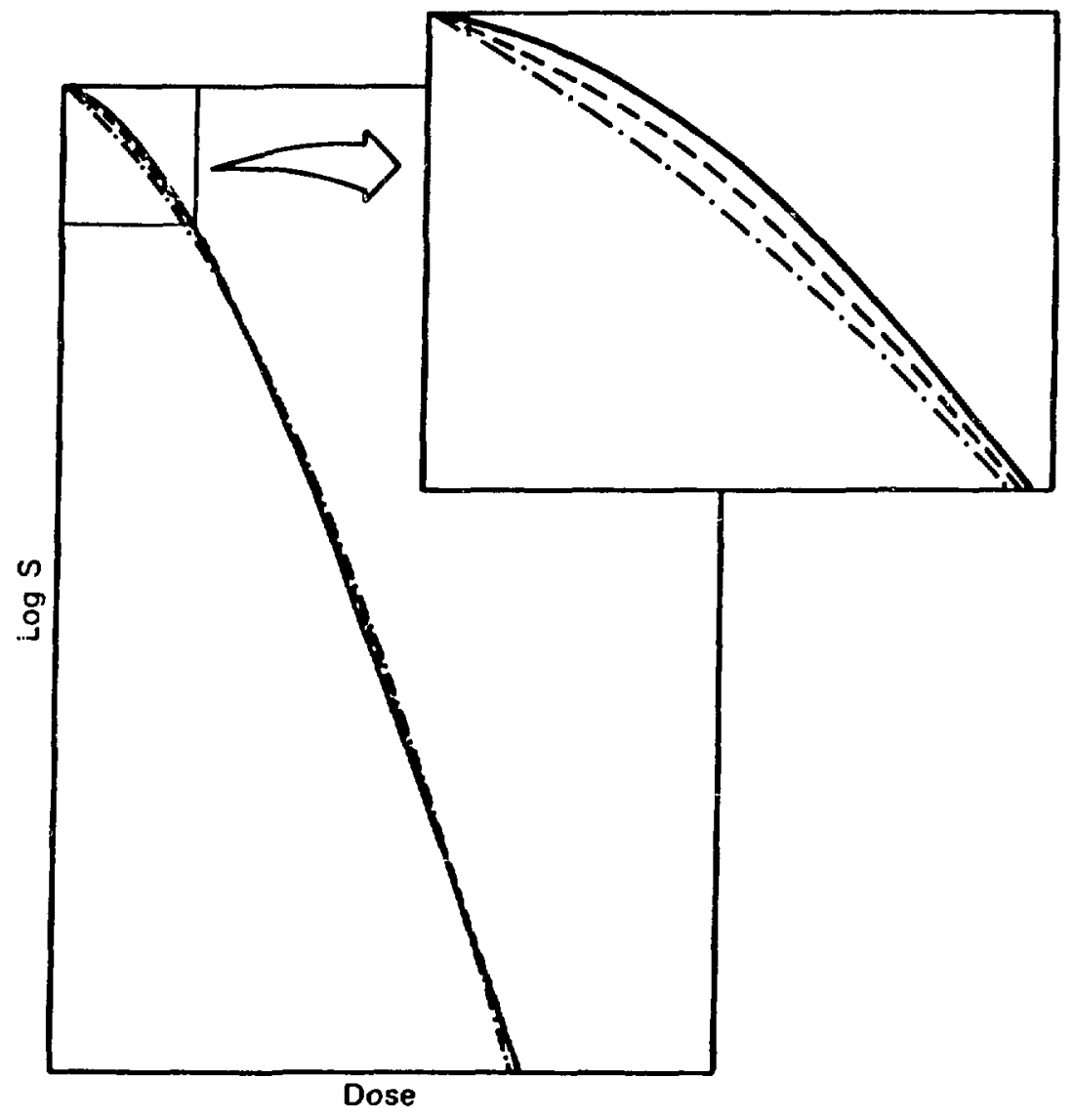

FIGURE I 

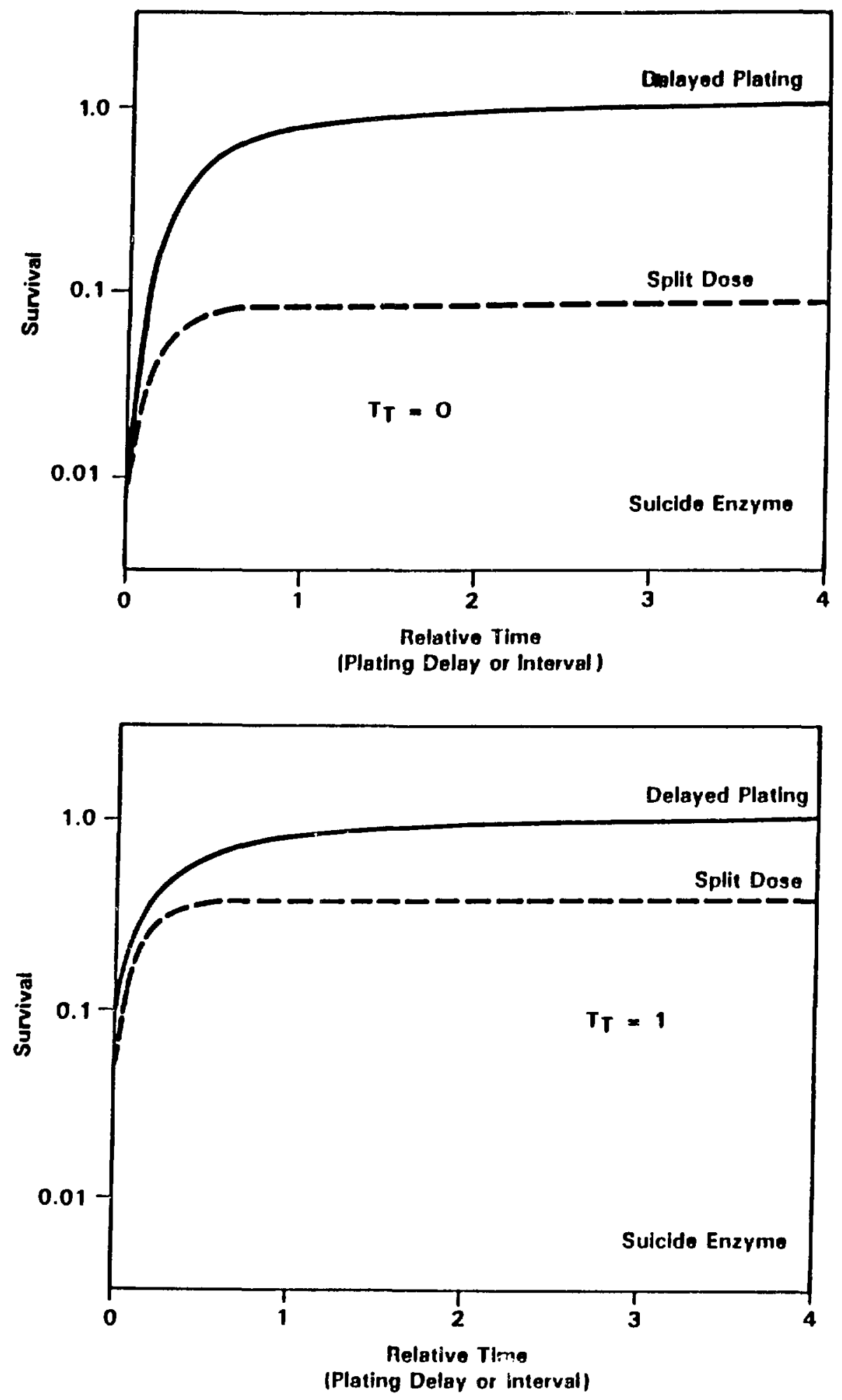

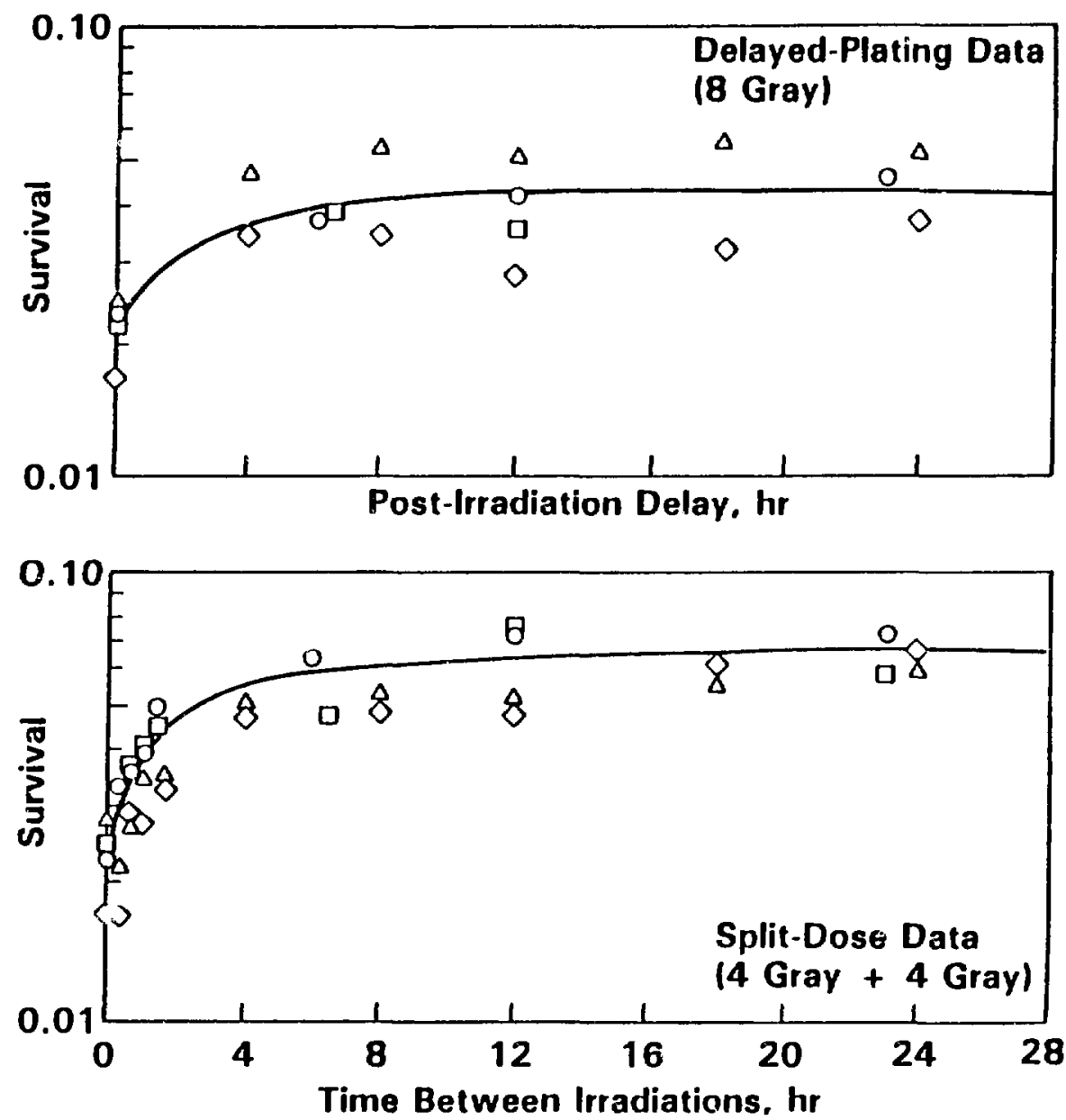

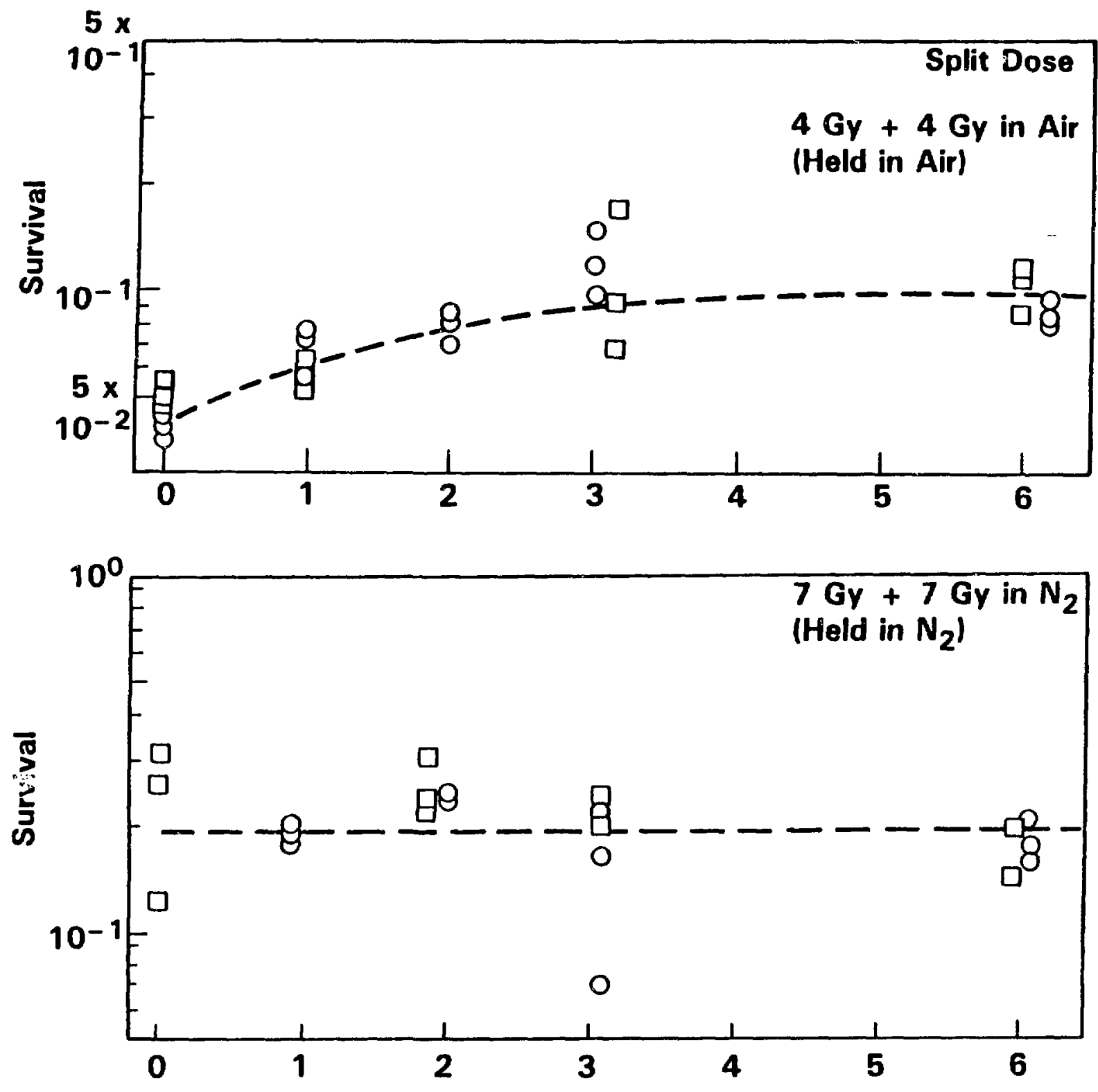

Time Between Doses, hr 


\title{
PRODUCTION OF HYDROXYL RADICAL INDUCED STRAND BREARS
}

\section{BI BIGB LBT PARTICLBS: A THEORBTICAL APPROACB}

\author{
By Aloke Chatterjee \\ Lawrence Berkeley Laboratory \\ Berkeley, CA 94720
}

ABSTRACT

The cross-sections for DNA single strand breaks have been calculated theoretically for different LET particles. Those breaks which are due to the indirect action of ionfing radiation have been inviestigated and the calculations are based on the mechanism of hydrogen abstraction by hydroxyl radicals from the deoxyribose. The results demonstrate that as the LET of the particles increase, the production of damage through this mechanism becomes less effective. It has been concluded that the RBE for indirect action of radiation damage is less than or equal to one.

\section{INTRODUCTION}

It is well known that hydroxyl radicals are capable of producing strand breaks when an aqueous solution of DNA is irradiated with lonizing radiation (1). The mechanism of this process involves the abstraction of various hydrogen atoms by the hydroxyl radicals from the sugar molecules present in a DNA chain. Some of these abstraction processes lead to "prompt" strand breaks and some lead to "latent" strand breaks. The latter type of breaks are generally expressed when the irradiated solution is treated with alkall, and hence sometimes referred to as alkali labile sites.

The analysis of radiation-induced cellular effects by manipulating the production as well as the availability of hydroxyl radicals for attack on a 
DNA chain has been incorporated in manst studies $(2,3)$. In some of these studies, high-LET charged particles and appropriate scavengers of these radicals have been used. For example, Roots et al. (2) used ethylene glycol to scavenge the hydroxyl radicals and thereby altering the survival curves for CHO cells. In the same study, they varied the radiation quality and concluded that for $X$-rays, about $65 \%$ of the damage is due to the Indirect action and this percentage reduces to $25 \%$ when low energy $(10 \mathrm{MeV} / \mathrm{n})$ neon particles are used for irradiation. Similar investigations have also been carried out with aqueous solution of DNA by Kraft et al. (3). In these investigations, the cross-sections for strand breaks have been measured for high energy iron particles, and the RBE for both double and single strand breaks is 0.6 , i.e., less than one. Moreover, at lower energies for the same iron nucle1, the RBE value for single strand breaks drops to less than 0.06 , and that for the double strand breaks drops to 0.1 . From these experiments, one can conclude that the RPE values for single and double strand breaks cannot be greater than one for high-LET charged particles.

In order to provide a theoretical basis for the above conclusion, we are reporting a method of investigation in which the effect of hydroxyl radicals in producing strand breaks has been studied exclusively. The indirect action of radiation on SV4O DNA in dilute aqueous solution has been calculated to determine the extent of $\cdot \mathrm{OH}$ reaction with the sugar molety and the bases. For positioning the various atoms and molecules along a DNA chain, the X-ray data on structural aspects of the macromolecule have been used. The calculation has been done for $\mathrm{Co}^{60}-\mathrm{r}$ rays, proton, helium, carbon, neon and argon particles. For each particle, the velocity has been varled in the calculation to span over a wide range of LET values. 
Dilute solutions of SV40 DNA molecules in $10 \mathrm{mM}$ tris buffer form a convenient system for the study of the action of water radicals on DNA. The concentration of DNA in the solution has been $10 \mu \mathrm{g} / \mathrm{ml}$ and hence the direct action of radiation (1.e., deposition of energy directly on the DNA molecule) has been neglected. At this concentration, the absorbed fraction of energy in DNA is $10^{-5}$ as compared to water. Christen et al. (4) found experimentally that radiation dose in the megarad range are required to detect measurable number of strand breaks by the direct effect in $\$ \times 174$. The water radicals, however, are capable of reaching from distances far enough away for the indirect effects to be quite large and radiation dose values of the order of hundreds of rads produce easily measurable effects. Hence, the dilute aqueous solution of SV40 DNA provides a convenient system for the study of indirect action of ionizing radiation.

In order to consider the effects of different qualities of radiation, the concepts of track structure have been used. These concepts along with the representation of DNA structure are described in the section on method of calculation.

\section{HETHOD OP CALCULATION}

There are two important aspects in our method to calculate the crosssection for single strand breaks. One deals with the track structure and the other with the geometrical representation of the three-dimensional DNA structure.

(i) Heavy Particle Tracks -- Within a very small diameter around a heavy particle trajectory, we consider the existence of physical "core" otherwise known as the high energy density region. In this volume, more than half of the total LET is deposited. Some of the radicals in this region react chemi- 
cally with each other and others diffuse out whlle intermingling with radicals from outside the core, called "penumbra". This process continues till the radical-radical interaction becomes negligible and the radical-buffer and radical-DNA (bases and sugars) interaction doninates. This phenomenon hrppens at a critical radius called the "chemical core" $\mathbf{r}_{\mathrm{ch}}$. A detalled description of these concepts and their applications in simple aqueous systems have been published elsewhere (5).

(1i) Representation of DNA Structure -- The SV40 DNA molecule has a molecular weight of $3.2 \times 10^{6}$ daltons which corresponds to 5226 base pairs; it is 18000 A long and has been considered to be in the B form in the present work. For this structure, the base pair separation distance is $3.4 \mathrm{~A}$ with a strand separation of $15.2 \mathrm{~A}$. In the Cartesian Coordinate System, the z-axis has been taken through the center of the polymer and along the long chain. The const1tuent atoms of the sugar molecules and those of the bases have been arranged to have definite $x, y$, and $z$ coordinates as given by the published stereochemical parameters including the bond lengths (6). After placing each pair of a nucleotide, a helical twist of $36^{\circ}$ has been considered for the subsequent arrangement of the next pair and this process has been continued till all the nucleocides have been accounted for. In the double hellx, there are 10 base pairs in a $360^{\circ}$ rotation. Although no cross-section calculation has been reported here for the double strand breaks, considerations have been given to understand their formation. For these breaks, the assumed requirement has been to find two single strand breaks on opposite strands separated by less than 10 to 12 base pairs.

(iii) Cross-Section for Strand Breaks -- Since the chemical stage of the track structure has been considered in terms of the chemical core and the penumbra, the strand break calculations are separated in two components: (a) 
contribution by the chemical core, and (b) contribution by the penumbra. From track structure formulae as given in Reference (5), the fraction of energy deposited in the chemical core, $f_{c h, c}$ ' and hence In the penumbra, $1-f_{c h .} c^{\text {' has }}$ been computed. In order to obtain the total cross-section for strand breaks, the respective contributions have been properly welghted by these fractions. Slightly different procedures have been adopted to calculate the efficiencies for strand breaks in the two regions, although the overall principle has been the same. Only OH radicals have been considered to induce strand breaks by abstracting hydrogen radical from the sugars.

(a) Contribution from the chemical core: By using proper differential equations for radical-radical interaction, as given in Reference (7), a decay curve ( $\cdot \mathrm{OH}$ yield vs. time) is obtalned. This curve is modifled (final decay curve) by further reactions of surviving oH radicals with the tris molecules. A decay curve provides information on the number of surviving $\cdot \mathrm{OH}$ at any given time. A Monte Carlo scheme ( 8 ) has been devised to simulate the diffusion of an oH radical from the point of its creation by making it fump in three dimensions with a fump-time of $3 \times 10^{-12}$ sec. In each fump, it is decided (by calling a random number and using the previously obtained final decay curve) whether the particular radical in question has survived or not. Through this procedure a surviving OH radical has been followed in space and $t$ Ime. If during the course of its diffusive motion, the radical happens to be within the reaction radil of the constituent molecules of the DNA chain, the radical is made to react with a probability of one. The respective reaction radil are determined from the experimentally measured rate constant values and given in Table 1. 
Consistent with the analysis of experimental data [see Reference (9) ], we have assumed that attack on the sugar only by an oH radical leads to strand breaks. Reactions with the bases do not produce strand breaks, but nay lead to other types of damages, e.g. mutations, etc. Through the above-mentioned procedure, the $D_{37}^{c h} . C$ values are calculated for different heavy charged particles.

(b) Contribution from the penumbra: As mentloned earlier, the penumbra contribution arises due to high energy electron tracks. These electron tracks have been analysed in terms of the track entities: spurs and blobs and the detalls are given in Reference (10). Through the concepts of these track entities, the final oH-decay curve (as referred earlier) is obtained (8) and the rest of the calculation procedure remains the same as described in the section on chemical core. The $D_{37}^{\text {pen. }}$ value is very similar to the $D_{37}$ value when calculated for $\mathrm{Co}^{60}-\gamma$ radiation. For this radiation quality, an average electron energy of $1.0 \mathrm{MeV}$ has been assumed.

Once the respective $D_{37}$ values for the regions of chemical core and penumbra are known, the cross-section for SSB is given by:

$$
\sigma_{S S B}(j \mathrm{~m})^{2}=\mathrm{KX}\left[\mathrm{f}_{\mathrm{ch} \cdot \mathrm{c}} / \mathrm{D}_{37}^{\mathrm{ch} \cdot \mathrm{c}}+\left(1-\mathrm{f}_{\mathrm{ch} \cdot \mathrm{c}}\right) / \mathrm{D}_{37}^{\text {pen. }}\right]
$$

where

$$
\begin{aligned}
& K=1.602 \times 10^{-9} \\
& X=\text { LET In eV/A } \\
& \ldots D_{37} \text { values are in krads. }
\end{aligned}
$$


RBSULTS

For $\mathrm{Co}^{60}-\mathrm{r}$ radiation, the $E_{1}$, value has been calculated to be $9.8 \mathrm{krads}$ which compares well with the experimentally measured values between 8.8 and $9.8 \mathrm{krads}$ (C.N. Trumbore, private communication). These values are for prompt single strand breaks which have been obtained by considering $70 \%$ efficiency for producing this damage as a result of the 0 oH at tack on the deoxyribose molecules (11). For delayed strand breaks (alkali labile), if the efficiency is assumed to be $100 \%$, then the theoretically determined value is $6.8 \mathrm{krads}$. This number also compares favorably with the experimentally determined value of 6.2 krads.

The resultant $D_{37}$ values for different heavy charged particles are shown in Figure 1. There are several features in this plot. For a given particle, as it slows down, its LET increases and so does the $D_{37}$ values. That means, with the increase of LET, the particle becomes less efficient in producing strand breaks through OH interaction mechanism. From the same figure, it is also quite clear that at a given LET value, two particles are not equally efficient in producing strand breaks. The particle of higher atomic number (Z) has a lower $D_{37}$ value. This is quite understandable because for the higher $Z$ particle, the velocity has to be higher for the LET values to be the same. High velocity means, the secondary electrons in the penumbra are produced with higher energies. Hence in the penumbra region, more $\cdot$ oH have a chance to escape for a possible attack on the DNA. Thus, at the same LET value, the higher $Z$ particle is more efficient in producing strand breaks.

In Figure 2, the cross-sections for single strand breaks have been plotted against LET. For each particle, the cross-section increases with the rate of energy deposition and finally the $\sigma_{S S B}$ goes through a maxima. Since the scales for the abscissa and the ordinate are the same, a line has been 
drawn at $45^{\circ}$ through the cross-section value for $C^{60}-r$ rays. As seen from the plot the cross-section values of all the heavy charged particles lie belov this line and hence, it is quite clear that the $\mathrm{Co}^{60}-\gamma$ rays are the most efficient, per unit energy deposition basis, to produce single strand breaks.

Thus, it can be concluded that for indirect action to cause single strand breaks, the RBE values (when calculated with reference to $\mathrm{Co}^{60}-r$ rays) cannot be greater than one.

\section{DISCUSSION}

In this paper, the results for single strand breaks have only been presented. It is quite well known that most of these breaks are repaired quite efficiently by the enzymatic processes. It is the double strand break that determines the fate of a living cell. We have made attempts to calculate double strand breaks through the $\cdot \mathrm{OH}$ attack mechanism. We have found that both for one and two tracks, the efficiencies of producing double strand breaks by two $\mathrm{OH}$ are quite insignificant $\left(<10^{-3}\right)$ compared to the experimentally measured yields. Hence, 1 t is quite possible that a single of may be responsible for not only creating single strand breaks but may even be responsible for producing breaks on both the strands. First, this radical at tacks a site on a deoxyribose molecule. A sugar fragment radical may be produced as a result of this attack. Then this new radical may have a reasonable chance to create a break on the opposite strand within 10 or 12 base pafrs from the first break. From our initial computations, it seems that this hypothesis has a reasonable chance to be successful. More work is in progress and will be reported in the future.

However, it appears that as long as the $\cdot \mathrm{OH}$ are involved, the conclusion for double strand breaks cannot be different from that for the single 
strand breaks. Hence, it is very likely that for all of mediated damage, the RBE cannot be greater than one. Whenever, RBE is measured to be greater than one, it is due to the contribution from the direct action mechanisms, i.e, a damage that is created by the direct deposition of energy on a DNA molecule by a charged particle.

\section{ACRNONLEDGHBNT}

This work was supported by the Office of Health and Environment Research, Office of Energy Research, U.S. Department of Energy, under Contract DE-AC03-76SF00098. 


\section{REPBRBNCES}

1. J.F. Ward and I. Kuo. Radiation damage to DNA in aqueous solution: $A$ comparison of the response of the single-stranded form with that of the double-stranded form. Radiat. Res. 75, 279 (1978).

2. R. Roots, A. Chatterjee, P. Chang, L. Lommel and E.A. Blakely, Characterization of hydroxyl radical-induced damage after sparsely and densely ionizing radiation. Int. J. Radiat. Biol. 47, 157 (1985).

3. G. Kraft, W. Kraft-Weyrather, E.A. Blakely, and R. Roots, Heavy-ion effects on cellular and subcellular systems: inactivation, chromosome aberrations and strand breaks linduced by fron and nickel tons. To be published in Advances in Space Research, 1987.

4. R. Christen, C.A. Tobias, ad W.D. Taylor, Heavy-ion induced single and double strand breaks in $\phi X-174$ replicative form DNA. Int. J. Radiat. Biol. 22., 457 (1972).

5. J.L. Magee and A. Chatterjee, Radiation chemistry of heavy particle tracks. 1. General considerations. J. Phys. Chen. 84, 3529 (1980).

6. S. Arnott and D.W.L. Hukins, Optimized parameters for A-DNA and B-DNA. Biochem. Biophys. Res. Comm. 47, 1504 (1972).

7. A. Chatt:arjee and J.L. Magee, Radiation Chemistry of heavy particle tracks. 2. Fricke dosimeter system. J. Phys. Chem. 84, 3537 (1980). 
8. A. Chat terjee and J.L. Magee, Theoretical Investigation of the production of strand breaks in DNA by water radicals. Radiat. Prot. Dosimetry 13, 137 (1985).

9. V.C. Sonntag, U. Hagen, A. Schonn-Bopp, and D. Schulte-Frohlinde, Radiation induced strand breaks in DNA: chemical and enzymatic analysis of end groups and mechanistic aspects. Adv. Radiat. Blol. 9, 109 (1981).

10. J.L. Magee and A. Chatterjee, Theory of the chemical effects of high energy electrons. J. Phys. Chem. 82, 2219 (1978).

11. F. Hutchinson, Chemical changes induced in DNA by lonizing radiation. Progress in Nucleic Acid Research and Molecular Biol. 32, 115 (1985).

12. M.V. Smoluchowski, Drei Vortragge Uber Diffusion, Brownsche Molekularbewegung und Koagulation von Kolloidteilchen. Physik Zeits 17, 557 (1916).

13. A. Chatterjee, P. Koehl, and J.L. Magee, Theoretical consideration of the chemical pathways for radiation-induced strand breaks. To be published in Advances in Space Research, 1987. 
TABLE 1. Reaction Radii for $\cdot$ OH Reactions

\begin{tabular}{lcc}
\hline Reaction Sites & $\begin{array}{c}\text { Rate Constant } \\
\left(\mathrm{mol}^{-1} \mathrm{~s}^{-1}\right)\end{array}$ & Reaction Radius (A) \\
\hline Deoxyribose & $1.5 \times 10^{9}$ & 1.0 \\
Adenine & $5.4 \times 10^{9}$ & 3.6 \\
Thymine & $5.3 \times 10^{9}$ & 3.5 \\
Guanine & $7.6 \times 10^{9}$ & 5.0 \\
Cytosine & $5.4 \times 10^{9}$ & 3.6 \\
\hline
\end{tabular}

*The reaction radii have been obtained by using the Smoluchowski equation, $K=4 \pi \mathrm{D}_{0 \mathrm{H}^{R}} \mathrm{R}$. $K$ is the experimentally measured rate constants, $D_{\mathrm{OH}}$ is the diffusion constant for $\cdot 0 \mathrm{f}$ in aqueous solution and $R$ is the reaction radius. For details, see References (12) and (13). 


\section{PIGURB LEGENDS}

Figure 1. The $D_{37}$ valies in krads for producing single strand breaks have been plotted against LET in eV/A for different heavy charged particles. $D_{37}$ is defined as the dose at which $37 \%$ of the DNA moleclues are undamaged. Higher $D_{37}$ means lesser efficiency in producing damage.

Figure 2. The cross-section $\left(\sigma_{S 5 B}\right)$ for single strand breaks in (um) ${ }^{2}$ has been plotted against LET (eV/A) for different charged particles. The cross-section increases with LET since more - OH are available for producing damage as the energy density increases. However, the rate of increase with LET is not large enough to be as efficient as $\mathrm{Co}^{60}-\gamma$ rays. After reaching a maximum, the $\sigma_{\text {SSB }}$ goes down because the energy density is very high and most of the $\cdot \mathrm{OH}$ recombine with other water radicals and hence only a few are available for damage. 


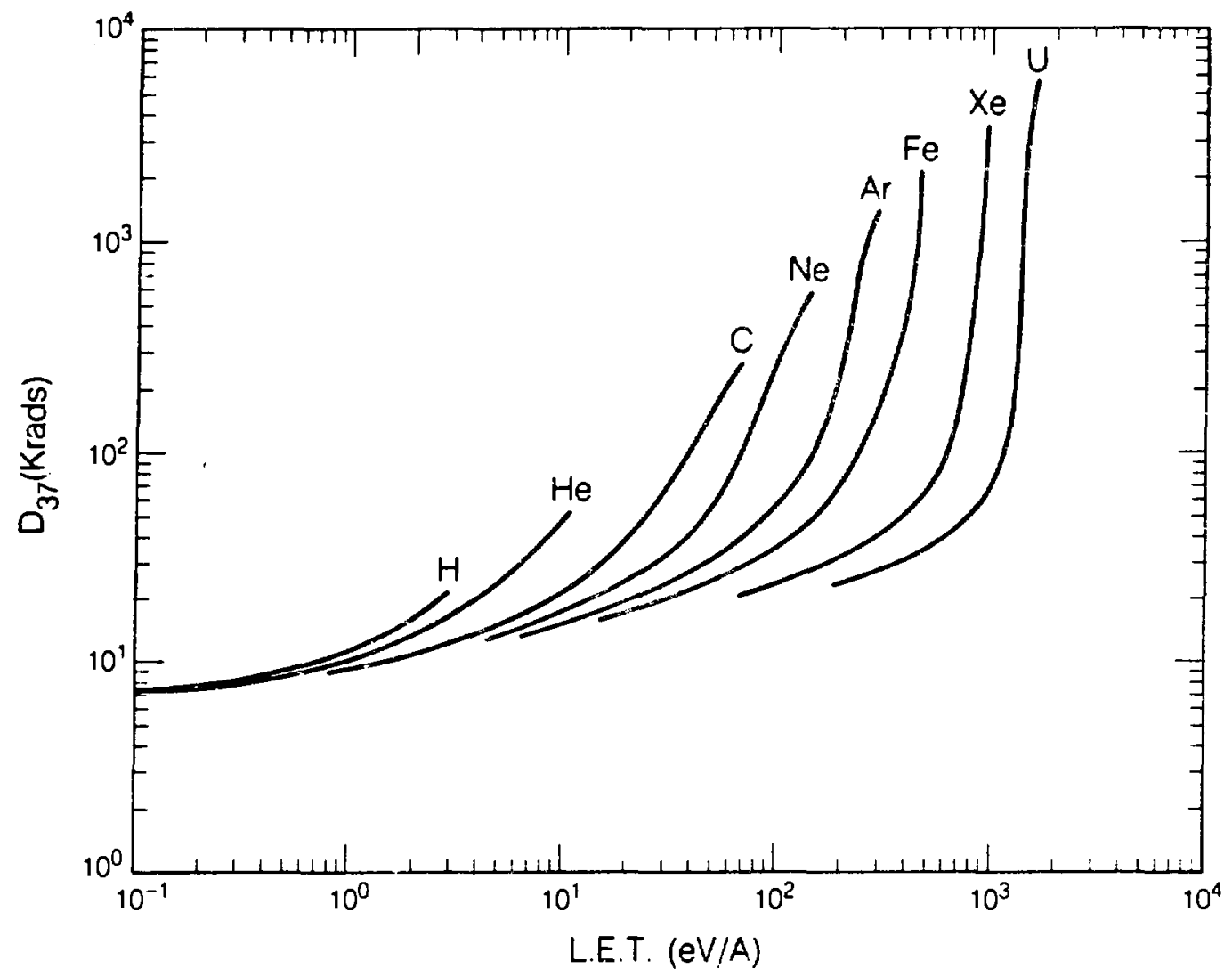

XBL Bò g:94

Figure 1 


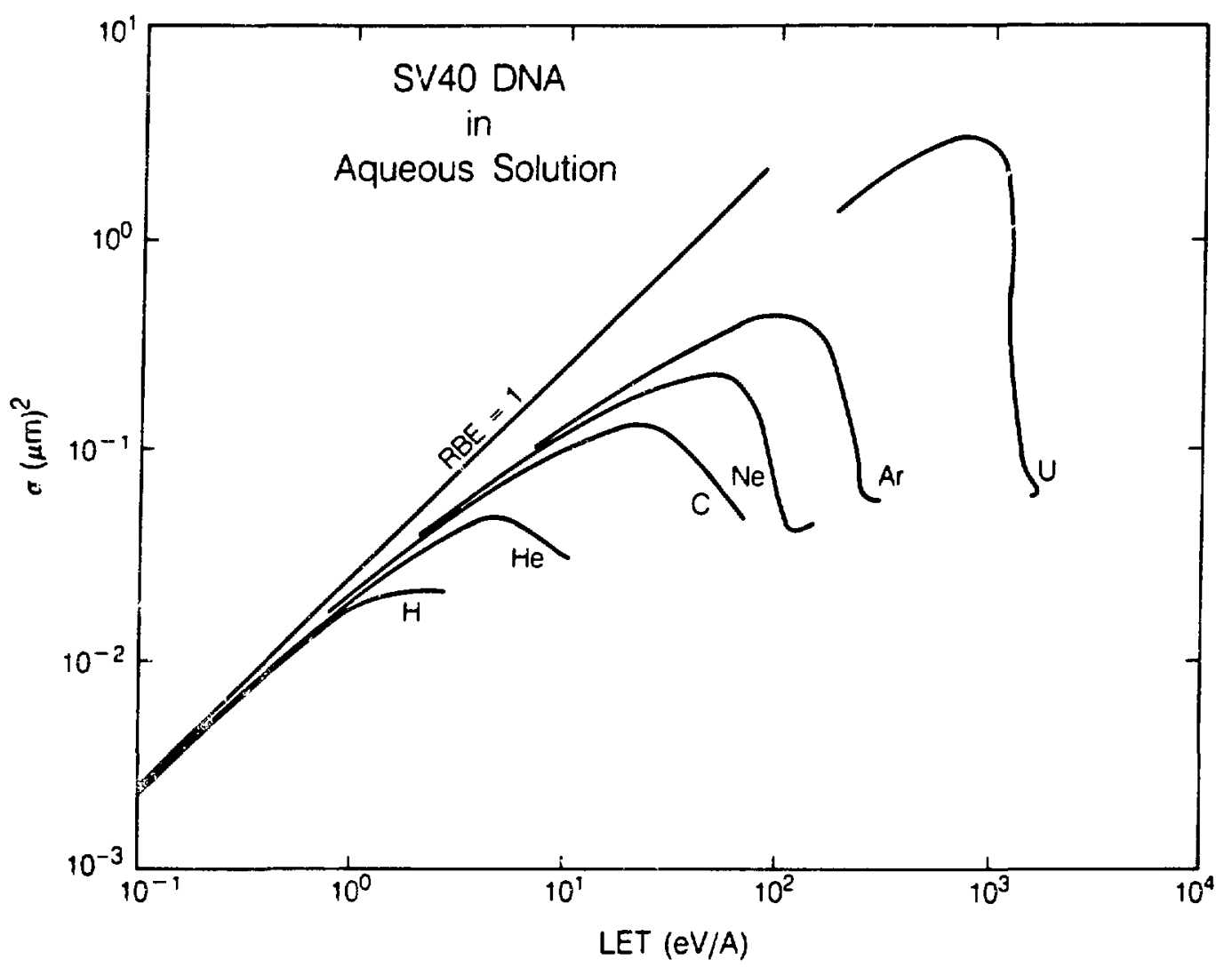

XBL $866 \quad 10879$

Figure 2 
RADIATION INDUCED RADICAL SPECIES IN DNA

by

Michael D. Sevilla

Oakland University

Rochester, MII 48063

Radiation damage to DNA results from the direct effect where positive ions, electrons, and excited states are formed in the DNA, and the indirect effect where radical species formed in the surrounding medium attack the ONA [1]. In water these species are primarily $e^{-}, \mathrm{OH}^{\circ}$ and $\mathrm{H}^{\circ}$. Radicals may also be formed in molecular species such as histones, and may then attack the DNA. Recent studies have also shown that ion radicals formed in the hydration water surrounding DNA transfer directly to DNA bases [2]. In this paper the contribution of ESR to the understanding of radicals produced by the direct effect is briefly reviewed.

The most important early ESR work on DNA was that of Graslund, et.al. These workers studied $\gamma$-irradiated moist oriented DNA at $77 K[3,4]$, and they reported only ion radicals. The anion radical was assigned to thymine, and the cation was assigned to guanine. These results suggest that these ion radicals on the DNA bases are primary intermediates in Y-irradiated DNA, at least at low temperatures.

Individual DNA Components. Since the individual DNA bases, nucleosides and nucleotides are less complex than the DNA molecule itself, much work has been performed on the firradiation of these smaller molecules. ESR studies of Y-irradiated single crystals of the DNA bases and ESR studies of the DNA base radicals in aqueous glasses have been reviewed several times [5-10]. These studies have been most useful identifying radical species which may be significant to the radiolysis of DNA.

Ion radicals of DNA bases have been identified in $\gamma$-irradiated crystalline thymine, thymidine, cytosine $[5,8]$; guanine $[11]$; as well as ONA itself. The cation and anion radicals of all the DNA base have been produced 
in irradiated or photolyzed aqueous glasses $[5,7,8,12]$. We have performed a study of various dinucleoside phosphate (DNP) $\pi$-cations.[12] Photolysis of these molecules in $8 \mathrm{M} \mathrm{NaClO}_{4}$ at $77^{\circ} \mathrm{K}$ resulted in the finding that principally the guanine m-cation is stabilized in DNA and in DNPs containing guanine. He have also found that the excess electron in DNP anion radicals transfers from the purine to the pyrimidine base at low temperature [13]. This initial unpaired electron distribution in the DNPs is a consequence of the relative attraction of the DNA bases for an excess electron. Results for the fon radicals of dinucleoside phosphates are thus in accord with those of Graslund et al., f.e. only $G^{ \pm}$and $T^{*}$ are found in irradtated DNA at low temperatures [3].

Reactions of the DNA Base Ion Radicals. The reactions of DNA base radical ions are important to understanding the effect of radiation on DNA. The most important reactions reported $[5-10,14]$ are: 1. Protonation of the thymine anion at C-6 to form $\mathrm{TH} \cdot($ reaction 1). This irreversible step follows the initial reversible protonation at an oxygen (C-4) observed in pulse radiolysis experiments. The irreversible protonation of the thymine anion is easily observed by ESR in irradiated DNA. 2. Reaction of the thymine cation by either deprotonation from the methyl group to form $T(-H)$. or hydroxyl ion addition at the 6-carbon to form $\mathrm{TOH}^{-}$(reaction 2). Only the latter reaction is observed in structures containing a deoxyribose group (TMP). Thus this reaction would be expected in DNA, but as yet has not been reported. 3 . Reaction of the guanine cation either by deprotonation from a ring nitrogen to form $G(-H)$. or hydroxyl ion addition at the 8-carbon position to form $\mathrm{GOH}$ (reaction 3). G(-H) - has been reported in single crystal of studies guanine [11] and suggested in irradiated DNA. Ion radicals of cystosine and adenine also react chiefly by deprotonation or hydroxyl ion addition to cations and 
protonation of anions [14]. These species, however, are not reported in irradiated DNA.

At low temperatures from work with model systems one would expect that in $r$-irradiated DNA the excess electron on thymine would protonate to form the TH* radical, as is found, and the positive charge on guanine would subsequently form $\mathrm{GOH}^{*}$ or $\mathrm{G}(-\mathrm{H})^{\bullet}$. These latter reactions have no: been verified in DNA. At higher temperatures ion radicals might be expected to react rapidly before significant migration. Whillans for example reports an upper limit of five base pairs for electron migration in DNA [15]. Thus radicals might be expected to form at the DNA bases which react rapidly (by deprotonation or $\mathrm{OH}^{-}$addition for cations and protonation for anions) not just at the DNA base ion radicals are most stable at $77 \mathrm{~K}$. To date, however, work on oriented DNA at room temperature has not found evidence for radicals on other bases [16].

Very Recent Developments in the ESR of Irradiated ONA During the past few years there have been several important reports dealing with irradiated ONA. Hüttermann et al. confirm that in a wide variety of oriented DNA samples of varying G-C content, only guanine cation $\left(G^{+}\right)$and thymine anion ( $\left.T^{-}\right)$are found from $4 K$ up to $200 K$ [17]. M.C.R. Symons and co-workers al so report that approximately equal amounts of $\mathrm{G}^{+}$and $\mathrm{T}^{-}$centers are formed at 77K [18]. They analyze for single and double strand breaks by using plasmid ONA and they find that both exist under conditions in which $G^{+}$: and $T^{-}$: are the only primary radical products at low temperature. They find extensive strand breaks upon annealing to room temperature. Most significantly, they observe that yields of double strand breaks (dsb) relative to singie strand breaks (ssb) are far greater than predicted statistically. These authors suggest that both $G^{+}$and T: centers lead to ssb, and that the unusually high yields of dsb are due to 
the fact that $G^{+}$and $T$ : centers are often trapped close to one another; $1 . e$. within $50 \AA$, but presumabiy on different strands.

Up to this time it was usually argued that hydroxyl radical attack was the princtpal mechanism for strand breaks. Ward et al. [19], however have found that random hydroxyl radical attack cannot account for DNA strand breaks and the work described herein suggests that anionic and cationtc centers may be more important in radiation damage to DNA than previously thought. The mechantsm for production of strand breaks from DNA base radicals has been suggested by work of Lemaire et al. on polyurac1l [20]. They find that uractl base radicals ultimately result in strand breaks by abstraction reaction from the ribose group.

In our own DNA work we have recently investigated radiation damage to DNA at elevated temperatures employing spin labeled DNA in solution [21]. This work has been quite useful in delineating the type of attack on the spin label that occurs as a function of distance from the DNA strand. We have found results which suggest that probes with short tethers (7 $\AA$ ) react mainly with DNA base radicals whereas longer length probes (15 $\AA$ ) react mainly with water and sugar ;adicals.

In our most recent efforts, in conjunction with $k$. Wheeler and co-workers, we are comparing the products of radtation damage in hydrated solid DNA under conditions where ESR experiments show that only ion radicals are intially formed, with those products formed in DNA in trradiated in vivo. A comparison of the products formed in the two systems will be a test of our hypothesis that the direct effect is the prime cause of radiation damage in living systems.

\section{ACKNOWLEDGMENT This work was supported by the office of Health}

and Environmental Research of the U. S. Department of Energy. 


\section{References}

1. J. F. Ward, Radiolytic damage to genetic material, J. Chem. Ed., 58 , 135-139 (1981).

2. S. Gregol1, M. Olast, A. Bertinchamps, Radiolytic pathways in irradiated DNA. Influence of chemical and conformational factors Radiat. Res., $\underline{89}$ 238-254 (1982).

3. A. Gräslund, A. Ehrenberg, A. Rupprecht and G. Ström, Ionic base radicals in irradiated orlented DNA, Biochim. Biophys. Acta, 254, 172-186 (1971).

4. A. Gräslund, A. Ehrenberg, A. Rupprecht, G. Ström, and H. Crespl, Ionic base radicals in irradiated oriented nondeuterated and fully deuterated DNA, Int. J. Radiat. Biol., 28, 313-323 (1975).

5. W. A. Bernhard, "Solid State Radiation Chemistry of DNA: The Bases," Adv. Radiat. Biol., Vol. 9, 199, (1981).

6. H. C. Box, "Radiation Effects," Acadenic Press, New York (1977).

7. M. D. Sevilla, "Mechanisms for Radiation Damage in DNA," in "Excited States in Organic and Biochemistry," B. Pullman and N. Goldblum, Eds., D. Reidel, Boston (1977).

8. J. Huttermann, Solid state chemistry of DNA and its constituents, Ul tramicroscopy 10, 25-40 (1982).

9. "Effects of Ionizing Radiation on DNA," J. Hüttermann, W. Kohnlein, R. Teole and A. J. Bertinchamps, Eds., Springer Verlag, Berlin (1978).

10. L. S. Myers in "Free Radicals in Biology," Vol. 4, Ed. by W.A. Pryor, Chapter 3, Academic Press (1980).

11. D. M. Close, E. Sagstuen, W. H. Nel son, ESR study of the guanine cation. J. Chem. Phys. $82,4386-4388$

12. M. D. Sevilla, J. B. D'Arcy, K. Morehouse and M. L. Enge?hardt, Photochem. Photobiol., 29, 37 (1979).

13. M. D. Sevilla, R. Failor, C. Clark, R. A. Holroyd, and M. Pettei, Electron transfer in dinucleoside phosphate anions, J. Phys. Chem., 80, 353 (1976).

14. S. Gregoli, M. Olast, and A. Bertinchamps, Charge-migration phenomena in irradiated costacking complexes of DNA nucleotides, Radiat. Res. 17, $417-431(1979)$.

15. D. W. Whillans, Studies of Electron Migration in DNA in Aqueous Solution using Intercalating Dyes, Biochim. Biophys. Acta 414, 193-205 (1975).

16. M. Sevilla and S. Swarts, results in preparation for publication. 
17. J. Hüttermann, K. Voit, H. Oloff, W. Koh lefn, A. Graslund and A. Rupprecht, Specific formation of electron gain and loss centres in $X$-Irradiated oriented fibres of DNA at low temperatures, Faraday DisC. Chem. Soc., 78135 (1984).

18. P. J. Boon, P.M. Callis, M. C. R. Symons, and B. W. Wren, Effects of Ionizing radiation on DNA and related systems. Part 1 . The role of oxygen. J. Chem. Soc. Perkin Trans. II 1393 (1984).

19. J. F. Ward, W. F. Blakely, and E. Joner, Mammalian Cells are not Killed by ONA Single-Strand Breaks Caused by Hydroxyl Radicals from Hydrogen Peroxide, Radiation Research 103, 383-392 (1985).

20. 0. G. E. Lemaire, E. Bothe, and D. Schulte-Frohlinde, Yields of radiation-induced main chain scission of poly $U$ in aqueous solution: strand break formation via base radicals. Int. J. Radiat. Biol. 45, 351-358 (1984).

21. S. Swarts and M. D. Sevilla, Radiolysis of spin labeled DNA: An ESR investigation, submitted for publication. 

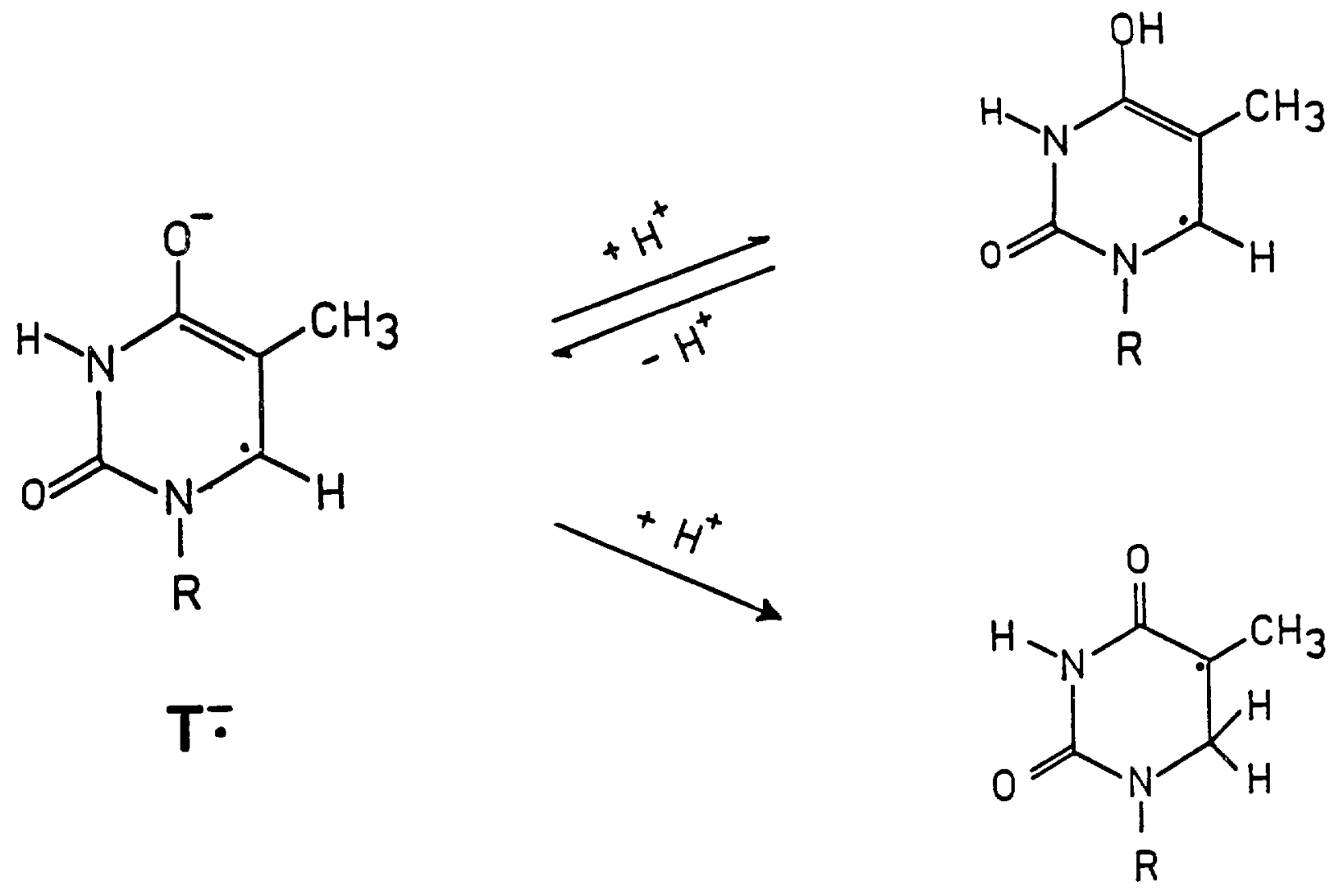

$\mathrm{TH}$.

REACTION 1 

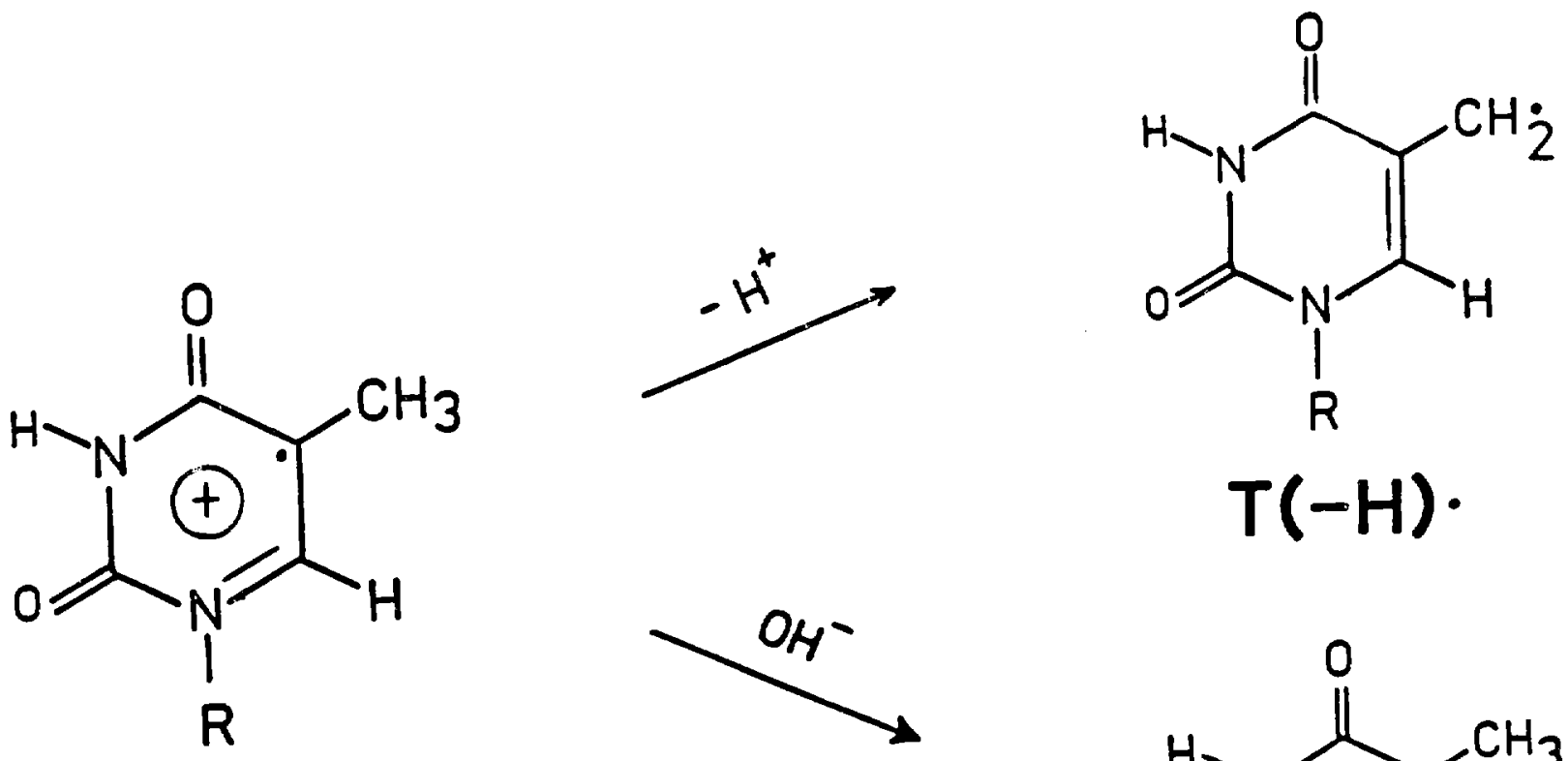

$$
T(-H) \text {. }
$$
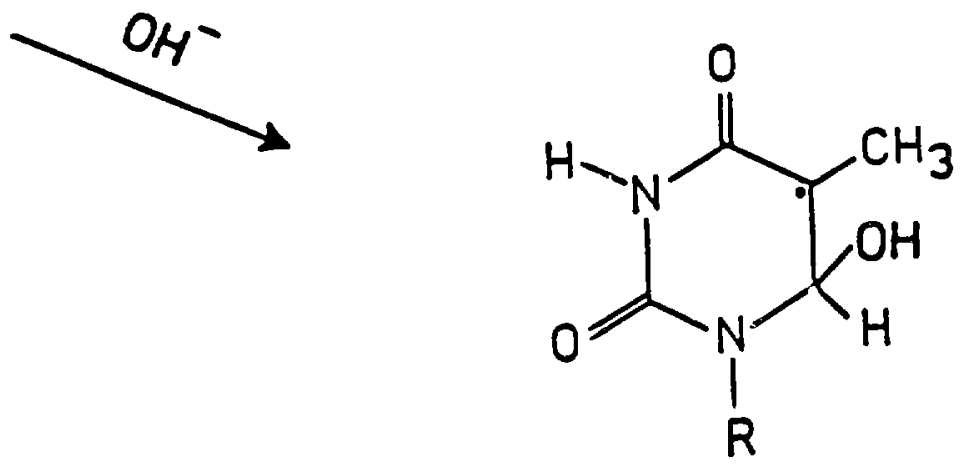

$\mathrm{T}(\mathrm{OH})$.

REACTION 2 

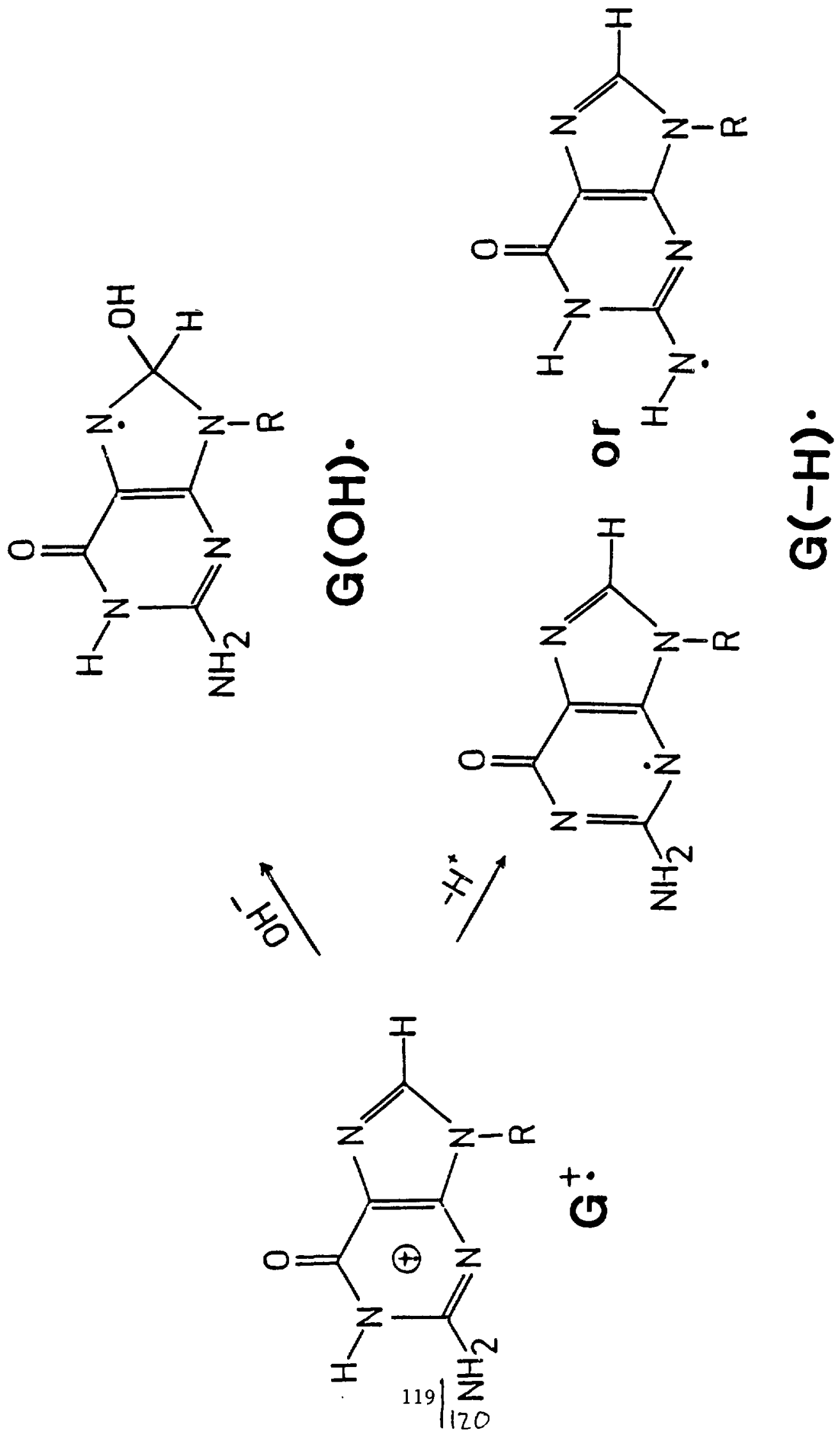


\section{J.F.Ward, \\ University of California at San Diego, M010, \\ La Jolla, CA 92093.}

Work in model systems has defined the free radical processes which lead to ionizing radiation induced DNA damage caused either via direct ionization or by intermediary OH radicals from water radiolysis. Most of the molecular products formed under defined conditions (model systems) are known. However, little is known of the intracellular yields of the majority of these types of radiation induced DNA damage. The general problem is sensitivity: After 5 Gray only about 1 in a million DNA monomer units within each mamalian cell is damaged and such damage is randomly distributed among a large variety of products. This randomness makes the use of modern molecular biology techniques difficult. The questions asked of such techniques must be carefully phrased.

Most of the cellular studies of DNA damage have concentrated on DNA single strand breaks (SSB)(1000 per cell per Gray) and double strand break (DSB) ( 40 per cell per Gray) measurements. (Some measurements of specific base damaged products have been made; thrmine product, 250 per cell per Gray; B-hydroxyadenine, 700 per cell per Gray). Measured yields of DNA breaks probably may not represent the numbers of these types of damage present in the cell. The techniques used for assay of strand break damage (both double and single) recruit damage into the break category which does not exist as a break in the cell.

The aternate to actual measurement of damage rields intracellularly is extrapolation from model systems. However such an extrapolation is difficult. A generality can be stated: The sum of the base damage yields is greater than the deoxyribose damage yield, from indirect effect the ratio, base/sugar damage is $2.8-4$ and for direct damage 1. Intraceliulariy the ratio is expected to be $2.3-3$. 
We have suggested that the mechanism by which the proposed lethal damage, the DNA DSB, is produced is via the formation of locally multiply damaged sites (LMDS)(formed in volumes of high local energy deposition). Of these LMDS it can be calculated that only $11 \%$ represent actual DSB the rest have a base damage component.

We have proposed that the individually damaged sites are biologically unimportant since they can be readily repaired. However in attempting to repair LMDS, cells are presented with a variety of problems. It is questionable whether such damage can be accurately repaired except by recombinational processes. It is possible that cells have not evolved repair system specific for ionizing radiation induced damage since the average cell exposed to background radiation will 'see' only one SSB per year and 1 DSB each 25 years.

(Supported by PHS Grant CA 26279). 
PADIATION INDUCED NUCLEOTIDE DAMAGE: METHHODS AND MODELS

K.T. Wheeler, Department of Radiology, Bowman Gray School of Medicine Winston-Salem, NC 27103

Although it has been known for decades that ionizing radiation can cause cells to die, mutate or transform, relatively little is known about the exact mechanisms responsible for these biolcgical phenomena. There are several common features to any proposed mechanism in mammalian cells. First, an energy deposition event occurs in or near the critical target that immediately alters the target chemically and structurally. Secondly, the initial damage is often unstable and nonenzymakic rearrangements occur to produce more chemically stable damage products and conformations. Thirdly, these damage products and conformations are modified by enzymatic processes. Finally, the enzymatically modified target interacts with all of the cellular biochemical and metabolic processes to produce a cell which either is indistinguishable from the original cell or is mutated, transformed or committed to death. The data convincingly argue that, in the majority of the cases, the critical target is the genetic material located in the cell nucleus.

In many respects, the failure to identify the exact mechanisms responsible for cell lethality, mutations and transformation stems from our lack of knowledge about the production and fate of specific lesions produced in the DNA at biologically relevant radiation doses. For example, no chemically distinct DNA lesion produced by ionizing radiation has been shown to be unmodifiable by enzymatic repair processes. The frequency of inserting erroneous bases during enzymatic modification or replication of specific radiation-induced DNA lesions is unknown. This list of examples is by no means exhaustive. 
In general, our limited knowledge is caused by both a lack of sensitive methods for measuring chemically distinct lesions in cellular DNA and a lack of models that can address fundamental questions that are peculiar to cellular DNA, but too complex to be studied in cellular DNA. Recently, Four methods (antibodies, GC/MS, HPLC and LC/MS) for measuring specific DNA lesions have become available. The advantages and disadvantages of these techniques, new approaches to improve their detection sensitivity, the influence of DNA sequence, conformation and oxygen status on the spectrum and quantity of specific lesions produced, and critical biological questions that are now experimentally addressable will be discussed. 
MUTAGENIC MUTATIONS: XERODERMA PIGMENIOSUM AND THE QUESTION OF THE XP VARTANT James D. Regan and Andrew A. Francis

Oak Ridge National Laboratory cak Ridge, TN 37831

INTRODUCTION

Cells from patients with the classical form of the sun sensitive hereditary disease xeroderma plgmentosum (XP) exhibit high sensitivity to ultravlolet (UV) radiation and chemlcal mutagens (e.g. benzo(a)pyrene diolepoxides, N-Acetoxy-2-acetyloaminofluorene) in terms or mutation induction and survival. The evidence indicates that classtcal XP cells are derlcient in the "bulky adduct" repalr system. Classical xp is thus a mutation-permisstye mutation. Cells from XP variant (XPV) patieats are $W$ sensitive for mutation Induction and cell k1lling but UV-induced pyrimidine dimers are exo1sed. In XPV cells chemlcal "bulky adducts" from benzo(a)pyrene diolepoxides and other such agents do not cause inoreased mutations or lncreased cell kllling above that seen in normal cells (1). Th1s evidence suggests that the XPV cells are not sensitive to pyrimidine dimers or otber bulky adducts, but that another UV-Induced DNA Iesion, not dealt with by the excision repair system, may be causing the increased mutation and the decreased survival after UV.

The molecular lesion in XPV has been attributed to a defeot in postreplication repair after UV (2). In normal cells, after UV, the nascent DNA is made in pleces smaller than usual. After about two hours the normal cells recover the ability to synthesize DNA of the proper size. The same process occurs in XPV cells except that this recovery process takes about elght hours. Note that in this mutation there appears to be no absolute defeot, that 13 , no repair function is completely missing in XPV. At best this mutation is "leaky". However, we have recently found that XPV cells 
are alssing a prereplication repalr function present in normal cells. There is a UV-induced, photosensitive lesion (not a 5,6 pyrimidine dimer) which is removed from nomal cells within five hours after UV Irradiation. XPV cells are totally Incapable of removing this lesion (3).

Our experiments have shown that the production of the lesions by $254 \mathrm{~nm}$ Irradiation is Independent of temperature which indicates a photodynamic and not an enzymatic or ohenical reaction is involved in the formation of the lesions. The disappearance of the lesion from the DHA, however, is temperature dependent and probably enzymatic. In an attempt to learn more about the nature of the lesion, the spectra of the lesion's formation and 1ts photolysis were measured. We found that the formation of the lesion occurs with roughly the same wavelength as in the formation of pyrimidine dimers. Photolysis of the lesion ocours with wavelengths less than $300 \mathrm{~nm}$ to $400 \mathrm{~nm}$ w1th a maximum at 313-317 $\mathrm{nm}$. These properties may indicate a possible involvement with the thymidine (6-4) photoproduct.

\section{MATERIALS AND METHODS}

Procedures for cell culture, DNA label1ng, UV Irradiation and DNA photolysis, and single strand break analysis by alkaline sucrose gradients have all been described in detall elsewhere (3).

\section{RESULTS}

Experiments were conducted to determine if the formation of the 313 sensitive lesion in the cellular DNA by 254 nm UV Irradiation was at all dependent on the temperature during irradiation, that 1s, to discover if there was any indication of a blological/enzymatic process involved in 
forming this lesion. Experiments were performed using $254 \mathrm{~nm}$ ov doses of 20 and $60 \mathrm{~J} / \mathrm{m}^{2}$ and cells were 1 rradiated at 0 and $37^{\circ} \mathrm{C}$. As shown in rigure 1 there was no effect of temperature on the formation of the lesion. Th1s evidence suggests that the formation of the lesion is a photodynamio process not 1nvolving an enzymatic or other temperature dependent activity.

Next it was necessary to determine if removal of the lesion from the DHA of normal cells was temperature dependent. B1gure 2 shows the results of these experdments. When the cells were held at 100 temporatures for eive hours arter $254 \mathrm{~nm}$ Irradiation and then 1rradiated with $313 \mathrm{~nm}$ to deteot the lesion, the number of lesions per $10^{8}$ daltons of DXA realned the same as at zero t1me. In the cells held at $37^{\circ} \mathrm{C}$ for the flve hours the lesions wore removed and no excess strand breaks were observed. This removal or repalr process is thus temperature dependent and probably enzymat1c.

Since the wavelengths of sunlight whlch penetrate the atmosphere are not in the range of 250-260 $\mathrm{nm}$ but are $>290 \mathrm{~nm}$. It was important to determine if the photosensitive DHA lesion could be induced by simulated sun11ght and thus be of blological significance in human exposure. F1gure 3 shows data of photoseasitive Iesion induction curves using $254 \mathrm{~mm}$ UV, Iodacel flltered FS40 sunlamp radiation (>290 nm) and mylar filtered FS40 sunlamp radiation $(>320 \mathrm{~mm})$. Exposures were used which produoed Induced photosensitive lesion Induotion with the $254 \mathrm{~nm}$ lamp and the Kodacel-riltered sunlamp. The mylar-filtered lamp did not produce the photosensitive lestons.

Further data on this aspect is presented in figure 4 which shows the action spectrui of Induction of the lesion in cellular DNA. The lesions 
were read1ly Induced at wavelengths $254-280 \mathrm{~nm}$. Above $280 \mathrm{~nm}$ the efficlency of induction drops precipitously. In determining the action spectrum for photolysis of the lesion we wero limited by two factors. We could only use the more intense mercury emission lines, and, at lower wavelengths, the photolysing light produced significant numbers of single strand breaks in the unirradiated control DNA. Nevertheless our results show that, among the photolysing wavelengths tested, the optimum one for photolysis of the lesion was $313 \mathrm{~nm}$ (F1gure 5).

Among the three genet1c types of human cells, XP classical (complementation Group A) XP yarlants and normal cells the handling or processing of the $313 \mathrm{~nm}$ photosensitive lesion $1 \mathrm{~s}$ markedly different in each cell type. Figure 6 shows the fate of the lesion in the three cell types with time arter $254 \mathrm{~nm}$ UV 1rradiation. In normal cells the lesion appears to be removed from the DNA at a rate such that it is nearly all gone by three hours and totally removed by five hours. In the XPV cells there is no change from 0 time up to 20 hours (the longest t1me we have made observat1ons). In the case of the XPA cells the interprotation of the results 13 less obvious. The curve we observe is essentially the reciprocal of that seen In normal cells with the number of photosensitive lesions increasing with time up to an apparent doubling of their number by five hours and remalning at that level for up to 20 hours.

DISCUSSION

From the data of figure 1 it seems apparent that the $313 \mathrm{~nm}$ sensitive lesion can be Induced at elther $0^{\circ} \mathrm{C}$ or at $37^{\circ} \mathrm{C}$ and the rrequency of induc- 
tion is quantitatively related to UV dose. In this sense the lesion is much like a 5,6 pyrimidine dimer, where the 1nduction process is a purely photodynamic process. Removal of the lesion is temperature dependent, suggesting an enzymatic process.

The photosensitive lesion can be induced by germicidal lamps and also by wavelengths present in natural sunlight. It 13 therefore not strictly a "laboratory" phenomenon and may have blological signislcance. The fact that an apparently enzymatic process has evolyed in normal cells for the leston removal is also indicative of blological significance.

As shown in figure 4 the action spectrum for induction of the lesion $1 \mathrm{~s}$ simllar to that for 5,6 pyrimidine dimers. The peak of the action spectrum for photolysis $13313 \mathrm{~nm}$ whlch $1 \mathrm{~s}$ also the peak reported for photolys1s of the (6-4) product(4). We do not know if the radiation product is a (6-4) adduct type or not. There are arguments for and against. The simflarity of photolysis peaks for the lesion reported here and the $(6-4)$ product argues that we are dealing w1th $(6-4)$ or perhaps a precursor thereof. However, the reported frequency of induction of (6-4) is about 20 t1mes h1gher than what we detect by our methods. Yet it is conceivable that in detecting one single strand break we are actually observing several photosensitive lesions, that 1s, they may occur in clusters as the curvilinear shape of our photolys1s curves suggests. Another argument against the photosensitive lesion being the $(6-4)$ product is the reported excision of (64) product from the DNA of XP variant cells when assaued with a polyclonal ant1body to $(6-4)(5)$.

The unlque handling of the photosensltive lesion among the three cell 
types (normal, classical XP and XPV) presents a problem in interpretation. For normal and XPV cells the results seem straight forward. In normal cells the lesion is Induced and then removed. In XPV 1t is induced but not renoved, that 1s, a clear cut repair defeot is observed. But what of the results in the classical XP cells? As seen in PIg. 6 while the number of lesions is decreasing in the normal cells after UV, it is proportionately Inoreasing in the XPA cells. At present we have no adequately proven explanation for the results. However we belleve it is conoelvable that the photosensitive lesion may be a precursor of the (6-4) produot ulth a lower sensitivity to $313 \mathrm{~nm}$ radiation. In normal cells it may be converted to a (6-4) and removed. In XPA cells it way be converted to (6-4) thus having higher sensitivity to $313 \mathrm{~nm}$. In the XPV cells no conversion takes place because the XPV cells may be mutant for the conversion enzyme. The correct answer awaits in future research. 


\section{REFERENCES}

1. Watanabe, M. V., V. M. Masker and J. J. McCormick. Exc1sion repalr of wV or benzo[a]pyrene diol epoxide-1nduced leslons in xeroderma plgmentosum cells 1s 'error-free'. Mutat. Res. 146: 285-294, (1985).

2. Lehman, A. R., S. K1rk-Bell, C. F. Arlett, M. C. Patterson, P. H. M. Lohman, E. A. deWeerd-Kastele1n and D. Bootsma. Xeroderma pigmentosum cells with normal levels of excision repalr have a defect in DNA synthesis after UV-irradiation. Proc. Natl. Acad. Sc1. (U.S.A). 72: 2192.23. ( 1975$)$

3. Francis, A. A. and J. D. Regan. Detection and repair of a UV-Induced photosensitive lesion of a UV-induced photosensitive lesion in the DNA of human cells. Mutat. Res. DNA Rep. Repts. 165: 151-157, (1986).

4. MItchell, D. L. and B. S. Rosenstein (1987). Ùse of specif10 radio1mmune assays to determine action spectrum for the photolysis of (6-4) photoproducts. Photochem. Photob1ol. 45: 781-786.

5. D. L. Mitchell, C. A. Halpek and J. M. Clarkson. Xeroderma pigmentosum cells are not defective in repalr of (6-4) photoproducts. Int. J. Rad. B1ol. In press. 
FIGURE LEOENDS

Figure 1. Formation of the $313 \mathrm{~nm}$ 11ght sensitive lesion in the DMA of human colls $0^{\circ} \mathrm{C}$ compared to $37^{\circ} \mathrm{C}$. Cells were 1 rradiated w1th 20 $(0,0)$ and $60 \mathrm{~J} / \mathrm{m}^{2}\left(\omega, \omega\right.$ of $\mathrm{W}$ 11ght at $0^{\circ},(w, 0)$; and at $37^{\circ} \mathrm{C}$ .0); then exposed to $313 \mathrm{~nm}$ 11ght. The resulting strand breaks are plotted vs the 313 nn 11 ght dose.

F1gure 2. Reuoral of UT-Induced $313 \mathrm{~nm}$ light sensitive lesions from the DHL of human oells at $37^{\circ} \mathrm{C}$ compared to $0^{\circ} \mathrm{C}$. Cells vere Irrad1ated w1th $20 \mathrm{~mm}$ OT 11ght then 1noubated for $0(0)$ and 5 hours at $37^{\circ}(\omega)$ and at $0^{\circ} \mathrm{C}(0)$. Photolysis curros plotted the sane as In F1g. 1.

Figure 3. Formation of the $313 \mathrm{~nm}$ sensigive lesion by irradiation with 20 $\mathrm{J} / \mathrm{m}^{2} 254 \mathrm{nn} 21 \mathrm{ght}(0)$ oompared to a dose of kodecil entered FS40 sunlamp 1rradiation which results in the same anount of pyrimidine dimers in the DMA ( 0$)$. The same dose $\left(\mathrm{J} / \mathrm{a}^{2}\right)$ of FS40 11ght filtored w1th wiar $(\square)$ produoed no deteotable 313 sensitire lesions.

Flgure 4. In action speotrum of the formation of the photosensitive lesion In the DWA of human oells. A dose response ourve was generated for each wavelength tested and the slope of this ourve was plottod vs. wavelenth. Each point on the curve required data from 18 Individual gradients. 
Figure 5. An action spectrum of photolysis or DNA containing photosens1tive lesions. Cells were Irradiated with $20 \mathrm{~J} / \mathrm{m}^{2}$ of $254 \mathrm{~nm}$ Ilght followed by 1rradiation with various wavelength light for photolysis. The 1nitial slope of the dose curve obtalned with each wavelength of photolysing light was plotted vs the wavelength ( 1$)$. The spectrum is ilmited to the more intense mercury emission IInes and also by the number of strand breaks produced in the unirradiated control DNa by the lower wavelengths of photolysing light $(0)$.

Figure 6. Maximum number of DNA strand breaks generated by $313 \mathrm{~nm}$ photoIysis at various times after $20 \mathrm{~J} / \mathrm{m}^{2}$ OV irradiation of: 0 , normal;A, XP-A; $D$, XP-var1ant (Pellay); $=$ XP-Varlant (HoMec);, XP-variant (GM 3055). Pellay, WoHec and GM 3055 are elbroblast oul tures from three XPV patients from different kindreds. 


\section{EXCESS STRAND BREAKS $/ 10^{9}$ DALTONS DNA}

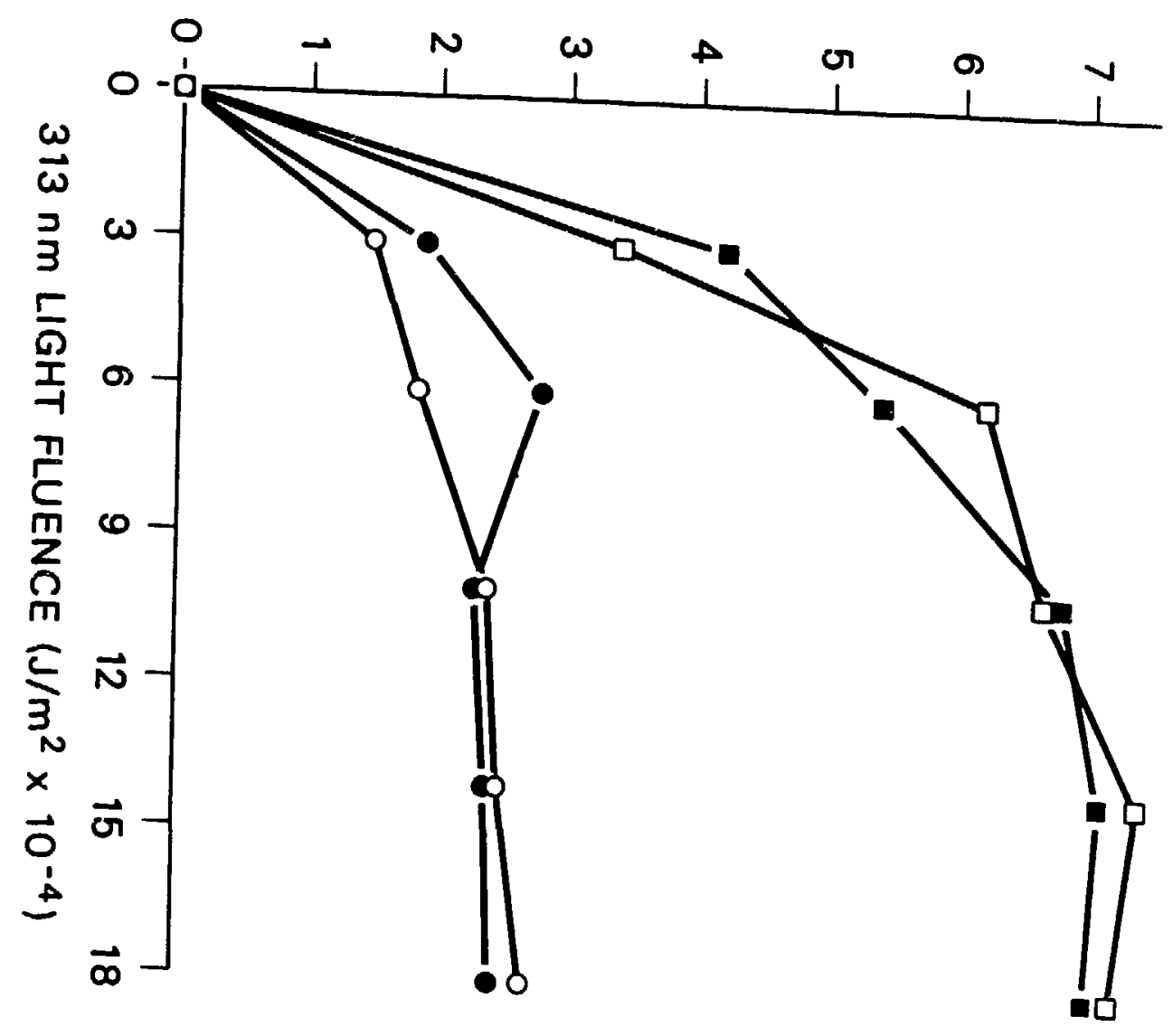




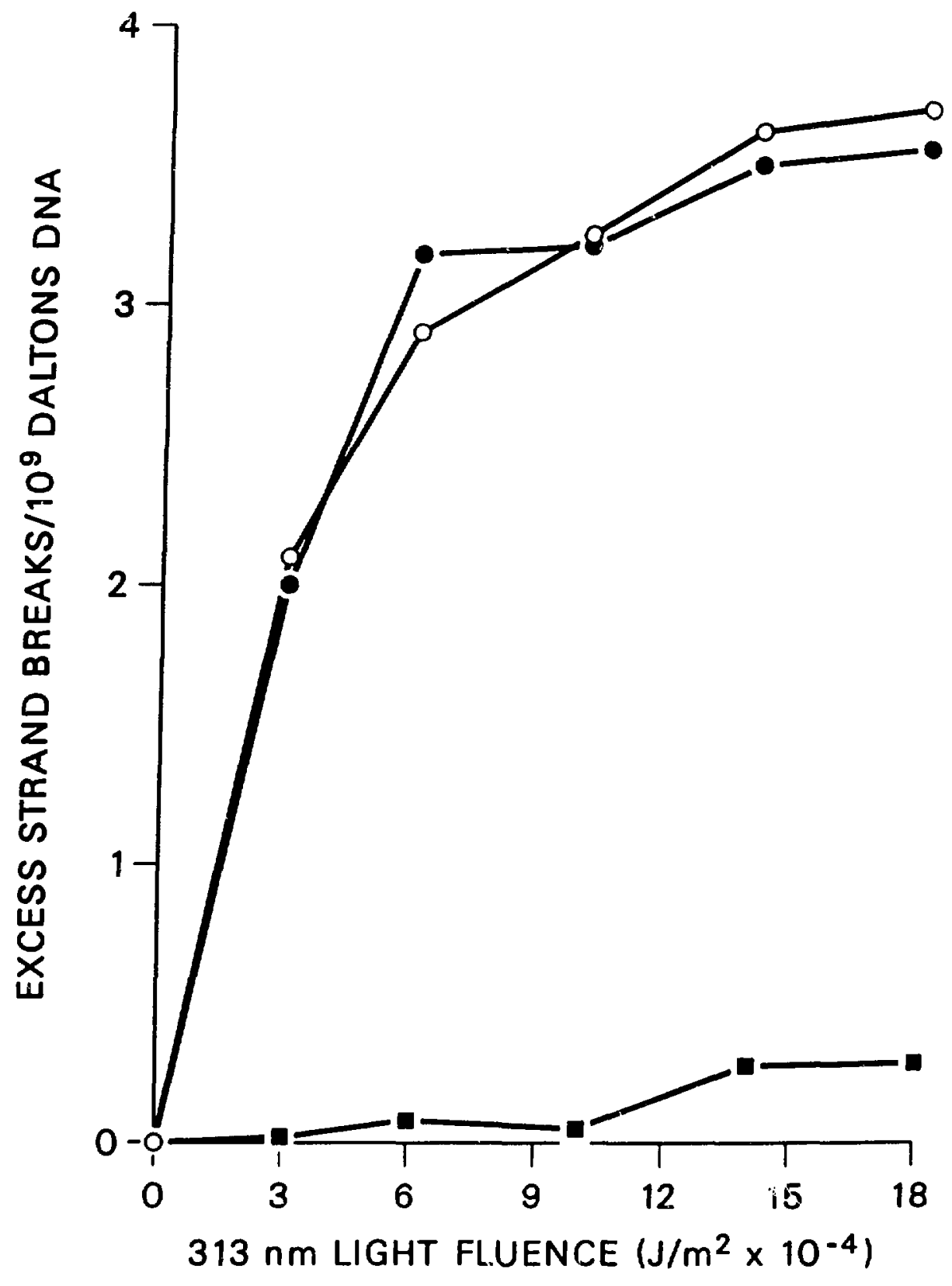


EXCESS STRAND BREAKS $/ 10^{9}$ DALTONS DNA

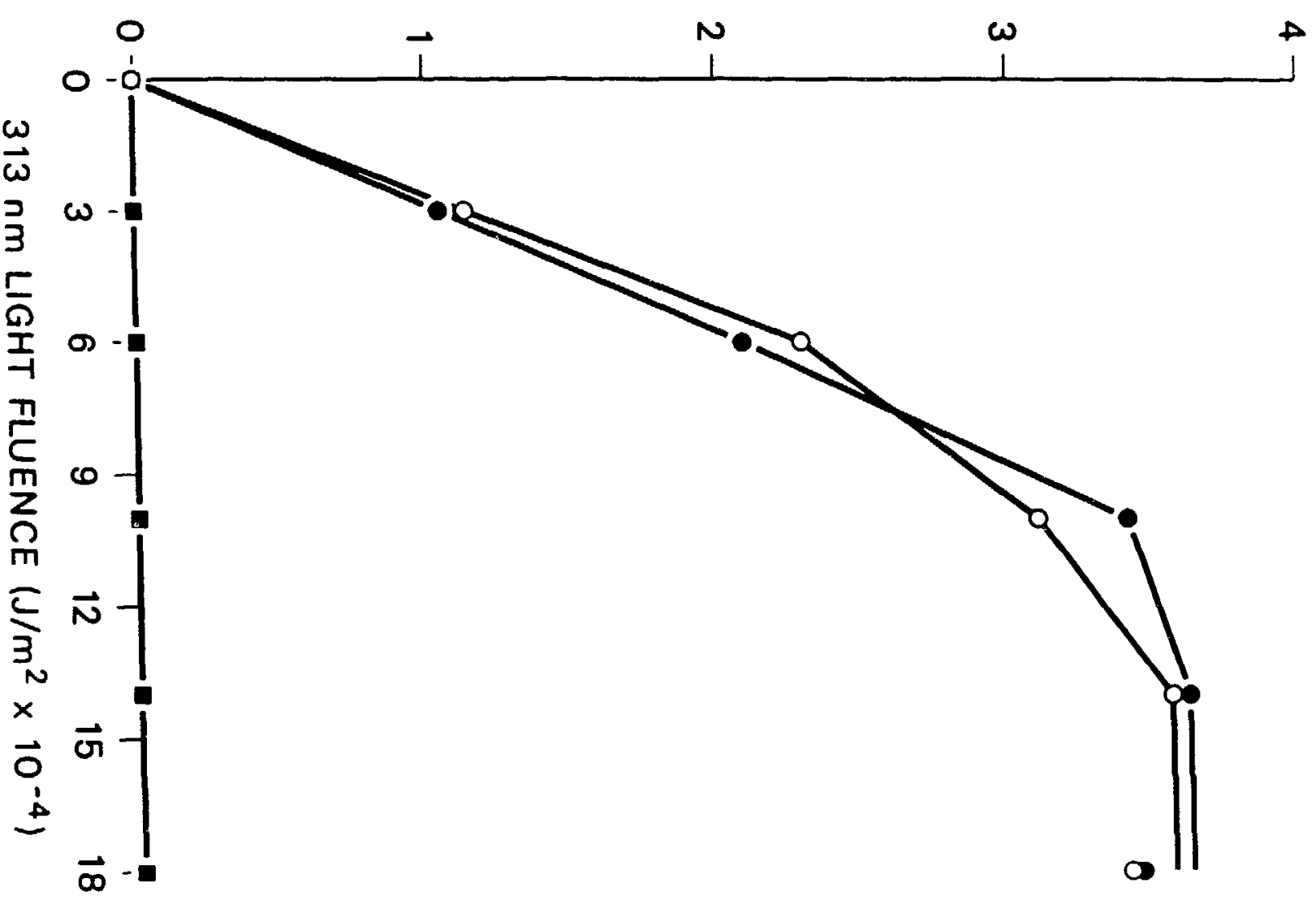




\section{EXCESS STRAND BREAKS $/ 10^{9}$ DALTONS DNA $/ \mathrm{J} / \mathrm{m}^{2}$}

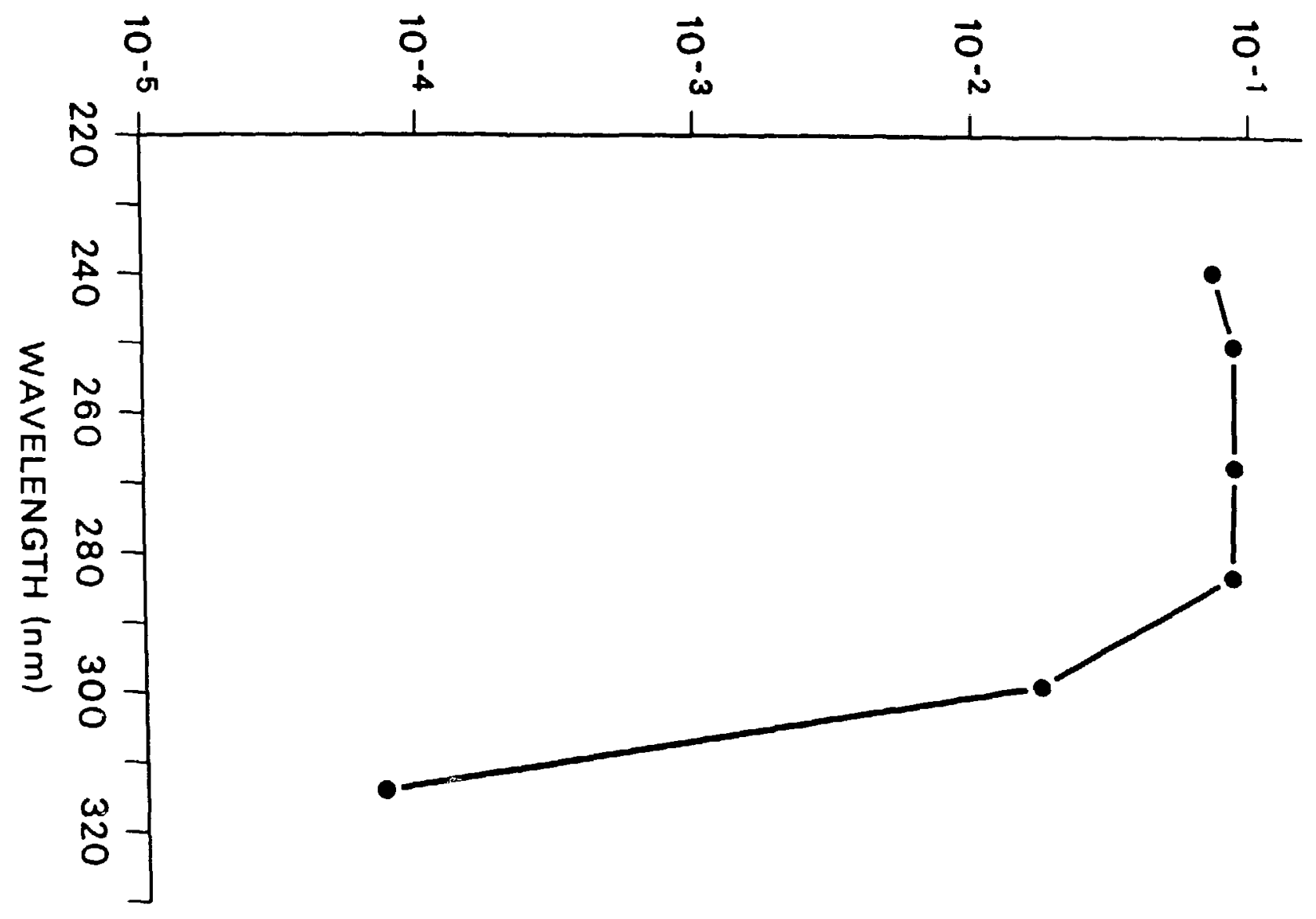




\section{EXCESS STRAND BREAKS $/ 10^{9}$ DALTONS DNA $/ \mathrm{J} / \mathrm{m}^{2} \times 10^{5}$}

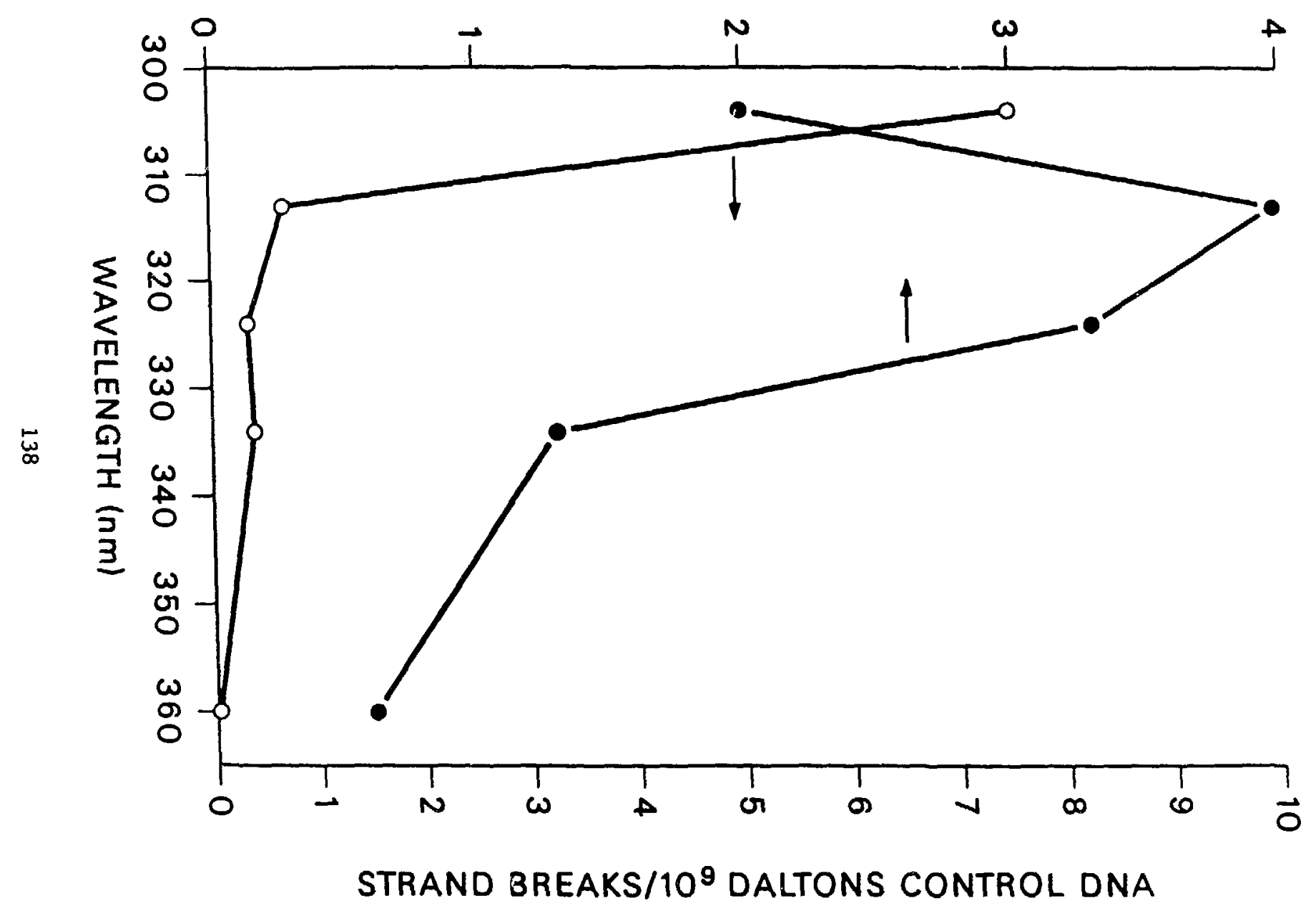




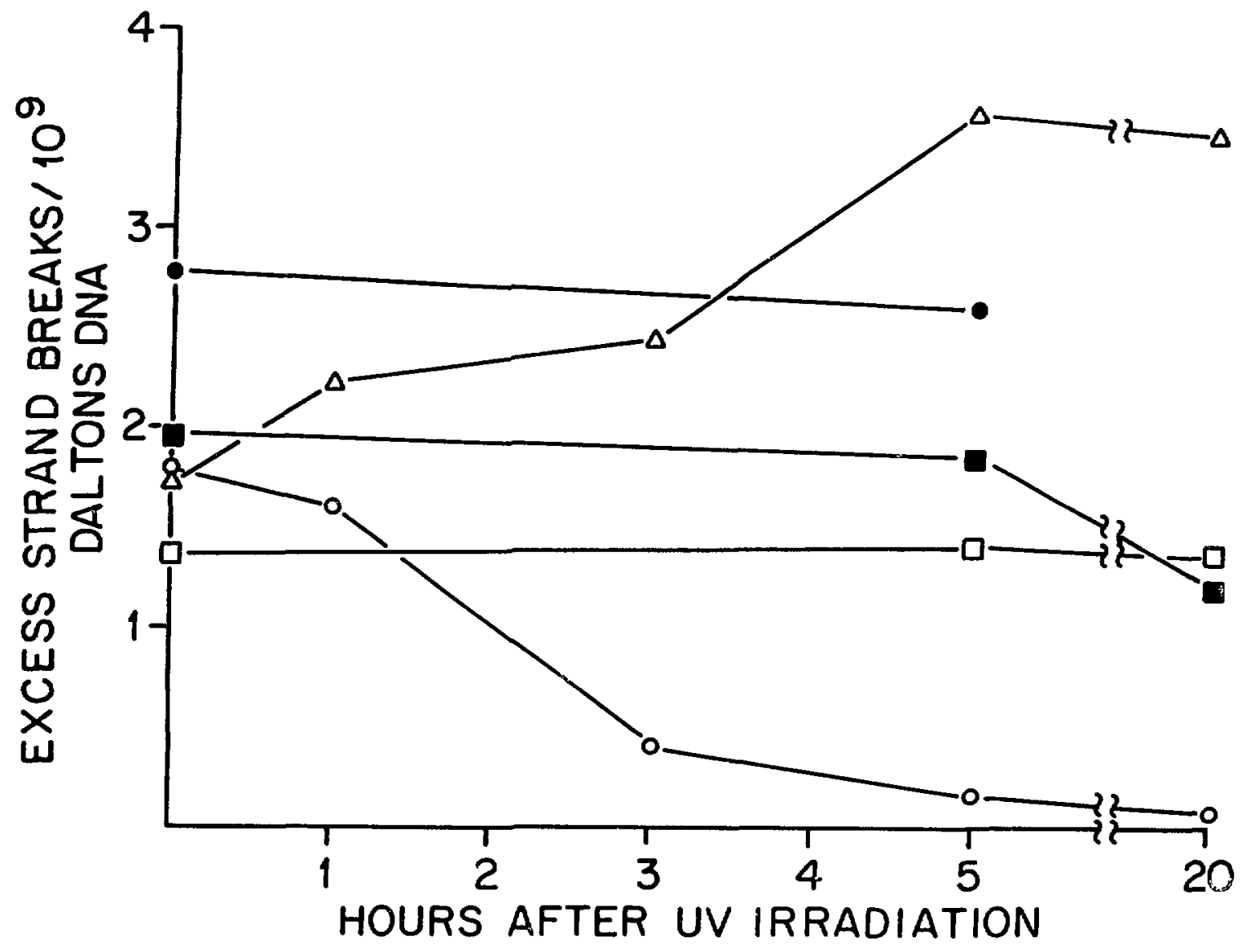

$139 / 140$ 
REPAIR/MISREPAIR AND LINEAR DOSE DEPENDENCIES.

M. M. Elkind, Department of Radiology and Radiation Biology, and the Cellular and Molecular Blology Program, Colorado State Unlversity, Fort Collins, Colorado 80523.

People at large are exposed to small doses of radiation usually protracted over extended periods of time. Consequently, blological effects, whlch are belleved to follow a threshold-type response, are thought to be unimportant because it is assumed that the damage due to doses in the threshold region is repalred. In contrast, dose-dependencles which are IInear are thought to be fully erfective. The number of individuals affected is taken to be the product of the number exposed, the jield per unit dose, and the dose. The protraction Interval ordinarily is not considered. Hence, the underlyling and lmplicit assumption is that a linear dose-effect results from a single event which is not modirlable by biochemlcal or biologlcal processes (see below). The unmodiflablilty of single-event damage is also consistent with the discrete and energetic nature of radiant energy absorption. A primary absorption event, due to a low-LET radiation, on average deposits $60 \mathrm{eV}$ over dimensions which are atomic in size.

When the number of cells at risk is not slgnificantly diminished over the dose range of Interest, a Ilnear dose dependency can be specified simply by the coefficlent of the Iinear term. Such is the case for mutation Induction and neoplastic transformation particularly if erequencies of induction are normalized by the fraction of cells surviving. When dose dependencles of cell kllilng are of interest. IInearlty may not be as readily evident. To begin with, the fraction surviving (S) is usually measured (1.e.. one minus the Iraction killed) and because the population at risk may be signiflcantly decreased with Increasing dose, I Inearlty takes the form or an exponential dependence on dose (D), e.8..

$$
S=e^{-v D} \cdot e^{-\lambda}
$$

In eq. (1), $\lambda$ increases Iinearly with dose and $\lambda$ is the average probabllity that an inactivating event will be scored. When $D$ is expressed as primary absorption events per unit volume, $\nabla$ is the volume of the target which has to be "nit" to k111 a cell. Hence, "Ilnear," or "single-event," or "single-nit" inactlvation is formally derived from Poisson statistics where the probability of survival is equated to the $P_{0}$ term, 1.e., the probability of no successes. It is the average probability of a "hit" $\lambda$ which depends on the coefflcient of the 1 Inear (and only) tera in the dose dependency. However, equating $S$ to $P_{0}$ implies the following. If $B(h)$ is the probability that a cell will survive when its target $\nabla$ is hit $h$ times, then implied by eq. (1) is the biological statement that:

$$
H(h)-\left\{\begin{array}{l}
1, h=0 \\
0, h \geq 1
\end{array}\right.
$$

Equation (2) states that exponential survival is an "all or nothing" process, a notion with which the end polnt colony formation has a rormal correspondence. Because of the meaning of this equation. It has been assumed that an exponentlal dose effect is not modirlable by dose protraction because the rate at which hits are reglstered should not have a bearing on whether or not a target is hit. The preceding implies, in turn, that the coefriclent $v$ 
is not modirlable by cellular processes whlch would be expected to come into play $1 f$ the time of dose protraction $1 \mathrm{~s}$ of the order of the times character1stic of blochemlcal or cellular processes. From the latter 1nference, the generalization frequently is made that exponential survival is independent of cellular repalr. Furthermore, the same 1 deas are applied to end points in addition to survival. with the recognition that single-hit inactivation is formally equivalent to a Ilnear dependence on dose "and to other inducing agents (e.g.. nonionizing radiations, chemlcals, blologlcal modifers, etc.) with the understanding that $D$ in eq. (1) is not specific to ionizing radiation.

To pursue blochemlcal/molecular méchanlsms underlying a ilnear dose dependency, it is necessary to know the boundary conditions lmposed by cellular responses. For this reason, the dependence of different end points on dose protraction, or other treatments which have been found to influence response, have been examined in reglons of effect whlch show a linear dependence on dose. Data ex1st, or are belng further developed, on DNA damage, cell survival, and neoplastic transformation; studies of mutagenesis are in progress. In several instances, the results show a strong dependence on dose protraction and/or a postirradiation treatment. Thus, Identify Ing sensitive

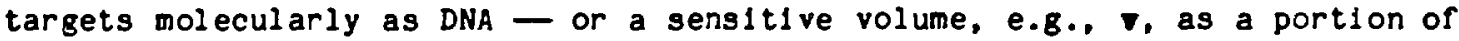
the genome - is generally an incomplete basis for stating the relationship between cause and degree of effect.

Although the Inferences of eq. (2) are not supported in several Instances, nonetheless a blophysical basis is avallable for understanding linear dose dependencles which are modiflable. This basls comes from a theorem due to T. A. Hall [Bull. Math. Blophys., 15, 43 (1953)] whlch leads a modification of eq. (2) as follows:

$$
H(h)=l_{0, n \rightarrow 0}^{1, n}=
$$

Equation (3) leads to an interpretation [M. M. Elkind, Radlat. Res., 71, 9 (1977)] that a proportion of the "hits" or "events" registered in a sensitive volume may be without effect because of repair processes which depend upon the blochemistry of the cell. (This Investigation was supported by PHS grant number CA 41483 awarded by the Natlonal Cancer Institute, DHHS.) 


\section{CHROMOSOMAL ABERRATIONS FROM RADIATION INDUCED \\ DNA LES IONS}

A.T. Natarajan and L.H.F. Mullenders

Departwent of Radiation Genetics and Chemlcal Mutagenesis State University of Leiden, Sylvius Laboratoria, Wassenaarseweg 72, $2333 \mathrm{AL}$ Lelden, and

J.A. Cohen Institute, Interuniversity Institute for Radiopathology and Radiation Protection, Leiden. The Netherlands 
One of the 1mportant blologlcal consequences of lonlzing radlations In eukaryotic cells is the formation of chromosomal aberrations. Classical basic radioblological concepts such as target theory have been based on the quantitative data on induced chromosomal aberrations in Tradescantia (1). Mechanistic aspects of chromosomal aberration formation following treatment with lonizing radiations were considered by Sax (2) and Revell (3). These hypotheses were proposed at a time when the knowledge of the structure of chromosome and DNA was not well understood. Bender and his colleagues (4) proposed a unifled model for the formation of different types of chromosomal aberrations following treatment of cells with short wave UV, fonfzing radfations and shemfcal mutagens. In this model, DNA double strand break has been considered as the most important leston leading to radiation induced chromosomal aberration.

Ionfzing radiations induce four different classes of DNA lestons, namely, single strand breaks (SSBs), double strand breaks (DSBs), varfous classes of base damage $(B D)$ and DNA-protein cross links. Both DSBs and $B D s$ have been considered as the possible candidates for the formation of aberrations $(5,6)$. Ionfzing radfations induce chromosome type of aberrations in $\mathrm{Gl}$ cells and chromatid type of aberrations in $S$ and G2 cells. Short wave UV and majorfty of the chemfcal mutagens induce mainly chromatid type of aberrations in $G 1$ and $G 2$ cells and the cells have to go through an $S$ phase before the aberrations can be visualized. The latter group of agents (the so called $S$ dependent agents) are potent inducer of sister chromatid exchanges (SCEs), in contrast to lonfzing radiations. Thus, from the pattern of aberrations formed, one can try to deduce the type of DNA lestons involved.

1. Experiments favouring the involvement of DSBS:

Most of the radiation induced lestons are repafred or mis-repaired very rapidly. Some or most of the SSBs are repalred by an excision pathway during which small single strand gaps are formed $(7,8)$. If one can convert these single strand gaps into DSBs, one would expect an increase in the frequencles of $X$-ray induced aberrations, provided DSBs lead to chromosomal aberrations. We X-1rradfated Chinese hamster ovary cells (CHO) In G2 or G1 phase of the cell cycle, made trem permeable with inactivated Sendal virus and introduced Neurospora endonuclease, an enzyme which can recognize single strand DNA stretches and digest them, thus Introducing DSBs (9). Such a post treatment increased the frequencles of all classes of aberrations, 1.e., 8 aps, breaks and exchanges by a factor 
of about 2. When CHO cells irradiated with fast neutrons (0.5 MeV) and post treated with NE no potentiation in the yleld of aberrations was observed, Indicating that no single strand breaks or gaps were avallable for the action of NE (10). NE treatment following X-1rradiation increased the frequencies of DSBs as determined by neutral sucrose gradlent centrifugation analysis (11). These data can be interpreted to mean that $X$-ray induced DSBs are directly involved in the formation of aberrations, as concomitant with the increase in the frequency of DSBs by $N E$, there is an increase in the frequency of chromosomal aberrations.

An ideal experiment to demonstrate the involvement of DSBs in the formation of aberrations, would be to induce only one class of lesion, namely DSBs and ask the question, whether these lesions induce chromosomal aberrations, and if so, whether the pattern of aberrations formed Is simflar to that observed following $X$-irraciation. Restriction endonucleases (REs) would be Ideal candidates for this purpose. When restriction endonucleases were Introduced in Chinese hamster cells permeabillzed with inactivated Sendal virus, a high frequency of chromosomal aberrations was observed $(12,13)$. REs, such as Eco RV and PVu II, which induce blunt DNA strand breaks were more efficient in inducing chromosomal aberrations than those which Induce cohesive breaks such as Bam HI $(12,13)$. In addition, REs induced chromosome type of aberrations in G1 and chromatid type of aberrations in G2, a pattern very similar to the one obtained following irradiation of cells with lonizing radiation (13, 14). These results point out that DNA DSBs should be the important leston for $\mathrm{X}$-ray induced chromosomal aberrations.

2. Evidence for the involvement of base damage:

When X-irradiated human peripheral blood lymphocytes are posttreated with cytosine arabinoside (ara C) for different periods, the frequencles of aberrations increase with duration of post treatment (6. 15, 16). Since most of the DNA strand breaks are repalred very fast, such an influence of ara $C$ on the yleld of aberrations has been interpreted as an effect on slowly repalring DNA base damage (6). It has been demonstrated earlier that SSBS accumulate, if UV Irradiated cells are post-incubated with ara $C$ due to its inhibition of the polymerisation or Iigation of the breaks generated during the repalr step in the exc1sion process to remove pyrimidine dimers (17). An analysis of the $x$-ray $1 n-$ duced chromosomal aberration data in studles involving ara $C$ shows that most of the increase in the frequency of aberrations occur during the first hour following irradiation, indlcating that most of the repalr of 
lestons which can be inhibited by ara $C$ occurs during the first hour following irradiation $(6,15)$. The Influence of ara $c$ treatment for shorter durations (15 min to $60 \mathrm{~m} 1 \mathrm{n}$ ) on the yleld of X-ray Induced chromosomal aberrattons in lymphocytes has been studied $(15,16)$. The maximum increase was found to be in the first 15 minutes (15). In a more detalled study Involving blood samples from 4 individuals, it was found the increase in yleld, due to ara $C$, saturates by 30 minutes (16). These results indicate that ara $C$ influences the repair of lestons which occur immediately following irradiation, rather than those repalred slowly. When $X$-irradiated lymphocytes were allowed to repalr for one hour and then challenged with ara $C$, no potentiation in the frequency of aberrations was observed in metaphase analysis (15). This indicates that the majority of the lesions whose repair is inhibitable by ara $C$ was already repalred by one hour.

In order to check whether the metaphase analysis is reliable in such studies, In view of the cell cycle delay that can occur, we analysed this problem using premature chromosome condensation (PCC) technique (15). Isolated lymphocytes were 1rradlated and fused lmmediately to mitotically dividing CHO cells, or allowed to repalr in the presence or absence of ara $C$ and then fused (15). The results show that ara $C$ completely inhibits the repair of breaks visualised as PCC. To get a blochemical Insight into this problem, the frequencles of DNA strand breaks induced by $X$-rays in lymphocytes and their repair in the presence or absence of ara $C$ were Investigated (15). Since it is not possible to radioactively prelabel the lymphocytes, nucleold sedimentation technique using ethidium bromide as DNA stain was used (15, 18). Lymphocytes 1rradiated with 10 Gy of $X$-rays repalr majority of the Induced strand breaks by one hour recovery time. When the cells were post-treated with ara $C$ the repair of strand breaks was completely inhibited (15). If the cells were allowed to recover for one bour and then challenged with ara $C$, there was no further increase in the frequency of strand breaks indicating that most of the strand breaks, the repalr of which could be Inhibited by ara $C$ were already repalred by one hour (15). In the nucleold sedimentation technique, neutral conditions are employed and thus, the strand breaks detected do not zepresent alkaline labile sites, such as base damage. The results obtained from the analysis of metaphase chromosomes, prematurely condensed chromosomes as well as measurement of DNA strand breaks by nucleold sedimentation technique, all point out that mafority of the aberrations induced by $X$-rays are formed by lestons 
which are repalred very fast, these lestons are DNA strand breaks and their repair can be effectively inhibited by ara $C$. This conclusion 18 also supported by studies on Induction and repalr of DNA strand breaks in lymphocytes, In the presence and absence of ara C using the DNA unwinding technique (16).

Experimental evidence exists for the capacity of ara $C$ to Inhibit repair of radiation induced DNA DSBs (19). It was of interest to see if ara C treatment will influence the frequencles of chromosomal aberrations induced by restriction endonucleases, as these aberrations are exclusively formed from the mis-repalr of DSBs. Ara $C$ was found to be effective in increasing the frequency of all types of aberrations Induced by Pru II In CHO cells and mouse PG 19 cells (13), as well as those induced by Alu I (20). Thus, It appears clear that potentiation of $X$-ray Induced aberrations by ara $C$ need not to be 1 ts influence on the slowly repalring base damage (6), but more likely to its influence on fast repalring DSBs. In fact, when the influence of ara $C$ on the yleld of dicentric chromosomes induced by $X$-rays, over a wide range of doses is evaluated, it appears that this influence is predominant at low doses (less than $2 \mathrm{~Gy}$ ) indicating an influence on the linear part of the dose response curve, which 1 s assumed to be the contribution of DSBs arising from a single tonization track (16).

Recent studies using mutants of CHO cells defective in repalr of DNA DSBs have pointed out to a strong correlation between the ability to repair DSBs and the frequenctes of X-ray Induced aberrations $(21,22)$. Earlier studies from our laboratory employing cells with chromosomes la Gl unffiliarly substituted with S-bromodeoxyuridine and exposed to UVA (to induce SSBs in one strand of the DNA) demonstrated that induced SSBs led mainly to chromatid type of aberrations (23). These results may rule out the possibility of X-ray induced SSBs in Gl leading to chromosome type of aberrations unless one assumes a qualitative difference between the SSBs Induced by $X$-rays in unsubstituted DNA and UVA on BrdUrd substituted DNA. All these results taken together support the conclusion that $X$-ray Induced DSB is the most important lesion responsible for the origin of chromosomal aberration.

Acknowledgements:

These Investigations were partly supported by an Euratom-Leiden University contract No. B16-166-NL. 
References :

1. D.W. Lea, Actions of Radiations on Living Cells. University Press, Cambridge, 1955.

2. K. Sax, An analysis of X-ray induced chromosomal aberrations in Tradescantia, Genetics 25, 4l-68, 1940.

3. S.H. Revell, A new hypothests for "chromat1d" changes. In Proc. Rad1ol. Symp. Liege, 1954. Eds. Z.M. Bacq and P. Alexander. Butterworths, London, 243-253, 1955.

4. M.A. Bender, H.G. Griggs and J.S. Bedford, Mechanisms of chromosomal aberration production III. Chemicals and Ionizing radlations, Mutation Res. 23, 197-212, 1974.

5. A.T. Natarajan, Mutagenesis and chromosome changes - Review, in Radiation Research, Proc. 7th Int. Cong. Rad. Res. (J.J. Broerse et al., Eds) 239-247, 1983 .

6. R.J. Preston, The effect of cytosine arabinoside on the frequency of X-ray Induced chromosome aberrations in normal leukocytes, MutatIon Res. 69, 71-79, 1980.

7. J.D. Regen and R.B. Setlow, Two forms of repa1r in the DNA of human cells damaged by chiemical carcinogens and mutagens, Cancer Res. 34 , 3318-3325, 1974.

8. W.D. Henner, S.N. Grunberg and W.A. Haseltine, Sites and Structure of $v$ radiation-induced DNA strand breaks, J. B1ol. Chem. 257, $11750-11754,1982$.

9. A.T. Natarajan and G. Obe, Molecular mechanisms Involved in the production of chromosome aberrations. I. Utilization of Neurospora endonuclease for the study of aberration production in G2 stage of the cell cycle, Mutation Res. 52, 137-149, 1978.

10. G. Obe, A.T. Natarajan and F. Palitt1, Role of DNA double strand breaks in the formation of radiation induced chromosomal aberrations. In DNA Repa1r, Chromosomal Alterations and Chromatin Structure (A.T. Natarajan, G. Obe and H. Altmann, Eds) 1-9, 1982.

11. A.T. Natarajan, G. Obe, A.A. van Zeeland, F. Palitt1, M. Meljers and E.A.M. Verdegaal-Immerzeel, Molecular mechanisms Involved in the production of chromosomal aberrations II. Utilization of Neurospora endonuclease for the study of aberration production by $X$-rays In $G 1$ and $G 2$ stages of the cell cycle, Mutation Res. 69, 293-305, 1980 .

12. P.E. Bryant, Enzymat1c restriction of mamalian cell DNA using Pvu II and Bam HI: Evidence for double strand break origin of chromo- 
somal aberrations, Int. J. Rad1at. B1o1, 46, 57-65, 1984.

13. A.T. Natarajan and G. Obe, Molecular mechanisms involved in the production of chromosomal aberrations. III. Restriction endonucleases, Chromosoma (Ber1.) 90, 120-127, 1984.

14. G. Obe and E.U. Winkel, The chromosome breaking activity of restrIction endonuclease Alu I In CHO cells is independent of the $S$ phase of the cell cycle, Mutation Res. 152, 25-29, 1985.

15. A.T. Natarajan, F. Darroud1 and L.H.F. Mullenders, The nature and repair of DNA lestons that lead to chromosome aberrations induced by Ionfing radiations, Mutation Res. 160, 231-236, 1986.

16. M. Holmberg and E. Gumauskus, The role of short lived DNA lesions In the production of chromosome-exchange aberrations, Mutation Res. $160,221-229,1986$.

17. E.A. Hiss and R.J. Preston, The effect of cytosine arabinoside on the frequency of single strand breaks in mammalian cells following irradiation or chemical treatment, Blochim. Blophys. Acta 478, 1-8, 1977.

18. L.H.F. Mullenders, A.A. van Zeeland and A.T. Natarajan, Comparison of DNA loop stze and super colled domlan size in human cells, Mutation Res. 112, 245-252, 1983.

19. G. Illakis and P.E. Bryant, Effects of nucleoside analogs a-araA, -araA, -ara $C$ on cell growth and repalr potential lethal damage and DNA double strand breaks in mammalian cell cultures, Ant Cancer Res. 3, 143-150, 1983.

20. G. Obe and A.T. Natarajan. Chromosomal aberrations 1nduced by restriction endonuclease Alu I In Chinese hamster ovary cells: Influence of duration of treatment and potentiation by cytosine arab1noside, Mutation Res. 152, 205-210, 1985.

21. L.M. Kemp and P.A. Jeggo, Radiation Induced chromosome damage in $X$-ray sensitive mutants (xrs) of the Chinese hamster ovary cell I1ne, Mutation Res. 166, 255-263, 1986.

22. F. Darroud 1 and A.T. Natarajan, Cytological characterization of Chinese hamster ovary $X$-ray sensitive mutant cells xrs 5 and xrs 6 . $I$, Induction of chromosomal aberrations by $X$-irradiation and 1 ts modulation with 3-aminobenzamide and caffeine, Mutation Res. In press.

23. A.T. Natarajan, B.A. Kihlman and G. Obe, Use of the 5-bromodeoxyuridine-labelling technique for exploring wechanisms involved in the formation of chromosomal aberrations. II. GI experiments with Chinese hamster ovary cel1s, Mytation Res. 73, 307-317, 1980. 
CHROMOSOMAL DAMAGE AS A FUNCTION OF RADIATION QUALITY

\author{
Charles R. Geard \\ Radiological Research Laboratory \\ College of Physiclans Surgeons \\ Columbia University, New York, N.Y. 10032
}

Induced alterations of chromosomes, disrupting the orderly sequence and/or constituents of DNA are accepted as being responsible for a significant proportion of cellular lethality, genetic mutation, and, as has become Increasingly apparent in recent years, human cancer. The quantitative microscopic observation of -hromosomal aberrations induced by lonizing radiations has shown that yleld changes with such parameters as cell type, cell stage in the cell cycle, oxygen concentration, absorbed dose, dose rate, temperature and 11 near energy transfer (LET). As LET Increases curvilinear dose responses become increasingly linear. It appears that the majority of chromosomal aberrations originate from molecular interaction between palrs of lesions (misrepalr). Th1s can formally be explained as follows. Chromosome breaks, a.k.a. lesions, a.k.a. sublesions are initiated by several fonfzations produced by a single charged particle and for low-LET radiations the yield of two-break aberrations (those most frequently observed) follows the form

$$
Y(y 1 e 1 d)=\alpha D+B D^{2}(D=\text { absorbed dose })
$$

Th1s formalism explains exchange aberration production as being due to two chromosome parts belng damaged by the same particle then interacting to produce the aberration (the linear term) or two chromosome parts being Individually damaged by two separate particles then interacting to produce the aberration (the quadratic term). As dose increases, particle proximity 
1s enhanced and hence the quadratic term predominates. At low dose and low dose rate, which allows for a time-dependent restitution before interaction can take place, the linear term predominates.

For low-LET radiations the linear-quadratic relation adequately deBcribes the vast majority of dose-response relations found for chromosomal aberrations in a variety of cell types from many widely divergent organisms but predominantly and preeminently man. As LET 1ncreases the frequencles of aberrations produced per unit dose increase up to an optimum as has been noted for other end points. Since chromosomal aberrations are responsible (at least in part) for radiation-1nduced cell lethality, radiation-1nduced mutation, and possibly radiation-induced cancer, there is a solid basis for concluding that interactions between pairs of entitles is an underpinning for blophysical mechanisms of radiation action.

It $1 \mathrm{~s}$ apparent that the rate of energy deposition along the track is the predominant Influence on Initlation of damage, and since most aberrations result from interactions between pairs of damaged sites, it is also necessary to assess over what distances such interactions can take place. For single track Induced aberrations this appears to be a few to a few tens of nanometers. However for aberrations resulting from "breaks" Induced by Independent tracks interaction distances appear to be a fraction to a few micrometers.

The dramatic nature of the LET influence can be 1llustrated in the following example. As LET increases by a factor of 8 (from 10 to $80 \mathrm{keV} /$ $\mu m$ ), the frequencles of aberrations per cell (at the same absorbed dose $\widetilde{<}_{1}$ Gy) Increases roughly by a factor of 4. At the same time particle fluence 1s decreasing by a factor of 8 . This means that on a per charged particle basis, one particle track at $80 \mathrm{keV} / \mathrm{\mu m}$ is about 32 times more likely to produce a chromosomal aberration than a $10 \mathrm{keV} / \mathrm{m}$ particle track. 
Lineal energy density is clearly of paramount importance in lesion Induction and aberration production however the relative probabilities of such aberrations leading to lethal or non-lethal and potentially carcinogenic events is less certain. Establishing greater certainty has profound Implications for understanding LET effects and the application of radiation protection 8 tandards.

Furthermore there are increasing indications that differentiationrelated DNA changes (e.g. B cell maturation, which when aberrant can lead to Inappropriate translocations and oncogene activation) may involve compartmentalisation in the cell nucleus. In this way accessibility of DNA lesions for interaction is likely to be both cell type and stage dependent. The use of definable radiation sources in conjunction with definable cellular sources is likely to be definitive in eliciting an understanding of the basis of chromosome aberration formation with its profound implications. 
FACTORS AFFECTING INDIVIDUAL SENSITIVITY TO

RADIATION AND OTHER ENVIRONMENTAL MUTAGENS

Robin C. Leonard, Jay C. Leonard, Judith M. Wieland, Michael A. Bender, and Richard B. Setlow

Brookhaven National Laboratory

Upton, New York 11973

ABSTRACT

An understanding of the variation in the abilities of apparently normal individuals to repair physical and chemical damage to their DNA is important to further evaluate the role of these repair processes in individual susceptibility to specific toxic agents as well as to certain disease processes. Identifying intrinsic sources of variation, such as age, sex, and race is important for the approprlate extrapolation of research findings to a "general" population that probably is composed of many sub-populations, each with its own range of susceptibllities. Our efforts have been directed to obtaining estinates of the means, standard deviations, and ranges of various DNA damage/repair measurements, and to identify demographic factors that have an effect on DNA repalr capacity. The endpoints include unscheduled DNA synthesis, sister chromatid exchanges, formation of micronuclei, and $0^{6}$ methylguanine methyl transferase activity. No conslstent effect of age or sex has been seen. Cigarette smokers showed a higher frequency of sister chromatid exchanges compared to nonsmokers. These increases, however, were not statistically significant. 
INTKODUCTION

An important factor in the evaluation of the effects of radiations and fuel-derived environmental mutagens and carcinogens on humans is the distribution of responses among exposed individuals. From the analysis of DNA repair-deficient human diseases, it is known that the population contains a few very small supersensitive subsets. This very restricted number of supersensitive individuals is not an important public health problem, but the existence of large numbers of individuals more sensitive than the average could be an important one. Are there such sensitive subsets in our population and, if so, how large are they? The answers to these questions are of obvious importance in setting standards for exposure levels and for extrapolating from iimited epidemiological studies to the entire population.

Individuals known to be defective in DNA repair are also cancer prone. In the homozygous genetic disorders xeroderma pigmentosum (defective excision of pyrimidine dimers or bulky adducts), ataxia telangiectasia (defective repair of $X$-ray induced lesions) and Fanconi's anemia (defective removal of DNA sirand cross-links) much is known about the nature of the repair defect (1-3). In Bloom's syndrome there is a high level of spontaneous chromosome abnormalities and sister chromatid exchanges, which are apparently related to a deficiency in DNA ligase I $(4,5)$ or topoisomerase II (6). Since large changes in DNA repalr ceem to result in several orders of magnitude higher cancer risk, small changes may also have significant effects.

A variety of isolated reports indicate that several factors varying within the human population affect the repair of DNA damage. In some cases, 
signiflcant variation has been documented, but the factors underlying this variation have not been identifled. We have found extensive variation among normal people in the abilitles of extracts of thelr lymphocytes to remove the putative mutagenlc and carcinogenlc alkylation product $0^{6}$-methylguanine, and have evidence to show that repalr capacity in lymphocytes can be enhanced by PHA stimulation (7).

A number of recent investigations have correlated chronic diseases with effects on unscheduled DNA synthesis in lymphocytes treated with radiation or chemicals. For example, DNA repair after UV-Irradiation is less In individuals with actinic keratosis than in normal people (8) and is also less in lywphocytes of patients with recurrent herpes simplex infection (9). Pero, et al. (10) demonstrated that lymphocytes from persons with high blood pressure were more susceptible to damage from NA-AAF (N-acetoxy-2-acetyl-aminofluorene) treatment than those of persons with average blood pressures. The hypertensive subjects showed more repalr, which seemed to have resulted from higher levels of NA-AAF damage per unit dose; there were equal amounts of repalr per unit damage.

Age also apparenty affects some aspects of DNA repalr. Lambert et al. (11) showed an association, although a weak one, between repair in lymphocytes after UV-irradiation in vitro and age of the donor, with older people having less repalr. Moreover, Schnelder (12) reported that age affects the level of chemically-induced SCE. In addition to age, there are reports of sex differences In spontaneous SCE frequencies $(13,14)$. There is also a suggestion that race may be a factor in the level of measured SCE ( 15 ). 
Iife-style factors also Influence unscheduled DNA synthesis. Madden et a1. (16) showed that leukocytes of smokers and drug addicts had less uDs after UV treatment than did controls. Furthermora, Chen et al. demonstrated increased chromosomal aberration frequencies in smokers compared to nonsmokers when the cells were grown in folate deficlent medium (17). The increased aberration frequencies were found to be correlated with reduced serum folate levels among smokers. The striking thing about most of these studies is not so much the correlations that are made with characteristics of the individuals, but the large varlation -- several-fold -- among apparently normal individuals in the populations.

We are currently engaged in a long-term project to measure this variation by analyzing the effects of UV, X-rays, MNNG, and witomycin C on lymphocyte cultures from a large sample of apparently normal individuals. The endpoints Include unscheduled DNA synthesis, sister chromatid exchanges (SCE), formation of micronucle1, and $0^{6}$-methylguanine methyl transferase activity.

METHODS

\section{Population}

Persons sampled are volunteer from among the employees of Brookhaven National Laboratory. The only exclusion criterla are previous chemotherapy or radlotherapy. Particlpants fill out a 4-page questionnaire contalning atandard demographic information, brief medical history, and a brief employment history which is primarily concerned with long-term use of radioactive and chemical substances on the job. 
II. Unscheduled DNA Synthesis

DNA repalr is estinated by measuring unscheduled DNA synthesis in treated lymphocytes using autoradlography. Autoradiography of $G_{1}$ lymphocytes pulse-labeled with $3 \mathrm{H}-$ thymldine allows the determination, by grala counting, of varlability in the amount of repalr synthesis among cells within ladividual samples. The repalr measurements are mads on both stimulated and unstimulated cells so that we can assess the effect of PHA on repalr processes. Extracts of lymphocyte cultures are also assayed for the level of proteln able to accept the methyl group from $0^{6}$-methylguanine.

III. SCE

Slster chromatid exchanges Induced by MNNG or mitomycin $C$ are monttored In perlpheral whole blood cultures. Cultures are exposed to 6 um MNAG (N-methyl-N-nitro-N-nitrosoguanldine) prlor to and 48 hours after phytohemagglutinin ( $P H A$ ) stimulation. This protocol evaluates frequencles of sister chromatid exchanges induced by MNNG in lymphocytes during $G_{0}$, and while cycling as well as the background frequency in solvent controls.

The frequencies of SCE's produced by a four-hour exposure to $0.5 \mu \mathrm{m}$ mitomycin C prior to PHA stimulation are also measured. We are attempting to confirm the prevlous finding that a caffeloe sensitive repalr system affects the frequencies of mitomycin C-induced SCE's and to determine the variabllity of the efficacy of thls system among individuals (18). 
IV. X-ray sensitivity

Ionizing radiation sensitivity is measured by the frequency of occurrence of micronuclei in whole blood cultures exposed to $3 \mathrm{~Gy}$ of $250 \mathrm{kvp} \mathrm{X}$-rays prior to PHA stimulation and harvested after 72 hours. Since the frequency of micronuclel depends upon the number of 1n vitro cell divisions subsequent to exposure, a paraliel group of cultures are grown and stained by the BrdU-Hoechst 33258-Giemsa method, so that we can assess the number of first, second, third, and greater than third division metaphases. These values are used to calculate the replicative index (19), which is used to adjust the data.

RESULTS

I. Unscheduled DNA synthesis

Table 1 shows the mean grain counts for control and UV-treated cultures, as well as the control + PHA and UV + PHA treated cultures. It is obvious that the Increase in grain count between the control and the PHA control is statistically significant, but the difference between the UV alone and the PHA $+U V$ is not. The ranges of the distributions for the UV-irradiated cultures are very wide; the increase due to uv treatment ranged from 1.5 to 120 fold in cultures with no PHA and from 3 to 44 fold in cultures with PHA. (data not chown)

T-tests on control and UV Irradiated mean grain counts, both with and without the addition of PHA, show there is no signiflcant difference between 
males and females or between smokers and nonsmokers. In addition, there is no significant effect of age on either of the control or uv-treated groups ( $\geq \geq$ $.57)$.

II. $X$-ray sensitivity (micronucleus formation)

Thirty cases have been scored Eor micronuclel among control cultures; 29 cases have been scored among frradiated cultures. There are no significant differences between males and females in total micronuclef counted, either in control $(p=.48)$ or 1rradiated $(p=.76)$ cultures. Nelther were there any signfficant differences between smokers and nonsmokers (p=.66). However, the smali number of current cigarette smokers (six) in the present sample makes it possible that an effect is being overlooked.

One major issue regarding the use of micronuclel to estimate individual sensitivity to irradiation is the large effect on the number of micronuclei observed caused by radiation-induced cell cycle delay. In an effort to adjust for this, we have calculated the replicative index for each control and Irradiated culture, and adjusted the total micronuclel count for this delay. The effect of this adjustment on the standard deplation of these distributions is striking, as is shown in Table 2. By substantially reducing the varlance of this measurement, but not the mean, in the population, this adjustment should make possfble a real discrimination of persons who are in the extremes of the distribution. 
III. Sensitivity to chemical mutagens (SCE's)

SCE's have been scored for lymphocyte cultures treated with MNNG or with mitomycin C. Table 4 shows the means, SEM's, and ranges of these measurements.

In mitomycin C-treated cultures, we find a large increase in SCE frequency if cells are incubated in caffeine ( 36.8 compared to 27.2); but this difference may be accounted for by the increase in frequency in control cultures incubated in caffeine (18.5 compared to 10.4). Thus there seems to be only an additive effect, and no interaction, betseen mitomycin $C$ and caffeine.

The stage of the cell cycle in which cells are treated with MNNG has a significant effect on the SCE frequency. After subtraction of the control value, the treated cycling cells have almost three times the frequency of treated $G_{0}$ cells.

The effect of cigarette smoking on SCE is well documented. However, in this study, al though cigarette smokers showed a highex frequency of SCE than nonsmokers in all treatment groups except that of caffeine alone, none of these increases were significant at the 5 percent level. The small number of smokers in this ample undoubtedly contributes to this finding. 
Based on data we have anaiyzed from other projects (13), we expected the SCE frequency to be affected by age, white blood count, and possibly sex. We found no differences between males and females in any treatment group. The only treatment group to show significant effects of age (p-.01) were the cycling cells treated with MNNG. There was, however, a consistent downard trend of SCE with increasing age in all other treatment groups. In addition, the cycling cells treated with MNNG was the only group to show a gigificant relationshlp to WBC $(r=.63, p<.001)$.

DISCUSSION

An understanding of the varlation in the abilities of apparently normal individuals to repair physical and chemical damage to their DNA is important to further evaluate the role of these repair processes in individual susceptibility to specific toxic agents as well as to certain disease processes. Identifylng intrinsic sources of variation, such as age, sex, and race is important for the appropriate extrapolation of research findings to a "general" population that probably is composed of many sub-populations, each with its own range of susceptibilities.

Our efforts have been directed to obtaining estimates of the means, standard deviations, and ranges of various DNA damage/repair measurements. With these estimates, we hope to Identify individuals whose lymphocytes show large deviations from the means of these measurements. This group can then be followed in an attempt to answer the following questions: 
1. Do fibroblasts cultured from these individuals also deviate from average? Are the responses of lymphocytes good Indicators of the responses of other tissues?

2. Can diet or life-style alter the cytogenetic responses to environmental agents, or affect DNA-repeir capacities?

3. Are deviant responses of lymphocytes predictors of disease or enhanced cancer risk?

Our findings so fer do not indicate that there are significant differences between sexes in the end-points we have chosen to measure. Our lack of significant results concerning cigarette omoking and SCE 1 s almost certainly due to the small number of cigarette smokers in this population sample. The lack of effect of age on these repair processes can be riewed as possibly due to the limited age range of the sample (18.2 - 56.6 years) or due to sample size inadequate for detecting a small effect. We are currently evaluating the effects of prescription drug usage, occupational exposure to radiation sources and solvents, as well as family history of cancer in en effort to identify other factors that may be contributing to the populetion's wide range of reaponses to toxic egents. 
REFERENCES

1. R. B. Setlow, Repalr-deflclent human disorders and cancer. Hature $27 \mathrm{~L}$, $713-717(1978)$

2. C. F. Arlett and A. R. Lehmann, Human disorders showing increased sensitivity to the induction of genetic damage. Ann. Rev. Genet. $12,95-115(1978)$

3. E. C. Friedberg, U.K. Ehmann and J. I. Hilliams, Human diseases associated with defective DNA repalr. Adv. Radiat. B101. 8, $85-174(1979)$.

4. A. E. Willis and T. LIndahl, DNA ligase I deflclency In B $100 \mathrm{~m}^{\prime} \mathrm{s}$ syndrome. Nature $325,355-357$ (1987).

5. J. Y. H. Chan, F. F. Becker, J. German and J. H. Ray, Altered DNA ligase I activity In Bloom's syndrome cells. Nature $325,357-359$ (1987).

6. M. W. Heartle1n, H. Tsuj1, and S. A. Latt, Exchange formation in Bloom's syndrome is assoclated with reduction in topolsomerase II activity. Exp. Cel1 Res. $169,245-254$ (1987).

7. E. A. Waldstein, E. - H. Cao, M. A. Bender and R. B. Setlow, Abilities of extracts of human lymphocytes to remove $0^{6}$-methylguanine from DNA. Mutat. Res. 95, 405-416 (1982).

8. J. M. Abo-Darub, R. Mackie, and J. D. PItts, DNA repalr deficiency in lymphocytes from patients with actinic keratosis. Bull. Cancer (Paris) 65, 357-362 (1978).

9. D. Fanta, A. Topalogloy and H. Altman, Studies on the DNA-excision repalr in lymphocytes of patients with recurrent herpes simplex. Bu11. Cancer (Par1s) 65, 341-346 (1978). 
10. R. W. Pero, C. Bryngelsson, F. Mitelman et al., High blood pressure related to carcinogen-induced unscheduled DNA synthesis, DNA carcinogen binding, and chromosomal aberrations in human lymphocytes. PNAS 73, 2496-2500 (1976).

11. B. Lambert, U. Ringborg and L. Skoog, Age-related decrease of ultraviolet light-induced DNA repair synthesis in human peripheral leukocytes. Cancer Res. 39, 2792-2795, (1979).

12. E. L. Schneider, D. Kram, Y. Nakanishi, R. E. Monticone, R. R. Tice, B. A. Gilman, and M. L. Nieder, The effect of aging on sister chromat1d exchange. Mech. Age. Develop. 9, 303-311 (1979).

13. M. A. Bender, R. J. Preston, R. C. Leonard, P. C. Gooch and M. D. Shelby, Chromosomal aberration and sister chromatid exchange frequencies in peripheral blood lymphocytes of a large human population sample. Mutat. Res. (Ir press).

14. B. H. Margolin and M. D. Shelby, Sister chromatid exchanges: A reexamination of the evidence for sex and race differences in humans. Environ. Mutegen. 7, (Supp1. 4), 63-72 (1985).

15. M. G. Butler, Slster chromatid exchange in 4 human races. Mut. Res. $91,377-379(1981)$.

16. J. J. Madden, A. Falek, D. A. Shafer and J. H. Glick, Effects of oplates and demographic factors on DNA repair aynthesis in human leukocytes. PNAS 76, 5769-5773 (1979).

17. A. T. L. Chen, J. A. Reidy, J. L. Annest, and T. Welty, The associetion between chromosome fraglilty, sooking, and folate. Amer. J. Hum. Genet. 39, 1108 (1986). 
18. X. Ishl1 and M. A. Bender, Caffelne Inhlbition of prereplication repalr of mitomycin C-1nduced DNA damage in human peripheral lymphocytes. Mutat. Res. 51, 419-425 (1978).

19. E. L. Schnelder and J. Lew1s, AgIng and sister chromatid exchange. VIII. Effect of the aging environment on elster chromatid exchange Induction and cell cycle kinetics in Ehrlich ascites tumor cells. A brief note. Mech. Age. Develop. 17, 327-330 (1981).

\section{ACKNOWLEDGEMENT}

Research carried out under the ausplces of the United States Department of Energy under contract no. DE-ACO2-76CHOOOL. 


\section{TABLE 1}

UDS - MEANS OF GRAIN COUNT BY TREATMENT

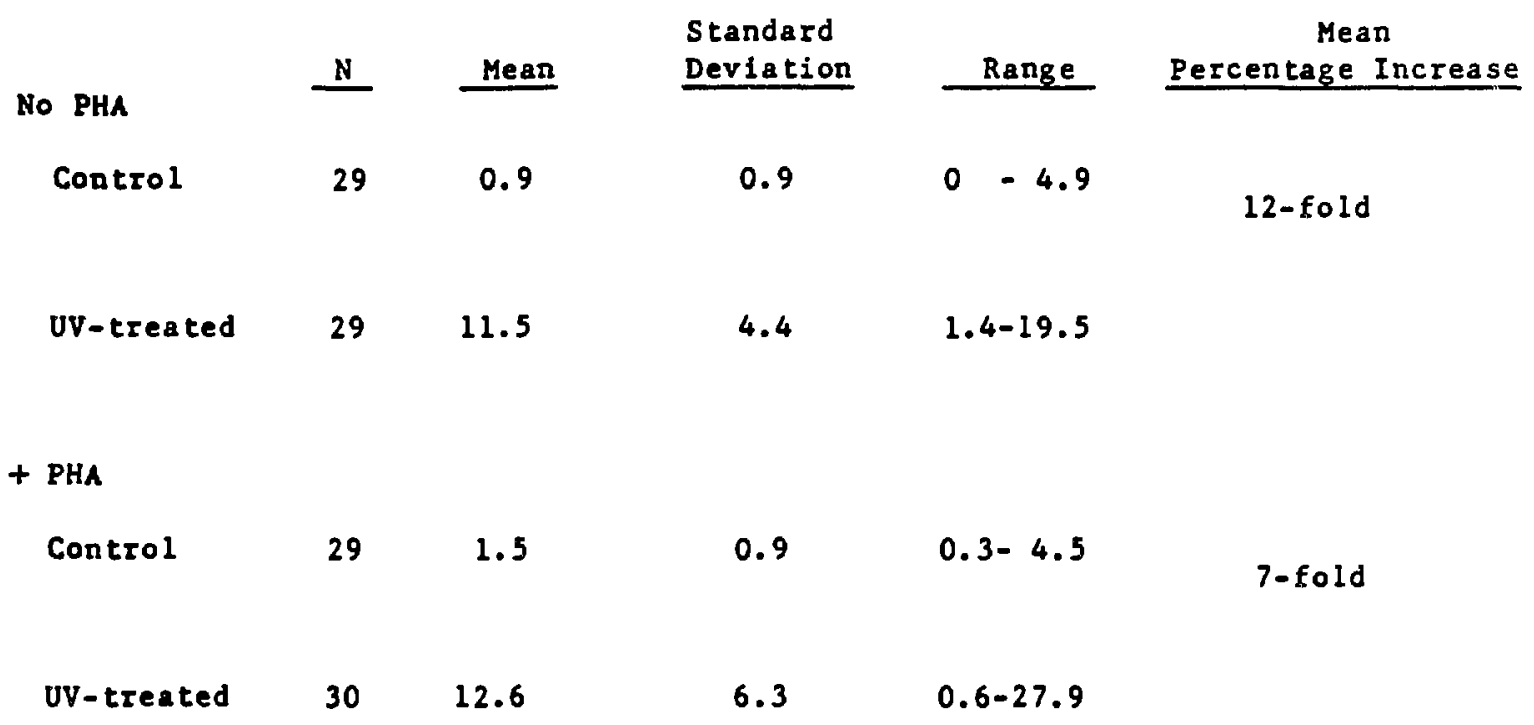


TABLE 2

MICRONUCLEI - SENSITIVITY TO IONIZING RADIATION

Mean number of micronuclei counted in 1000 cells

\begin{tabular}{|c|c|c|c|c|}
\hline & $\underline{N}$ & Mean micronucle1 & SEM & Range \\
\hline Control & 30 & 14. & 2. & 4. - 55. \\
\hline 3 Gray & 29 & 147. & 11. & 20. -255 . \\
\hline $\begin{array}{l}3 \text { Gray } \\
\text { (adjusted for } \\
\text { cell cycle delay) }\end{array}$ & 20 & 145. & 1. & 136. -158 \\
\hline
\end{tabular}


TABLE 3

SCE - SENSITIVITY TO CHEMICAL MUTAGENS

Treatment Group

Control - MNNG

MNNG - $G_{0}$

MNNG - Cycling

Control - Mit. C

Mitomycin C

Mit.C + Caffeine

Caffeine $(0.77 \mathrm{mM})$
N

Mean

9.28

12.81

19.42

31

32

30

18

22

10.45

27.24

36.78

18.55
SEM

0.30

0.65

0.77

$12.80-30.88$

0.37

1.02

1.80

1.37

Range

$6.52-14.32$

$8.68-29.32$
$6.12-15.60$

$12.32-35.52$

$15.60-50.60$

$9.00-36.35$ 
ESTIMATING THE RADIATION INDUCED GERMINAL GENE MUTATION

RATE: CURRENT STATUS AND FUTURE PROSPECTS

Harvey W. Mohrenweiser

University of Michigan Medical School, Ann Arbor, MI 48109-0618

A major problem encountered in estimating a germinal gene mutation rate. is the rarity of mutational events, accompanied by an inability to obtain a significantly large data base from each proband and thus the necessity for a very large cohort for study. It has been difficult, therefore, to develop a benchmark, based upon human data, for estimating the increase in mutation rate associated with exposure to a mutagenic agent. Three points, relative to this problem, namely the current status of human mutations studies, lessions from experimental models and possible future techniques will be briefly described in this overview. Current Status of Human Mutation Studies: Current estimates of the germinal mutation rate in man are derived from three general approaches. The sentinal phenotype approach monitors the frequency of occurrence of a series of sex linked recessive and dominantly expressed genetic traits that are easily recognized and associated with infertility (1). Among the loci screened, wide variations in the mutation rate are observed but the current estimate, based upon the average rate at 15-18 1oci, is 2.0 $\times 10^{-5}$ per locus per generation. A second approach has monitored a series of population characteristics such as sex ratio, early death, etc., each of which have a genetic component. This approach suggests a background mutation rate which is responsible for 1 death in every 400 livebirths in Japan (2).

Recently, biochemical techniques, specifically electrophoresis and quantitative enzyme assay procedures, have been employed in studies to estimate human mutation rates. Electrophoretic techniques have been employed in studies in the United Kingdom (3), Germany (4, Altland, personal communication), Japan (5) and the United States (6). Seven 
mutations, giving rise to proteins with altered electrophoretic mobility have been identified in approximately $1.5 \times 10^{6}$ locus determinations; the estimated mutation rate is $0.4 \times 10^{-5}$. This estimate is not significantly different from the value of $0.3 \times 10^{-5}$ obtained from a study of hemoglobin variants ( 7 ).

A smaller data base from studies in Germany (8), United States $(6,9)$ and Japan $(10,11)$ is available for estimating the frequency of mutations which give rise to the absence of functional protein. This class of mutation would result from molecular events in addition to some base substitutions, including deletions and rearrangements (9). Approximately 125,000 locus determinations have been completed, in these three studies, without the identification of a mutational event. [If one mutation had been detected, the rate would be $0.8 \times 10^{-5}$ ]

Efforts to estimate the induced mutation rate in man are limited. No evidence for induced mutations, using sentinel phenotypes as the endpoints, was observed in the offspring of cancer patients (12). The RERF study has reported a positive but nonsignificant relationship between both untoward pregnancy outcome and $F_{1}$ mortality and parental exposure (2). Biochemical endpoints have also been employed in these studies. Three electrophoretic mobility mutants have been detected in 725,587 locus tests for a mutation frequency of $0.4 \times 10^{-5}$, a frequency which is similar that observed in the control group ( 3 in 539,170 locus tests) (11). One enzyme deficlency mutant has been identified in 55,696 determinations, for a mutation rate of $1.8 \times 10^{-5}$ (11). No null mutations were observed in a similar riumber of determinations in the control group studied at RERF nor have any enzyme deficiency mutations been detected in other studies of unexposed individuals, as noted above. 
There should be no disagreement that radiation is an agent that induces germinal gene mutations in man. The significant question is the relationship between exposure and increased genetic risk and subsequently, the relationship between increased mutation rates and the health burden to the individual and society.

The currently estimated gonadal doubling dose for genetic damage in man is 40 rem and is largely derived from mouse data $(13,14)$. It has been suggested that the human may be more resistent to radiation induced genetic damage than is the mouse (2). But, in the absence of an appropriate data base from humans as a reference point, it is really impossible to refine the current estimate of the risk to man much beyond current standards.

Germinal Mutations in Model Systems: An extensive data base is available on the radiation induced mutation rate in mice. This data, especially with the visible specific locus assay (15) and the skeletal malformation endpoints (16) are the primary basis for the current estimate of 40 rem for the genetic doubling dose for man $(13,14)$. Less data are available using the biochemical endpoints, especially for radiation exposure, although the data provide insight into the molecular basis for mutation and the importance of endpoint selection in a monitoring effort. First, following treatment with a series of chemical mutagens, approximately $50 \%$ of the mutations are associated with the loss of protein or protein function (17-20). This is a class of genetic variation which has the potential for significant health consequences in the hemizygous or homozygous individual $(9,21)$. Secondly, the null to electromorph ratio is increased, as is the mutation rate, in the offspring of radiation treated mice or Drosophila, relative to the ratio in offspring of 
chemically treated individuals or controls (22-24). Thus radiation, not only increases the mutation rate but also induces a class (predominantly) of recessively inherited traits with potental health significance.

Future Directions: AnY effort to estimate a human mutation rate must recognize that germinal mutations are rare events. Secondly, the exposed populations are usually small, at least relative to the number of observations necessary for detecting a mutation. Thus, it is critical to obtain a significant amount of data from each proband. Several potential approaches have recently been proposed for obtaining a data base of the necessary scale.

Two-dimensional gel electrophoresis techniques have been used extensively to study cellular proteins. This technique separates the proteins of the cell on the basis of isoelectric point and molecular weight. Although not all proteins which can be detected on a gel would be suitable for inclusion in a mutation monitoring protocol, it is potentially possible to study the products of several hundreds of gene products for mutations which result in proteins with altered electrophoretic mobilities (25). The 2-D gel electrophoresis techniques have been employed to detect germinal mutations in mice (26) and also to detect mutations in ENU treated human somatic cells (Hanash, personal communication). Significant progress has been made in automated analysis of the positions of the proteins on the gel (27) and computerized image analysis may make it possible to identify null as well as mobility variants by 2-D gel analysis.

The second general approach is less defined at this time but is built upon the recently developed molecular techniquas for the study of 
DNA organization and sequence. The potential techniques were summarized at a recent conference by Delehanty et al. (28). They were also reviewed in the recent office of Technology Assessment report on "Technologies for detecting heritable mutations in human beings" (29). These two documents are a description and discussion of a series of molecular techniques which could be used for detecting mutations. Also, restriction enzyme mapping, with a limited number of enzymes and a large battery of probes, has been proposed as a method for the detection of insertion/deletion/rearrangement mutations (30). As much of the radiation induced damage is assumed to involve the deletion or rearrangement of genetic material (31), this approach could be especially useful in studies of radiation exposed populations.

An advantage of both the biochemical and molecular approaches to the study of mutation rates in humans is that the same approaches, with the same endpoints (same loci), can be employed in experimental systems. This has already been accomplished in mice $(17-20)$ and man $(5,6,9,11)$ with the one-dimensional electrophoresis and quantitative enzyme assay approach. The 2-D gel electrophoresis and the molecular approaches that are eventually developed and which could be used for monitoring human populations, could also be employed in studies of mice or somatic cells. This would be a significant step in providing a data base, especially when coupled to comparable indicators of exposure, for estimating genetic risk in humans by extrapolation from lower organisms and other prodictive systems. 


\section{REFERENCES}

1. J.J. Mulvihill and A. Czeizel. Perspectives in mutations epidemiology 6:A 1983 view of sentinel phenotypes. Mutat. Res. $123: 345-361$ (1983).

2. W.J. Schull, M. Otake and J.v. Neel. Genetic effects of the atomic bombs: a reappraisal. Science 213:1220-1227 (1981).

3. H. Harris, D.A. Hopkinson and E.B. Robson. The incidence of rare alleles determining electrophoretic variants: data on $\$ 3$ enzyme loci in man. Ann. Hum. Genet. (Lond) 37:237-253 (1974).

4. K. Altland, M. Kaempfer and M. Forssbohn. Mass screening technique for detecting globin variants from newborn dried blood samples. Prog. Mut. Res. 3:153-157 (1982).

5. J.v. Neel, Satoh, C., K. Goriki, M. Fuyita, N. Takahashi, $\mathrm{J}$. Asakawa and $\mathrm{R}$. Hazama. The rate with which spontaneous mutation alters the electrophoretic mobility of polypeptides. Proc. Natl. Acad. Sci. USA $83: 389-393$ (1986).

6. J.V. Neel H.W. Mohrenweiser and H. Gershowitz. A pilot study of the use of placental cord blood samples in monitoring for mutational events. Mutat. Res., (in press), 1987.

7. G. Stamatoyannapoulos and P.E. Nute. De novo mutations producing unstable Hbs or Hbsm. II: Direct estimates of minimum nucleotide mutation rates in man. Hum. Genet. 60:181-188 (1982).

8. H.K.G. Krietsch, H. Krietsch, ผ. Kaiser, M. Dunnwald, G.พ.K. Kuntz, J. Duhm and T. Bucher. Hereditary deficiency of phosphoglycerate kinase: a new variant in erythrocytes, not associated with haemolytic anaemia. Eur. J. Clin. Invest. 7:427-435 (1977).

9. H.ผ. Mohrenweiser. Enzyme deficiency variants: Frequency arit 
potential significance in human populations. Isozymes: Curr. Top. Biol. Med. Res. 10:51-68 (1983).

10. C. Satoh, J.V. Neel, A. Yamashita, K. Goriki, M. Fujita and H.B. Hamilton. The erequency among Japanese of heterozygotes for deficiency variants of 11 enzyme. Am. J. Hum. Genet. 35:656-674 (1983).

11. C. Satoh, K. Goriki, J. Asakawa, M. Fujita, N. Takahashi, R. Hazama, H.B. Hamilton and J.V. Neel. Effects of atomic bomb radiation on the induction of gene mutations. Prog. Clin. Biol. Res., in press.

12. J.J. Mulvihill and J. Byrne. Offspring of long-time survivors of childhood cancer, childhood cancer : Late effects. Clin. in Oncology $4: 333-343(1985)$.

13. National Research Council, Comnittee on the Biological Effects of Ionizing Radiation, The Effects on Populations of Exposure to Low Levels of Ionizing Radiation. National Academy Press, Washington, D.C., 1980.

14. UNSCEAR Report. Sources and effects of ionizing radiation. Report of the United Nations Scientific Committee on the Effects of Atomic Radiation. United Nations, New York, 1982.

15. W.L. Russell. Relation of mouse specific locus tests to other mutagenicity tests and to risk estimation. Environ. Sci. Res. $28: 109-123(1983)$.

16. P.B. Jelby. Applications in genetic risk estimation of data on the induction of dominant skeletal mutations in mice. Environ. Sci. Res. 28:191-210 (1983).

17. S.E. Lewis and F.M. Johnson. Dominant and recessive effects of 
electrophoretically detected specific locus mutations. Environ. Sci. Res. 28:267-278 (1983).

18. S.E. Lewis and F.M. Johnson. The nature of spontaneous and induced electrophoretically detected mutations in the mouse. IN: Genetic Toxicology of Environmental Chemicals, Part R: Genetic Effects and Applied Mutagenesis, eds. Ramel, C., B. Lambert and J. Magnusson, Alan R. Liss, Inc. New York, pp. 359-365, 1986.

19. W. Pretsch, and D.J. Charles. Detection of dominant enzyme mutants in mice: Model studies for mutations in man. IN: Monitoring Human Exposure to Carcinogenic and Mutagenic Agents. eds. A. Berlin, M. Draper, K. Hemminki and H. Arinio. IARC Scientific Publications, Lyon, France. Pp. 361-369, 1984.

20. W. Pretsch. Protein-charge mutations in mice. IN: Genetic Toxicology of Environmental Chemicals, Part B: Genetics Effects and Applied Mutagenesis. Alan R. Liss, Inc. Pp. 383-388, 1986.

21. A.G. Searle and J.H. Edwards. The estimation of risks from the induction of recessive mutations after exposure to ionizing radiation. J. Med. Genet. 23:220-226 (1986).

22. D.J. Charles and ค. Pretsch. Enzyme-activity mutations detected in mice after paternal eractionated irradiation. Mutat. Res. $160: 243-248(1986)$

23. H.V. Malling and L.R. Valcovic. Biochemical specific locus mutation system in mice. Arch. Toxicol. 38:45-51 (1977).

24. R.R. Racine, C.H. Langley and R.A. Voelker. Enzyme mutants induced by low-dose-rate $y$-irration in Drosophila: Frequency and Characterization. Environ. Mutag. 2:167-177 (1980).

25. J.V. Neel, B.B. Rosenblum, C.F. Sing, M.M. Skolnick, S.M. Hansah 
and S. Sternberg. Adapting two-dimensional gel electrophoresis to the study of human germ-line mutation rates. IN: Two Dimensional Gel Electrophoresis of Proteins. Eds. J.E. Celis and R. Bravo. Academic Pres5, New York, pp. 259-306, 1984.

26. R.R. Marshall, A.S. Raj, F.J. Grant and J.A. Heddle. The use of two-dimensional electrophoresis to detect mutations induced in mouse spermatogonia by ethylnitrosourea. Can. J. Genet. Cytol. $25: 457-466(1983)$.

27. M.M. Skolnick and J.V. Neel. An algorithm for comparing two dimensional electrophoretic gels, with particular reference to the study of mutation. Adv. Human Genet. 15:55-160 (1986).

28. J. Delehanty, R.L. White and M.L. Mendelsohn. Approaches to determining mutation rates in human DNA. Mutat. Res. 167:215-232 (1986).

29. Office of Technology Assessmen:. Technologies for detecting heritable mutations in human beings. OTA-H-298. Washington, D.C: U.S. Government Printing office, 1986.

30. H.W. Mohrenweiser and R.D. Larsen. Ascertainment of the frequency of insertion/deletion/rearrangement variants in the human genome. Proc. 7th Int. Cong. Human Genetics, Berlin, FGR, PP. 763, 1986.

31. L.B. Russell. Qualitative analysis of mouse specific locus mutations: Information on genetic organization, gene expression, and the chromosomal nature of induce lesions. Environ. Sci. Res. $28: 241-258(1983)$. 
APPENDIX I

$181 / 182$ 
PROBLEMS AND RECOMMENDATIONS FOR FUTURE RESEARCH

(Compiled by the ad hoc committee)

Specif1c Biological Problems

1. Studies of the factors that influence expression of intial events require the application of new techniques, $1 . e .$, the introduction of specific genes into cells and into ova. The use of transgenlc mice promises the possibility of studying the role of host factors on expression of genes and oncogenes that are relevant to radiation-induced cancer.

2. Studies of repair of the Inttial events involved in cancer. Is oncogene activation reversible? Is ant 1 -oncogene inactivation reversible?

3. Determine the size and number of targets involved in radiation-induced cancer.

4. Determine the cell-stage susceptibflity for malignant transformation.

5. Data are required about the induction of cancer at low dose rates, for both low- and high-LET radiations.

6. Obtain the necessary data and formulate a model, or mathematical description, of neutron dose-response relationships for the Induction of cancer. The Initial part of the curve may be linear and the curve bends, but no single description of complete curves has been derived.

7. Studies of protraction with both low- and high-LET radiations: if low dose-rate exposures are extended over time with mounting total doses, does additivity hold? There are no general models of fractionation effects. 
9. Does a long latent period mean that the expression of initiated and potential cancer cells is suppressed? If so, how?

10. We have risk estimates for very few organs, even from experimental work. This should be remedied.

11. Development of methods of extrapolation across species are needed.

12. Endpoints that relate to mutagenesis and transformation, should be used to study the action of radiation (hIgh- and low-LET) in combination with other physical and chemical agents of speclal as pollutants in the environment. Supra-additivity may be a special feature of combined effects.

13. The Incidence of transformation Induced by a given dose of radiation can be altered dramatically by factors such as the division and nutritional status of the cell. These can be greatly modifled by the levels of hormones. These "blological factors" are of much greater influence on transformation incidence (and carcinogenesis in animals) than changes of radiation quality, but are poorly understood.

Chromosomes

A major thrust is warranted towards new and better lmaging techniques for chromosome studies. Integration of cytogenetics with molecular studies will clearly lead to major advances in this field.

Along with the utilization of the newer techniques in molecular biology and cytogenetics, it should be recognized that the dramatic advances in cancer blology in recent years came about by interactions between the disciplines. In order to establish en understanding of mechanisms, knowledge of the basis of the Inftiation and development of radiogenic change at the single cell level predetermines the later recognition of change in cell populations. Evaluation of the spectrum of damage and the distribution and interaction of such damage in Individual cells exposed to well characterized radiations wil further understanding. Since there are clear differences between cell types, 
establishing senstivities will require study of a range of cell types, at different stages of the cell cycle and ascertaining both frequencies and spectra of changes. Such changes can differential'y result in later lethality or enhance oncogenic or mutational consequences.

Two specific areas are of particular current importance.

1. Malignancy signatures. At the present time there is no way to know whether a given malignancy is "spontaneous", radiation induced or caused by a chemical or virus. There are some indications that the oncogene profile of a given cancer or leukemia may give some clue to its origin. Alternatively, specific chromosome translocations are more likely to be caused by one means or another. This would be a fruitful area for research and would Impact on the concept of attributable risk.

2. Determine whether the known association between specific chromosome aberrations and spectflc leukemlas (and solid cancers) is a causal relationship and whether radiation-1nduced specific aberrations are causally related to specific leukemias.

Myeloid leukemia in mice provides an Ideal test system. The findings, together with other studies, can also contribute to an understanding of extrapolation across species.

Energy Deposition at the Molecular and Cellular Level

1. Different radiation flelds usually have different blological radiation effects. These differences can only be due to differences in the primary track structures of charged particles. It should be investigated which properties of these primary event pattern essentially determine the type and severity of biological radiation action.

2. For charged particle track structure calculations concerning blological effects of radon daughter products, of neutrons, and of fast therapy lons, better knowledge is required regarding the energy and momentum transfer cross sections to target electrons and atoms from heavy charged 
particles in condensed matter, in particular at medium and low energies.

3. Slow secondary electrons ( $\leq 100 \mathrm{eV}$ ) play an important role in track formation. Better information is needed on their production cross sections by primary charged particles, their interaction processes during slowing down and their fate at thermal energies in matter of biological importance (recombination, attachment, hydratisation, etc.).

4. Energy absorption from incoming charged particles in condensed matter can excite collective reactions of target electrons leading to fast delocalization of transferred energy quanta. The importance of such collective responses in cellular materials should be determined.

5. Whereas at least some information is available about the probability per path segment for the incoming radition to transfer a certain energy and momentum quantum to target matter leading to transient excitations, much less is known about the nature and location of primary chemical species produced by the subsequent decay of such excited states of biological molecules in situ, 1.e., in a cell. Since these primary chemical species represent the essential starting points for all later chemical, biological and, finally, medical reactions, high emphasis should be put on the determination of these decay modes (e.g., dissociation, ionization) of molecules of radiation blological importance after a given energy absorption.

6. Since dosimetric quantities are not sufficient to characterize the impact of irradiation on biological objects, one should search for better quantities useful for classification of radiation action ("quality") to be able to intercompare the effects of different radiation fields.

7. Technical radiation protection instruments should then be developed which permit directly or indirectly the measurement of these relevant quantities in a mixed radiation field. 
While there is an abundance of models involving cell lethality, these are few for cell transformation or carcinogenesis in whole-animals. The ultimate afm must be an ambitious program to model cancer in the whole organism, starting from energy deposition and molecular changes, through cellular effects to the whole organism. This requires incorporating the modulating influence of hormones, cell to ce1l contact, physiology, etc. This is the major challenge of the modelling field.

DNA Damage Due to Radical Production

Over the last decade or so, a lot of attention has been paid to the mechanism of damage to a DNA molecule by radicals produced from the radiolysis of water. From numerous experimental data, the role of these radicals $\left(\cdot \mathrm{OH}, \cdot \mathrm{H}\right.$, and $\left.\mathrm{e}_{\mathrm{aq}}^{-}\right)$and their various sites of attack on the polymer chain are becoming more and more apparent. It is expected that within a few years frorn now, further clarification will be sought with respect to additional detalls regarding this "indirect" action of londzing radiation. One of the key questions that needs to be addressed Immediately is the quantitative relationship between the production of strand breaks and the release of bases. Fror our present understanding of the mechanism of damage, for every strand break produced by a hydroxyl radical, there is a corresponding release of an undamaged base in presence of oxygen. However, this hypothesis has not been proven by experimental measurements. The measurements must be made under alkaline conditions so that the "latent" strand breaks under neutral conditions are also expressed. The result of this particular measurement is going to be the most critical deciding factor for future direction of research In this area.

Another Important question regarding the mechanism of the production of double strand breaks by the "Indirect" action needs to be clarified through future studies. Most people belleve that the attack by two hydroxyl radicals on the oppostie strands leads to the creation of double strand breaks. However, theoretical calculation based on this hypothesis leads to the yields of double strand breaks which are several orders of magnitude less than the experimentally measured values. It may be that the secondary radicals are 
involved in the production of double atrand breaks. This aspect of our understanding has to be investigated through experinental measurements and theoretical calculations. The in vitro system has to be chosen properly in the sense that it represents a concentrated scavenger system as encountered in a cellular environment.

Thus, with respect to the "Indirect action" mechanism involving damage production by water radicals, the two most important questions for future studies are: (1) What is the quantitative correlation between the production of strand breaks and the release of undamaged bases? (2) What is the mechanism for the production of double strand breaks?

Another aspect of radical damage involves the deposition of energy directly on the DNA molecule by charged particle tracks. This is generally referred to as the "direct action" mechanism. Most of the Information avallable with respect to this mechanism is from DNA crystals and the extent of their validity in the case of cellular DNA is rather speculative. Information is also avallable on direct effects from in vitro systems having a very high scavenger concentration. In such a system, it has been hoped that the scavenger forbids any interaction between $\cdot \mathrm{OH}$ and DNA and hence any measured damage is due to direct effects only. However, it is not clear at all regarding the possible complications due to the presence of a very high scavenger concentration and its interaction with radiation field. This question has not been addressed properly.

In view of these difficulties, the future research effort in this area may have to be directed through a theoretical approach. Yields of specific products need to be calculated which then should be verifled by experimental measurements. The selection of products must be made to correlate with the direct action only, i.e., the products must be formed without any $\mathrm{OH}$ interaction. Thus, with respect to "direct actior:" mechanism the important questions need to be addressed in future are: (1) How many ways a sugar molecule can be damaged (de-protonation, cleavage of the $c-c$ bond, etc.) by the direct deposition of radiation energy? (2) What are the relative probabilities of the different possibilities of damage as a function of LET? (3) What happens to the bases (purine and pyrimidine) when energy is deposited directly on them?

The above-mentioned questions for the "indirect" and "direct" action 188 
mechanisms must be understood through future research. Unless we know these answers, we will not be in a position to determine the chemical nature of initial ( $\left.10^{-6} \mathrm{sec}.\right)$ lesions which ultinately decides the characteristics of damage that have to be reparied by the enzymes at a later time.

Molecular Changes in DNA and Repair Processes

Experimental approaches to many important mechanistic questions about the relationships among energy deposition, DNA damage induction, DNA repair and their biological consequences are presently feasible or soon will be. Future research directions should include the following. Continued improvement and refinement of the techniques for detection of chemically distinct DNA lestons a low doses will be required. The spectrum and distribution of specific DNA lestons before and after irradiation as a function of dose, dose rate, energy deposition profiles and state of cellular differentiation should be emphasized. Particular attention should be given to the kinetics of DNA removal because time to repair appears to be important for many biological phenomena. The influence of specific chemical- or radiation-induced DNA damage products in a domain on the spectrum and distribution of the subsequent radiation damage induced in that domain should be explored. The use of we11defined repair deficlent mutants and molecular biology techniques to isolate repair genes and products, assess lesion induction and removal from active and inactive genes and determine the role of base sequence and conformation on induction and removal of chemically distinct lesions should be vigorously pursued. Information on the mechantsms by which the intracellular and extracellular environment modify the spectrum or distribution of DNA lesions, and the biological consequences of these modifications over prolonged periods of time should be developed. Finally, evidence should be sought for the long term accumulation of restdual unrepalred lestons in dividing and nondividing ce11s.

Although these mechanistic studies may not significantly alter present risk assessment values by themselves, they may provide valuable information to design interventions that could ultimately reduce the long term risks assoclated with exposure to ionizing radiation. 
APPENDIX II

$191 / 192$ 


\section{Particlpants}

The participants in the workshop included the following:

Benjamin Barnhart

OHER, U.S. Department of Energy

John W. Baum

Brookhaven National Leboratory

Victor Bond

Brookhaven National Laboratory

Les Braby

Pacific Northwest Laboratory

Randa11 S. Caswell

National Bureau of Standards

Aloke Chatterjee

Lawrence Berkeley Laboratory

Mortimer M. Elkind

Colorado State University

Jim Evans

Untversity of California, San Diego

R.J. Michael Fry

Oak RIdge National Laboratory

Charles Geard

Columbia University

Douglas Grahn

Argonne National Laboratory

Rtchard Griffith

Lawarence Luermore National

Laboratory

Er1c J. Hall

Columbia Univeraity

Rob1n C. Leonard

Brookhaven National Laboratory

Lucy L. Ling

Untversity of California, San Diego
A. T. Natarajan

Ryksuniversitelt Lefden

(The Netherlands)

Herwig G. Paretzke

Institut fur Strahlenschutz

(Munlch)

James Regan

Oak Ridge National Laboratory

Ja1me S. Rubin

Columbia Unfversity

Michael D. Sevilla

Oakland University

Warren K. Sinclair

National Councli on Radiation

Protection and Measurements

Gary Strniste

Los Alamos National Laboratory

Cornelius A. Tobias

Lawrence Berkeley Laboratory

Matesh Varma

OHER, U.S. Department of Energy

John F. Ward

University of California, San Diego

Kenneth T. Wheeler

The Bowman Gray School of Medicine

Robert W. Wood

OHER, U.S. Department of Energy

Harvel Wright

Oak RIdge National Laboratory

Robert Yoder

DP, U.S. Department of Energy 